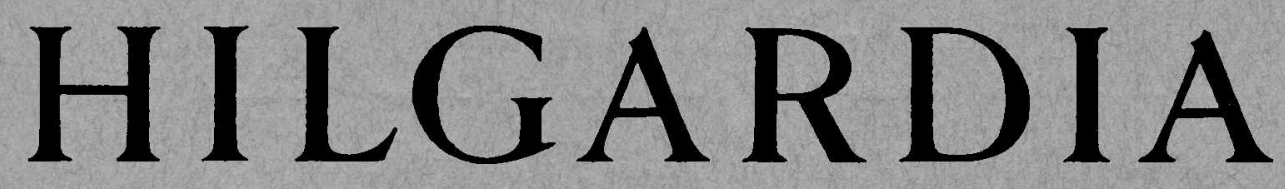

A Journal of Agricultural Science Published by the California Agricultural Experiment Station

\title{
CONTENTS
}

\section{MORPHOLOGY OF REPRODUCTION IN GUAYULE AND CERTAIN OTHER SPECIES OF PARTHENIUM}

KATHERINE ESAU 


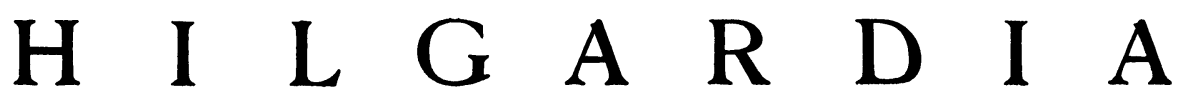

A Journal of Agricultural Science Published by

the California Agricultural Experiment Station

VOL. 17

JANUARY, 1946

No. 2

\section{MORPHOLOGY OF REPRODUCTION IN GUAYULE AND CERTAIN OTHER SPECIES OF PARTHENIUM ${ }^{1}$}

\author{
KATHERINE ESAU ${ }^{2}$
}

\section{INTRODUCTION}

Studies on hybridization in guayule (Parthenium argentatum Gray) conducted under the Guayule Research Project of the United States Department of Agriculture at Salinas, California, revealed that apomixis occurred in this species (Powers and Rollins, 1945). ${ }^{3}$ This observation contradicts the reports in earlier morphologic work on guayule, according to which this plant shows no asexual reproduction (Kirkwood, 1910; Kokieva, 1932; Dianowa et al., 1935). A reinvestigation of the morphology of reproduction in guayule was therefore necessary. The present study on megasporogenesis, megagametogenesis, and embryo formation of Parthenium was undertaken in response to this need. The first findings of these morphologic studies, which confirmed the conclusion of Powers and Rollins (1945) on the occurrence of apomixis in guayule, were reported in a preliminary paper (Esau, 1944b). Since then additional types of guayule and two other species of Parthenium (P. hysterophorus L. and $P$. incanum H.B.K.) have been examined, and the complete data assembled for the present paper.

\section{REVIEW OF LITERATURE}

Since the literature on apomixis has been thoroughly reviewed by Stebbins (1941), the only papers considered here will be those that bear most directly on the present study. The writer previously reported (Esau, 1944b) that in apomictic guayule the megaspore mother cells commonly fail to undergo meiosis and directly develop into diploid embryo sacs. According to the terminology proposed by Winkler and Fagerlind (see review by Stebbins, 1941), this type of embryo-sac formation is designated by generative apospory, a term signifying that a generative cell (the megaspore mother cell ${ }^{4}$ ) gives rise to an

\footnotetext{
${ }^{1}$ Received for publication July 18, 1945.

${ }^{2}$ Associäte Professor of Botany and Associate Botanist in the Experiment Station.

"See "Literature Cited" for complete data on citations, referred to in the text by author and date of publication.

"If the generative cell does not produce spores, it is not, strictly speaking, a megaspore mother cell'; but since it has the potentialities of such a cell, it is termed in this paper "megaspore mother cell" whether or not it ultimately produces megaspores.
} 
embryo sac without the formation of spores (megaspores). In contrast, somatic apospory (Stebbins, 1941) refers to the development of an embryo sac from a somatic cell without meiosis and spore formation. Generative and somatic apospory are the two main types of apomeiosis; and, as the present paper will show, both occur in guayule.

The principal evidence of generative apospory-the substitution of somatic divisions for meiosis in the megaspore mother cell-is difficult to obtain, because division figures are rarely encountered in the female generative cells of apomicts. This feature has been previously stressed in the literature (Juel, 1900; Holmgren, 1919; Kiellander, 1935) and is strikingly displayed by the apomicts of guayule (Esau, 1944b). Proof of generative apospory must be sought, therefore, in phenomena other than those of nuclear division.

The scarcity of division figures in the female generative cells is, in itself, evidence of apomixis. According to many students of apomixis (Juel, 1900; Holmgren, 1919; Chiarugi and Francini, 1930; Rosenberg, 1930; Stebbins, 1932 ; Kiellander, 1935, 1937 ; Afzelius, 1936 ; Bergman, 1937 ; Fagerlind, 1940), the megaspore mother cell of apomicts, which fails to undergo meiosis, remains in a resting stage for a long time; but it enlarges, becomes highly vacuolated, and thus acquires the morphologic characteristics of the uninucleate embryo sac. The enlarging megaspore mother cell often crushes and pierces the enclosing nucellar layer and emerges into the eavity formed by the integument overgrowing the nucellus. Such crushing occurs, for example, in apomictic $A n$ tennaria, whereas in the sexual species of the same genus nucellar cells are crushed only after the formation of the tetrad of megaspores (Juel, 1900). According to Rosenberg (1930), the megaspore mother cell of the habitually parthenogenetic plants has a somatic appearance from its initial stages of development. Some workers (Holmgren, 1919; Stebbins, 1932) have observed that the nucleus of the megaspore mother cell in apomicts shows low chromaticity. The enlargement of the megaspore mother cell of apomicts is accompanied by an increase in size of the ovule containing it. Thus Holmgren (1919) found that in Eupatorium glandulosum the ovules with unreduced uninucleate embryo sacs (enlarged megaspore mother cells) were similar in size to those containing reduced binucleate embryo sacs (that is, structures removed from the megaspore mother cell by three nuclear divisions) in sexual species.

In some apomicts, however, the division in the megaspore mother cell is not delayed. According to Chiarugi and Francini (1930), the development of the aposporic embryo sac is precocious in Ochna serrulata. Holmgren (1919) reported that the nucleus of the megaspore mother cell divides nearly at the same time in the sexual and asexual Erigeron species. The nucellus is still intact during this division. Then comes a lag in nuclear divisions in the apomict; but the unreduced binucleate embryo sac, resulting from the first division, enlarges, the nuclei migrate to the opposite poles, and a large vacuole appears in the center of the sac. The nucellus is finally pierced, and the embryo sac fills the integumentary cavity.

Despite these exceptions, the abundance of views showing enlarging vacuolating, but mostly resting, megaspore mother cells in sections of ovules may be regarded as the first outstanding feature of plants manifesting generative apospory. The second important feature is the absence (or scarcity, if the 
plant is only partly apomeiotic) of tetrads of megaspores. As Kiellander (1937) has pointed out, the presence of tetrads, intact or degenerating, is a criterion of preceding meiosis; conversely, their absence indicates apomeiosis. Exceptions to this rule possibly occur. According to Murbeck (1901), for example, in the apomictic species of Alchemilla the megaspore mother cell divides mitotically into three daughter cells, one of which forms the embryo sac.

In somatic apospory the cell that forms the embryo sac is highly vacuolated, and its vacuolation further increases as the cell enlarges (Stebbins and Jenkins, 1939). This cell arises near the sporogenous tissue and, in its early stages of development, may crush the latter (Rosenberg, 1908 ; Chiarugi and Francini, 1930; Stebbins and Jenkins, 1939; Häflinger, 1943). The aposporic sac may be derived from differently situated cells in different species-from an integumentary cell, from a cell in the chalazal region, or from an epidermal cell of the nucellus (Rosenberg, 1908). The chalazal region appears to be an especially frequent place of origin of aposporic saes (Rosenberg, 1908; Stebbins and Jenkins, 1939 ; Tinney, 1940). Judging from the literature, the aposporic sac may be initiated while the normal ${ }^{5}$ is still in the stages of megasporogenesis (Rosenberg, 1908; Stebbins and Jenkins, 1939) or somewhat later (Chiarugi and Francini, 1930).

If a plant shows apomeiosis, this phenomenon does not necessarily occur in all ovules. Both the generative and the somatic apospories may combine with normal development to varied degrees (Rosenberg, 1908; Chiarugi and Francini, 1930 ; Kiellander, 1935, 1937 ; Stebbins and Jenkins, 1939). If sexual and asexual reproductions occur in the same plant, apomixis (or apomeiosis, or apospory) is termed facultative (Stebbins and Jenkins, 1939). Generative and somatic apospories also may be combined in the same plant (Murbeck, 1901; Chiarugi, 1926 ; Chiarugi and Francini, 1930).

If apomeiosis results in the formation of a functioning embryo sac, the latter has the somatic number of chromosomes, and the diploid egg is commonly capable of developing into an embryo without fertilization. Such embryo development may be initiated precociously, or it begins later. (See review by Stebbins, 1941.) Murbeck (1901) reported that in the apomictic Alchemilla the embryo and endosperm are often present while the flower is still in bud. According to most workers, however, although the embryo is initiated in the apomicts without pollination, the endosperm develops only after pollination (Gentcheff and Gustafsson, 1940 ; Tinney, 1940 ; Åkerberg, 1943 ; Håkansson, 1943 ; Häflinger, 1943). Tinney (1940) observed no pollen tubes in the embryo sacs, but others have reported views of triple fusion (Gentcheff and Gustafsson, 1940; Åkerberg, 1943). The phenomenon of sporophyte development from a diploid gametophyte with the aid of pollination but without fertilization of the egg (autonomous embryo development) is termed unreduced pseudogamy (Stebbins, 1941).

It seems characteristic of the apomicts that the embryo and endosperm de-

\footnotetext{
${ }^{5}$ Here and elsewhere in the paper, the word normal is used to describe a condition, structure, or quality which, so far as is known, is ordinary, usual, or average in most plants. (See Webster's dictionary.) Thus the sexual cycle and all features and structures involved are defined as normal; the apomictic cycle is regarded as abnormal, anomalous, unusual, out of the ordinary, although, in a narrow sense, apomixis has become the normal condition in certain plants or groups of plants.
} 
velopment are not well correlated : in the same plant the endosperm is initiated sometimes before, sometimes after the embryo has begun to develop; or the two are initiated together (Murbeck, 1901; Chiarugi and Francini, 1930 ; Stebbins, 1941). Endosperm may develop entirely without the embryo (Chiarugi and Francini, 1930).

As the writer (Esau, 1944b) has previously indicated, the early morphologic literature on guayule described certain features that suggested apomictic reproduction, but did not present conclusive evidence for the latter. Kirkwood (1910) noted that views of dividing megaspore mother cells and of megaspores were lacking; he also recorded the absence of uniformity in the relative development of embryo and endosperm. Kokieva (1932) mentioned irregularities of chromosomal behavior during meiosis; long duration of the uninucleate stage of the embryo sac (probably the stage of enlarging megaspore mother cell) ; lack of relation between endosperm and embryo development; variability in size of young nucellus and of embryo sac in different stages of development. Despite these observations, Kirkwood (1910) and Kokieva (1932) assumed that reproduction in guayule was of the usual sexual type. Dianowa and her co-workers (1935) held the same view because, when they checked the occurrence of parthenogenesis in guayule by emasculations and exclusion of pollination, they obtained no seed setting under these conditions.

By comprehensive breeding experiments Powers and Rollins (1945) have recently shown that the type of reproduction in guayule varies in relation to the chromosome numbers. Plants with the somatic numbers of chromosomes of $36+$ were found to be almost, if not completely, sexual, with both meiosis and fertilization occurring in their reproductive cycle. The polyploid groups with $54 \pm, 72 \pm$, and $108 \pm$ chromosomes consisted mainly of facultative apomicts with pseudogamy. Similarly mariola (Parthenium incanum) rarely showed normal sexual reproduction. The apomixis was evidenced by the predominance of maternal phenotypes in the $\mathrm{F}_{1}$ generations from intra- and interspecific crosses; pseudogamy was revealed by the lack of development of seeds with full-sized embryos when pollination was excluded. In the preliminary morphologic study by the present writer (Esau, 1944b), the megasporogenesis and embryo-sac development in 36-chromosome guayule usually followed the course characteristic of the normal sexual cycle, with abundant views of megaspore mother cells in meiosis and of tetrads ; and no embryos developed in emasculated nonpollinated flowers. In the 72-chromosome plants, enlarging but resting megaspore mother cells predominated before anthesis, tetrads were scarce, and embryos occurred in emasculated nonpollinated flowers.

\section{MATERIAL AND METHODS}

The guayule (Parthenium argentatum Gray) plants used for studies of reproduction were raised at three locations in California (table 1) : at Manzanar; at the United States Department of Agriculture Station, Salinas; and at the University of California College of Agriculture, Davis. Part of the plants were growing in the open field; others in boxes or cans in greenhouses. The material from Manzanar was furnished by Dr. G. L. Stebbins, Jr., of the University of California ; that from Salinas by Drs. R. C. Rollins, LeRoy Powers, and A. D. Bergner, all of the Guayule Research Project of the United States Department 
of Agriculture at Salinas, California. The plants raised in the open field at Davis were transplanted at different times from Salinas. The method of reproduction in guayule was compared with that in P. hysterophorus L., an annual species that occurs widely in the southern states, particularly around the Gulf of Mexico, and with that in P. incanum H.B.K. (mariola), a perennial species.

Most of the material was collected from open-pollinated plants not subjected

TABLE 1

Description of Material Used in the Study

\begin{tabular}{|c|c|c|c|c|}
\hline \multirow{2}{*}{ Lot no. } & \multicolumn{2}{|c|}{$\begin{array}{l}\text { Approximate } 2 n \text { num- } \\
\text { ber of chromosomes }\end{array}$} & \multirow{2}{*}{$\begin{array}{l}\text { Location } \\
\text { of plant } \\
\text { in } \\
\text { California }\end{array}$} & \multirow{2}{*}{ Identification no. } \\
\hline & In plant & $\begin{array}{l}\text { In accession } \\
\text { or variety }\end{array}$ & & \\
\hline \multicolumn{5}{|c|}{ Parthenium argentatum Gray (guayule) } \\
\hline $1 \ldots$ & 36 & $\ldots \ldots$ & Manzanar & A6104* \\
\hline $2 \ldots$ & 36 & $\ldots \ldots$ & Manzanar & A6111* \\
\hline $3 \ldots$ & 36 & $\ldots \ldots$ & Manzanar & A6113* \\
\hline $4 \ldots$ & 36 & $\ldots \ldots$ & Davis & $8118-11$ accession $4253 \dagger$ \\
\hline $5 \ldots$ & . & 36 & Salinas & $8118-17$ accession $4253 \dagger$ \\
\hline $6 \ldots$ & . & 36 & Salinas & $8118-21$ accession $4253 \dagger$ \\
\hline $7 \ldots \ldots$ & 54 & & Salinas & $8132-12$ accession $4264 \dagger$ \\
\hline $8 \ldots \ldots$ & . & $54,58,72$ & Davis & Variety $111 \ddagger$ \\
\hline $9 \ldots \ldots$ & . & 72 & Davis & Variety $406 \ddagger$ \\
\hline $10 \ldots \ldots$ & . & 72 & Davis & Variety $593 \ddagger$ \\
\hline $11 \ldots \ldots \ldots$ & . & 72 & Davis & Variety $406 \ddagger$ \\
\hline $12, \ldots \ldots \ldots$ & $\ldots$ & 72 & Davis & Variety $593 \ddagger$ \\
\hline $13 \ldots \ldots$ & 72 & $\ldots \ldots$ & Davis & Variety 49 , plant $3 \dagger$ \\
\hline $14 \ldots \ldots$ & 108 & $\ldots \ldots$ & Salinas & $44-2003-45 \dagger$ \\
\hline
\end{tabular}

Parthenium hysterophorus L.

\begin{tabular}{l|c|c|l|l}
\hline $15 \ldots \ldots \ldots \ldots \ldots \ldots \ldots \ldots \ldots$ & $\ldots$ & 34 & Salinas & $43-699 \dagger$ \\
$16 \ldots \ldots \ldots \ldots \ldots \ldots \ldots \ldots \ldots$ & $\ldots$ & 34 & Salinas & $43-700 \dagger$ \\
\hline \multicolumn{3}{c|}{ Parthenium incanum H.B.K. (mariola) } \\
\hline $17 \ldots \ldots \ldots \ldots \ldots \ldots \ldots \ldots$ & $\ldots$ & 54 & Salinas & $42207-\mathrm{III} \dagger$ \\
\hline
\end{tabular}

* Numbers assigned by G. L. Stebbins, Jr.

† Numbers assigned by United States Department of Agriculture.

$\ddagger$ Numbers assigned by W. B. McCallum.

to any special treatment. This material, used in studying the embryo sac and embryo, is described in table 1. (In this table, lots 1-7 and 11-17 are collections from single plants ; lots 8-10, mass collections.) In addition, some fertilization and controlled-pollination studies were carried out to determine the origin of the embryo and endosperm. (Only one of the plants used in these studies is listed in table 1.) The controlled-pollination studies were made with plant 3 , variety 49 and plant 4 , variety 427 . These numbers were assigned by workers of the United States Department of Agriculture. In the text and in tables 9 and 10 , the two mother plants are designated 49-3 and 427-4. In the cross-pollination experiments plant 49-3 was pollinated with pollen from a plant of Dr. W. 
B. McCallum's variety 406 ; 427-4 was crossed with a plant of his variety 444 . All four plants had $72 \pm$ as the somatic number of chromosomes.

In the fertilization studies the following combinations were used: A 36 chromosome plant of United States Department of Agriculture accession no. 4253 was pollinated with pollen from a plant of McCallum's variety 593, having $72 \pm$ chromosome. Plant no. 593-I was pollinated with pollen from plant no. 42354-II ; both of these plants had $72 \pm$ chromosomes. The numbers of the last two plants were assigned by workers of the United States Department of Agriculture.

The emasculations and pollinations, as well as fixations of material used in the controlled-pollination and fertilization studies, were made at Salinas by Dr. R. C. Rollins.

The $2 n$ chromosome numbers reported for guayule are $36,38,54,58,72,74$, and 108 to 111 (Bergner, 1944; Stebbins and Kodani, 1944). As table 1 shows, the principal chromosomal types of guayule were represented in the material used in the present study. The chromosome numbers given in the table are qualified as "approximate" because the actual numbers sometimes deviated by small amounts from those in the table. Thus, for example, the plant in lot 4 had two small chromosomes in addition to the normal 36, and the plant in lot 7 had three small chromosomes besides the 54 given in the table. Lot 8 is indicated as a mixture of individuals with different chromosome numbers. Stebbins and Kodani (1944, p. 165) published a statement that variety 111 (lot 8, table 1) "contained at least some plants with $2 n=58$." In a personal communication to the writer, Dr. G. L. Stebbins, Jr. added that $2 n=72$ and probably $2 n=54$ also occur in this variety, which appears to be a result of segregation from an unstable hybrid.

The material was fixed in chrome-acetic-formalin and in formalin-aceticalcohol mixtures. After a fixation lasting 24 to 48 hours it was transferred directly into 70 per cent alcohol. When several changes had been made in this medium, the material was dehydrated and carried over into paraffin according to the normal butyl-alcohol schedule. The imbedding medium was a paraffinbeeswax-rubber mixture. The sections were cut 10 microns thick and were stained according to a schedule earlier described by the writer (Esau, 1944a).

To obtain sections of small flowers, entire heads were cut; the large flowers were removed from the heads before fixation. Usually the corolla and the upper part of the achene were cut away in the large flowers, or the ovules were dissected out.

\section{GENERAL CHARACTERISTICS OF THE FEMALE REPRODUCTIVE STRUCTURES OF GUAYULE}

Since the inflorescence and flowers of guayule were lately described and illustrated in detail by Artschwager (1943), they need not be discussed here. The development of the ovule and of the embryo sac, also considered in the literature (Kirkwood, 1910; Kokieva, 1932), must be reëxamined because the previous writers failed to distinguish between the phenomena of the sexual and asexual methods of reproduction.

A single ovule occurs at the base of the ovarian cavity (plate $1, A$ ). In the initial stages of development the small protuberance that represents the pri- 
mordium of the ovule is upright. The megaspore mother cell appears somewhat to one side in the hypodermal layer of the primordium. The single integument arises at the surface of the ovule, near the base of the megaspore mother cell. Since the most active cell divisions concerned with the integument formation occur above the laterally placed megaspore mother cell, the ovule becomes inverted, and the micropyle eventually points downward in the ovarian cavity (plates 1 and 5).

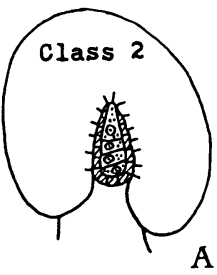

A

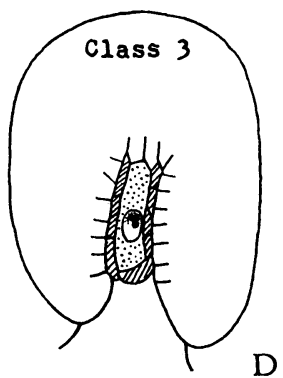

$\mathrm{D}$

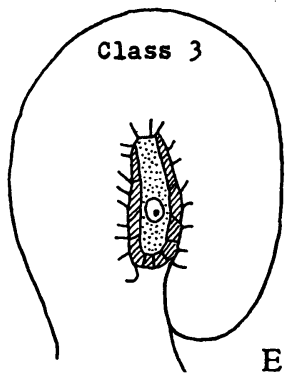

$\mathrm{E}$

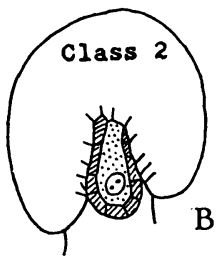

B

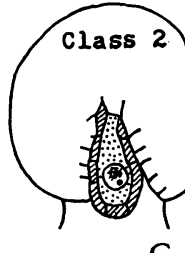

C
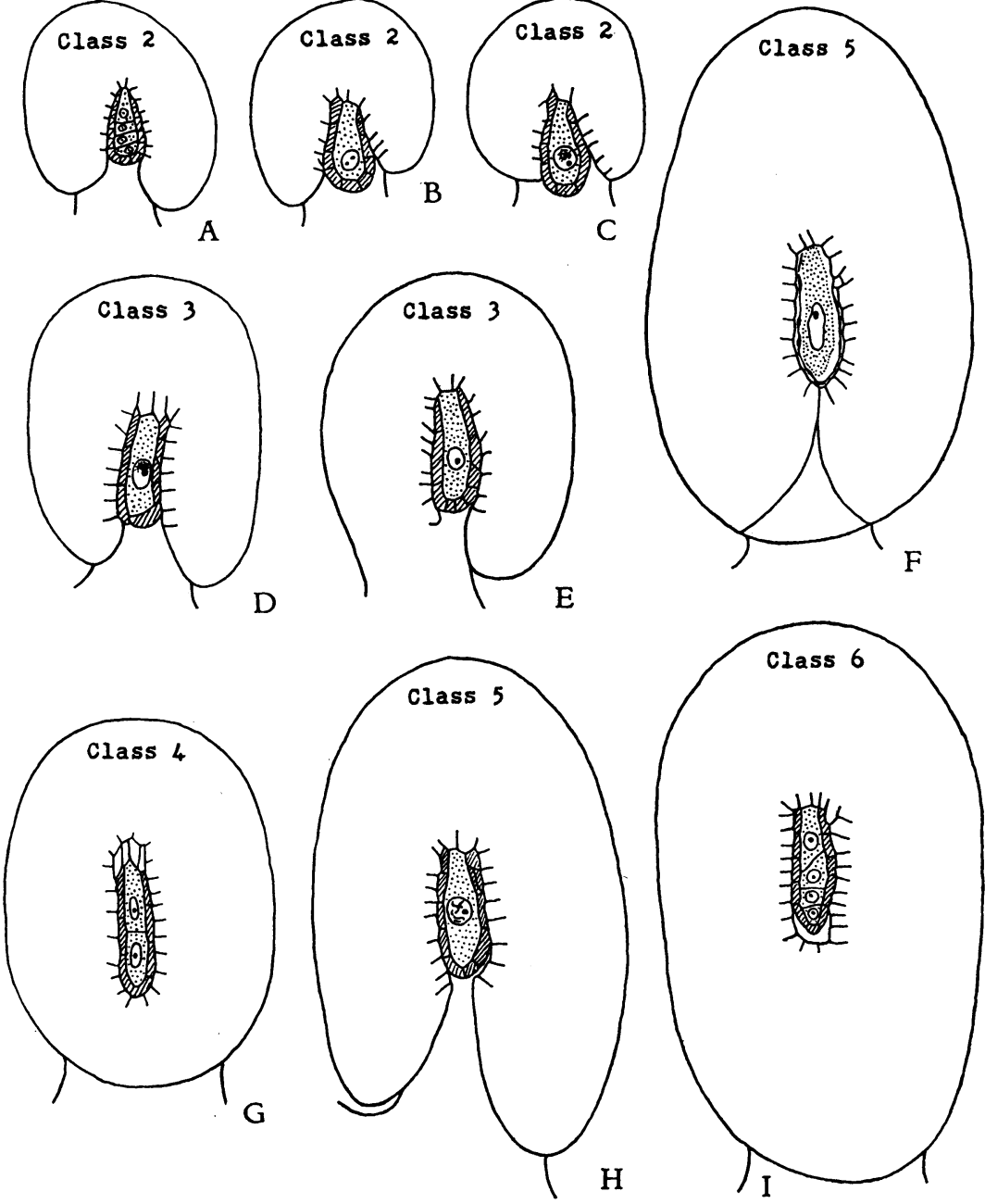

Fig. 1.-Diagrams of longitudinal sections of guayule ovules containing megaspore mother cells in resting stage $(B, E$, and $F)$ and in meiotic prophases $(C, D$, and $H)$; a dyad $(G)$; and tetrads of megaspores ( $A$ and $I$ ). The ovule in $A$ is from a 36-chromosome plant; the others are from a 72-chromosome type. In all drawings the protoplasts of the megaspore mother cells and of the dyad and tetrad members are stippled. The nucellar epidermis enclosing the generative cells is singly hatched. The nucellus projects beyond the integument in $B$ and $C$; in all other figures it is partially or completely enclosed by the integument. The funiculus is indicated at the base of each ovule. The size classes of the ovules are given on the drawings. (All $\times$ 194.) 

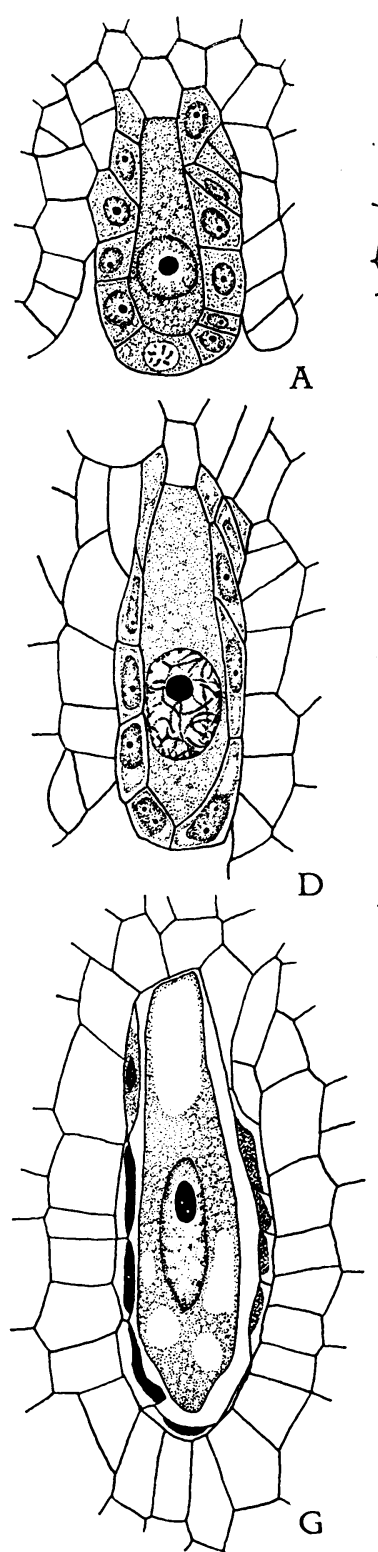

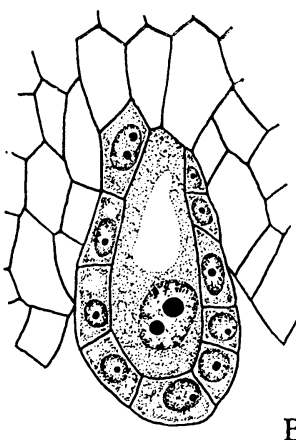

B
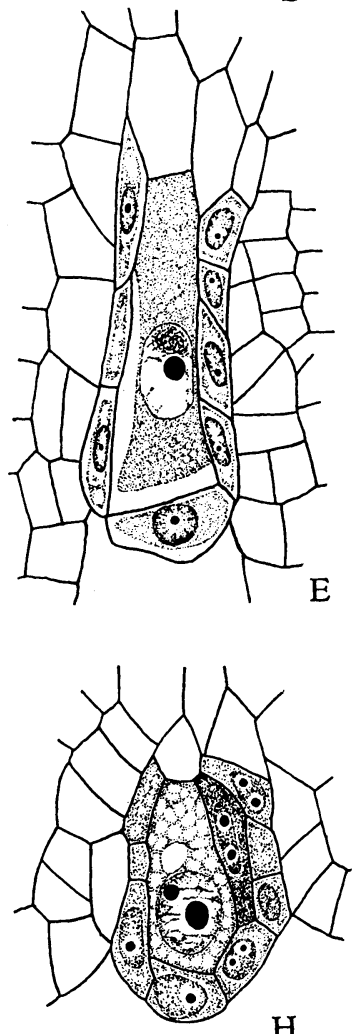

$\mathrm{H}$

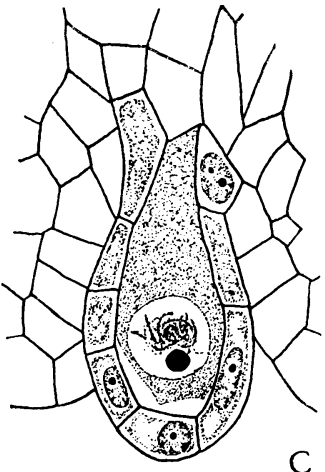

C

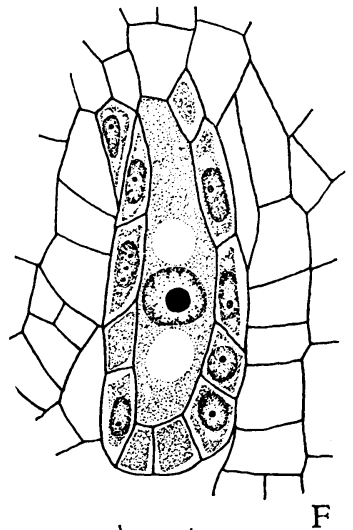

$\mathrm{F}$

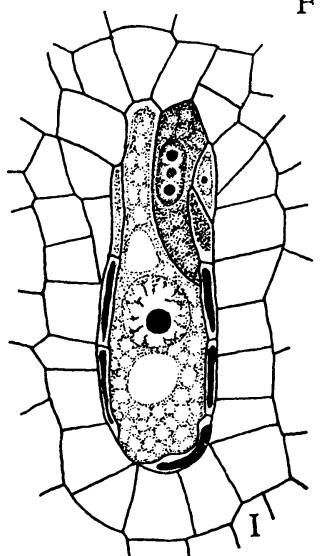

Fig. 2.-Longitudinal views of megaspore mother cells and enclosing nucellar epidermal cells from 72-chromosome guayule. The protoplasts of the megaspore mother cells are stippled; those of the nucellar epidermis are stippled or are shown in black. The blackening indicates that the cells are partly crushed. In $A-G$ one megaspore mother cell occurs in each nucellus; in $H$ and $I$ two such cells, a large one and a small one, are present in the same nucellus. The megaspore mother cells in $C, D$, and $E$ are in meiotic prophases; all others are resting. The drawings were made from ovules of the following size classes (see fig. 1 and text): $A-C$ and $H$, class $2 ; D-F$, class $3 ; I$, class $4 ; G$, class 5 . (All $\times 600$.) 
In keeping with the original terminology (Schneider, 1917), the ovule is here interpreted as composed of the nucellus (which constitutes the inner portion of the ovule), the integument, and the funiculus. No sharp line of demarcation can be drawn between any two of these three parts. The megaspore mother cell occurs at one end of the nucellus, and most of it is covered only by the nucellar epidermis. ${ }^{6}$ The latter forms a distinet uniseriate layer that grows by anticlinal divisions and tangential stretching of cells during the enlargement of the megaspore mother cell (figs. 1 and 2 ; plates $1, A$ and $B ; 2 ; 3, \mathrm{~A}$ ).

In the normal cycle of reproduction, the megaspore mother cell passes through the usual stages of meiosis (plate $2, A$ and $B$; plate $3, A$ and $B$ ). The first meiotic division is followed by cytokinesis (plate $2, C$ ), and dyads are formed (plate $2, D$ ). The dyad nuclei typically occur in the stage of interkinesis (plate 2, $C$ and $D$ ). The second meiotic division gives rise to tetrads of megaspores. These are arranged in one longitudinal row (plate $2, E$ and $F$ ); or the two megaspores nearest the micropyle occur laterally side by side, and then certain longitudinal sections show only three of the tetrad members (plate $3, C)$.

The cytoplasm of the megaspore mother cell, of the dyads, and of the young tetrads is relatively uniform throughout the cell, with no conspicuous vacuoles (plate 2). The chalazal megaspore, which becomes the embryo sac, is, from the beginning, the largest member of the tetrad (plate 2, $E$ ). Upon starting to elongate, it develops a prominent, often sharply delimited vacuole at the chalazal end (plate $3, C$ ). The three megaspores toward the micropylar end are gradually crushed by the functioning megaspore. The cell nearest to the latter usually is destroyed first (plate $3, C$ ). When the functioning megaspore reaches the stage of a uninucleate embryo sac, it commonly develops one or more large vacuoles in its micropylar end. The nucleus then becomes located in the relatively dense central part of the young sac, with highly vacuolated areas on either side of it (plate $3, D$ ). Fully developed uninucleate embryo sacs associated with completely crushed megaspores (as in plate $3, D$ ) are rarely encountered in sections. Apparently the enlargement of the functioning megaspore is quickly followed by the nuclear division that forms the binucleate embryo sac. The two nuclei first occur in the center of the embryo sac (plate $3, F$ ), then migrate to the two opposite ends of it (plate $3, E$ ).

The nucellar epidermis is stretched and crushed during the development of the uninucleate and binucleate embryo sacs. Commonly this process begins at the sides of the tetrad group or of the young embryo sac (plate $3, C-F$ ). Eventually the nucellar epidermis is pierced, either at the side of the embryo sac or at its micropylar end; and the embryo sac emerges into the cavity formed by

${ }^{6}$ Satina (1945) has suggested denoting as nucellus only the part of the ovule that originates in the subepidermal layer of the placenta, and distinguishing it from the derivatives of the outer layer of the placental wall. According to this definition, the megaspore mother cell is partly imbedded in the nucellus, but on the periphery it is covered by nonnucellar cells. One might question the usefulness of such a partitioning of an organ based on the origin of parts in the meristem: the fate of the histogen theory has shown the fallibility of the "attempt to assign specific destinies... to the various regions of the meristem" (Foster, 1939, p. 457). The only reason for retaining the term nucellus in modern literature seems to be the convenience in describing ovules; for the sake of simplicity, it may well continue to be used with reference to the main body of the ovule within the integuments, including the epidermis that covers the sporogenous tissue. 
the overgrowing integument (plate $4, B$ and $C$ ). The remnants of the crushed megaspores usually are evident as long as the embryo sac has one or two nuclei (plate 3, $D-F$ ). After the nucellus is pierced, these remnants become indistinguishable, though sometimes they may be detected at the tetranucleate stage on one or the other side of the embryo sac.

After the nucellar epidermis is destroyed, the embryo sac comes into contact with the inner epidermis of the integument. During the dyad stage this epidermis begins to assume its characteristic appearance-that of a layer of rather densely staining, orderly arranged cells lining the cavity that was formed by the integument back of the micropyle (plates $2, D ; 3, C-F ; 5, A$ ). With further enlargement of the integumentary cavity, the cells lining it divide anticlinally and become narrow, with their long diameters perpendicular to the periphery of the cavity (plates $1, C ; 4, B$ and $C$ ). In keeping with the common terminology, this layer is here called the "nutritive jacket," though its real function is still obscure. Possibly some nucellar cells also take part in forming the nutritive jacket, since in later stages of development this tissue almost encloses the embryo sac (figs. 4 and 5 ; plates 11-13).

In the apomictic cycle the nuclear division in the megaspore mother cell is delayed, but the latter enlarges and vacuolates, assuming the appearance of a uninucleate embryo sac. Figure $2, A, C-E$, plates $2, A$ and $B$, and $3, A$, show megaspore mother cells with normal-appearing cytoplasm free of large vacuoles. Several of these cells are in meiotic prophases (fig. $2, C-E$; plates $2, A$ and $B$; and $3, A$ ). In contrast, figure $2, B, F$, and $G$, and plate $4, A$, illustrate megaspore mother cells with conspicuous vacuoles in their cytoplasm. Such vacuolating megaspore mother cells are common in material taken from apomictic plants, while those with the relatively dense cytoplasm are characteristic of the sexually reproducing guayule.

Before its nucleus divides, the enlarging megaspore mother cell of the apomictic guayule frequently crushes the nucellar epidermis or even pierces it. In figure $2, G$ and $I$, and plate $4, A$, vacuolated megaspore mother cells are associated with a more or less crushed nucellar epidermis. The absence of crushed megaspores in these views proves that these cells are not the reduced uninucleate embryo sacs formed after meiosis. Such megaspore mother cells may be conveniently called unreduced, or aposporic, or apomeiotic embryo sacs, because upon division they give rise to binucleate structures, whose further development resembles that of ordinary binucleate embryo sacs.

As was mentioned previously, views of divisions are rarely encountered in the megaspore mother cells of the apomicts. Those observed were not sufficient to show whether a semiheterotypic or a purely mitotic division occurs in the formation of the binucleate embryo sac from the unreduced uninucleate structure. Immediately after the first division, the unreduced binucleate embryo sac differs strikingly from the dyads. In the latter the nuclei are usually in interkinesis, with the chromatic units sharply outlined on their periphery (plate $2, C$ and $D$ ) ; and the cell plate appears as a narrow line between the two nuclei (plate $2, C$ ). Just after formation the unreduced binucleate embryo sac has two nuclei, with the chromatin more or less netted in appearance and spread out through the nucleus. Instead of a cell plate between the nuclei, there is a wide band of somewhat darkly stained material (probably remnants of the 
spindle fibers), which later disappears (plate $6, B$ ). Belated meiotic divisions and formation of tetrads occurred in much-enlarged megaspore mother cells, which were contained in ovules considerably larger than those usually assoeiated with the stage of meiosis.

The degree of predivisional enlargement of the aposporic uninucleate embryo sac varies. The unreduced binucleate structure in plate $6, B$, is still enclosed within the nucellus. In plate $6, A$, an enlarged megaspore mother cell has pierced the nucellar epidermis; although the remnants of the latter are very conspicuous, no megaspores are present. Sometimes the young aposporic embryo sac grows so vigorously that it pushes through the micropyle into the ovarian cavity ; its nuclei then lie free in this cavity, surrounded only by the cytoplasm of the embryo sac (plate 6, $C$ ). (In some of the older ovules, embryos occurred in the micropyle and in the ovarian cavity. They probably developed in embryo sacs that protruded beyond the usual confines.)

After the binucleate stage is reached, the development of the embryo sac is similar in the normal and aposporic cycles of reproduction. The two nuclei of the binucleate embryo sac divide to form a tetranucleate embryo sac (plate 4, $B$ and $C$ ). Each of the four nuclei divides again, giving rise to the eight-nucleate embryo sac. Since this last nuclear division in the maturation of the embryo sac is immediately followed by cy tokinesis, cell plates appear between the members of each of the four pairs of new nuclei. Plate 7, $A$ and $B$, illustrates this stage of development. In this plate, nuclei 1-3 are antipodal nuclei; 4 and 5, polar nuclei ; 6 , the egg nucleus; 7 and 8 , synergid nuclei. No cell plate was yet evident between the nuclei 2 and 3 , but one was about to be formed. Perhaps this wall is sometimes omitted, for guayule embryo sacs may show two, sometimes three antipodals (figs. $4 ; 5 ; 6, A$ and $B$; plate $7, D$ ).

In older embryo sacs, the antipodal nuclei are rather large and foamy, with more than one nucleolus (fig. 6, $A$ and $B$ ). The antipodals may have more than one nucleus, or the single large nucleus is lobed. Often the antipodals persist long after the embryo starts developing. The two synergids show the usual vacuolation of the broad end turned toward the interior of the embryo sac (plate $8, A$ ). The dense narrow end pointing toward the micropyle contains the nuclei. In the preparation of the material for microscopic study, the vacuolated part of the synergids commonly collapses, and the synergids assume the peculiar shape illustrated in plate $8, B$. The polars fuse soon after being formed (plate $8, B$ ), and the polar fusion nucleus occurs near the egg in the mature embryo sac (plate $9, B$ ). The egg is of the usual type, with a vacuole in the narrow end near the micropyle and a nucleus in the broad dense end turned toward the interior of the sac. The eggs of the 36-chromosome guayule are obviously smaller than those of the predominantly apomictic 72-chromosome plants (plate 9). The polar fusion nuclei also differ in the two kinds of plants. Those in the 36-chromosome plants are rounded or somewhat elongated structures, each with one large nucleolus (plate $9, B$ and $C$ ); in the apomictic plants the polar fusion nucleus commonly becomes large and lobed and contains many nucleoli (fig. $6, H-J$; plates $8, C$; and $12, C$ ). When all parts of the embryo sac are differentiated, seven cells are present in it: the egg, the two synergids, the three antipodals, and the large central primary endosperm cell that contains the polar fusion nucleus. If there are only two antipodals, the embryo sac is 
divided into six cells only. For convenience, however, the mature embryo sac is here always called the "7-celled embryo sac."

The abnormalities in the embryo and endosperm development will be considered elsewhere in this paper. The apparently normal development for guayule may, however, be outlined briefly. Plate $11, A$ and $B$, shows two very young embryos. Both are associated with a developing endosperm, which, from the beginning, is usually cellular. A somewhat older embryo and a cellular endosperm are depicted in plate $11, C$. The embryo in plate $12, D$ is at the stage just before the cotyledons emerge. The latter had been initiated in the embryo in plate $13, A$. In plate $13, B$, the embryo has prominent cotyledonary primordia and a procambial system; and in $13, C$, it is mature. In the young achenes the cotyledons are oriented with their broad sides perpendicular to the broad sides of the achene (fig. $5, I$ and $L$; plate $13, B$ ), whereas in the mature state the broad sides of the cotyledons usually parallel the broad sides of the achene (plate 13, $C$ ). Seemingly, at some time between the stages depicted in plates $13, B$ and $C$, the embryo turns about halfway around its longitudinal axis.

During the development of the embryo, the sac containing it also enlarges. The nutritive jacket, which remains uniseriate, is much stretched. The ovular tissues (parts of the nucellus and of the integument) are gradually destroyed and, presumably, absorbed. Plate 5, $C$, illustrates the dense staining of the ovular cells that are the first to break down during the enlargement of the sac. The collapse of these cells is initiated on the flanks of the embryo sac (plates 11 and 12); later (plate $13, A$ and $B$ ) it is more prominent at the chalazal end. (The breaks at the top of the ovules in plate $13, A$ and $B$, were caused by the removal of corollas in preparation for fixation; the collapse of cells near the embryo sac is natural.) No special cells connect the vascular tissue with the embryo sac. The single vascular bundle passes near the periphery of the ovule from the funiculus into the outer part of the integument and ends blindly without reaching the tip of the ovule (plate $5, C$ ).

\section{COMPARISON OF EMBRYO-SAC FORMATION IN THE DIFFERENT CHROMOSOMAL TYPES OF GUAYULE AND IN MARIOLA}

Two features - the abundance of enlarging, vacuolating, but resting megaspore mother cells and the scarcity of megaspores-proved to be the best criteria for recognition of apomeiosis in this study. In an attempt to estimate the duration of the different stages of embryo-sac development, these stages were related to the sizes of the ovules in which they occurred. The ovules were measured between the point of attachment of the funiculus to the ovary wall and the top of the ovule. For the preparation of tables $2,3,5$, and 6 the ovules were sorted into size classes at 50-micron intervals. The first class contained the smallest ovules, 50 to 100 microns high ; the eighth class the largest ovules, 400 to 450 microns high. (Ovules of size 8 are not given in table 2 , since those belonging to this class in the 36-chromosome plants contained only 7-celled and older embryo sacs. They were relatively older than the ovules of class 8 in the polyploid plants.)

In the tables, the term "resting megaspore mother cells" is applied to those whose nuclei were not preparing for division. Figure $2, A, B, F$, and $G$, and plates $4, A$, and $6, A$, illustrate such megaspores. The various stages of pro- 
phase (fig. 2, $C-E$; plates $2, A$ and $B$, and $3, A$ and $B$ ), as well as the metaphases and anaphases, identified the "dividing megaspore mother cells." The dyads are, as a rule, clearly defined; and they are distinct from the tetrads of megaspores. Since, however, the crushing of the nonfunctioning megaspores is a gradual process, the line of division between the tetrad stage and that of the reduced uninucleate embryo sac must be drawn somewhat arbitrarily. When the nonfunctioning megaspores occupied a fraction of their original space (but were not necessarily entirely crushed), the stage was called "uninucleate embryo sac with crushed megaspores." For identifying the occurrence of meiosis in the reproductive cycle, the reduced uninucleate embryo sacs are

\section{TABLE 2}

Relation between Size of Ovule and Stage of Embryo-Sac Development in 36-Chromosome Guayule, as Determined by Classifying

346 OVULES OF LOT 4 IN TABLE 1

\begin{tabular}{|c|c|c|c|c|c|c|c|c|}
\hline \multirow{2}{*}{ Contents of ovules } & \multicolumn{7}{|c|}{$\begin{array}{l}\text { Percentages of different contents in ovules of the } \\
\text { various size classes }\end{array}$} & \multirow{2}{*}{$\begin{array}{l}\text { Total } \\
\text { per cent } \\
\text { for each } \\
\text { item }\end{array}$} \\
\hline & 1 & 2 & 3 & 4 & 5 & 6 & 7 & \\
\hline Resting megaspore mother cells.......... & 2.6 & $\ldots$. & $\ldots$ & $\ldots$. & $\ldots$ & $\ldots$. & $\ldots$ & 2.6 \\
\hline Dividing megaspore mother cells......... & 10.1 & 17.1 & 2.3 & $\ldots$ & $\ldots$ & $\ldots$ & $\ldots$ & 29.5 \\
\hline Dyads............................. & $\ldots$. & 1.4 & 0.9 & 0.6 & $\ldots$ & $\ldots$ & $\ldots$ & 2.9 \\
\hline Tetrads of megaspores................... & $\ldots$ & 2.6 & 8.4 & 4.9 & $\cdots$ & $\ldots$ & $\ldots$ & 15.9 \\
\hline \multirow{2}{*}{$\begin{array}{l}\text { Uninucleate embryo sacs with crushed } \\
\text { megaspores } \ldots \ldots \ldots \ldots \ldots \ldots \ldots \ldots \ldots\end{array}$} & & & & & & & & \\
\hline & .. & 0.9 & 0.9 & 7.5 & 1.7 & $\ldots$. & . & 11.0 \\
\hline Binucleate embryo sacs........ & $\ldots$ & 0.3 & 1.4 & 6.1 & 5.8 & 1.3 & $\ldots$ & 15.0 \\
\hline Tetranucleate embryo sacs..... & .. & $\ldots$ & $\ldots$. & 2.6 & 3.3 & 1.9 & 0.8 & 8.6 \\
\hline Seven-celled embryo sacs.......... & $\ldots$ & $\cdots$ & $\cdots$ & 1.8 & 3.4 & 3.8 & 5.5 & 14.5 \\
\hline Total...$\ldots \ldots \ldots \ldots \ldots \ldots$ & 12.7 & 22.3 & 13.9 & 23.5 & 14.3 & 7.0 & 6.3 & .... \\
\hline
\end{tabular}

as useful as the tetrads of megaspores. The remnants of the crushed megaspores are, as a rule, easily detected in the uninucleate-embryo sac stage; their final obliteration occurs in the older stages. In the tables the presence of remnants of megaspores in stages beyond that of the uninucleate embryo sac was disregarded, because their absence in these stages did not necessarily indicate that they were not present at any time: they may have been crushed beyond recognition. The binucleate, tetranucleate, and 7-celled embryo sacs are easily distinguished from one another. If the contents of the ovule were too much disorganized for identification, they were called "degenerated material."

Table 2 relates the stage of embryo-sac development to the size of the ovule in 36-chromosome guayule. With the increase in ovule size, the number of the megaspore mother cells quickly falls off, because most of these cells undergo. meiosis and become dyads and tetrads. The dyad stage is apparently brief, as evidenced by the small percentage of ovules showing dyads. With further growth of ovules, the tetrad stage is followed by the successive stages of embryo-sac development. The orderly succession of stages with the increase in ovule size is clearly demonstrated by the downward displacement of the figures from left to right in table 2 . The different stages did not often overlap, except that the binucleate embryo sacs were encountered in five different sizes of 
ovules. The last column ("total per cent for each item") emphasizes two features. A great majority of the megaspore mother cells were in division; and megaspores, intact or more or less crushed (items "tetrads of megaspores" and "uninucleate embryo sacs with crushed megaspores"), were common in sections. Degenerative stages were not encountered in this group of ovules.

The relation between ovule size and stage of embryo-sac development in 72-chromosome guayule strikingly contrasts with that in the 36-chromosome plants (table 3 ). Among all types of structures the resting megaspore mother cells are the most abundant, and they occur in all the size classes of ovules. Figure 1 illustrates the sizes of ovules containing megaspore mother cells and

TABLE 3

Relation between Size of Ovule and Stage of Embryo-Sac Development in 72-Chromosome Guayule, as Determined by Classifying 953 OVULES OF LOTS 11 AND 12 IN TABLE 1

\begin{tabular}{|c|c|c|c|c|c|c|c|c|c|}
\hline \multirow{2}{*}{ Contents of ovules } & \multicolumn{8}{|c|}{$\begin{array}{c}\text { Percentages of different contents in ovules of the } \\
\text { various size classes }\end{array}$} & \multirow{2}{*}{$\begin{array}{l}\text { Total } \\
\text { per cent } \\
\text { for each } \\
\text { item }\end{array}$} \\
\hline & 1 & 2 & 3 & 4 & 5 & 6 & 7 & 8 & \\
\hline Resting megaspore mother cells.. & 4.2 & 10.8 & 16.6 & 14.7 & 9.4 & 4.6 & 2.5 & 0.1 & 62.9 \\
\hline Dividing megaspore mother cells. & $\ldots$ & 0.4 & 2.3 & 3.5 & 1.2 & 0.3 & 0.2 & 0.1 & 8.0 \\
\hline 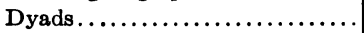 & $\ldots$ & $\ldots$ & 0.1 & 0.6 & 0.2 & 0.2 & $\ldots$ & $\ldots$ & 1.1 \\
\hline Tetrads of megaspores............ & $\ldots$ & $\ldots$ & 0.1 & 1.6 & 2.5 & 2.2 & 0.8 & 0.3 & 7.5 \\
\hline $\begin{array}{l}\text { Uninucleate embryo sacs with } \\
\text { crushed megaspores........... }\end{array}$ & $\ldots$ & & $\ldots$ & 0.2 & 1.0 & 0.3 & 0.2 & $\ldots$ & 1.7 \\
\hline Binucleate embryo sacs........... & $\ldots$ & & 0.2 & 2.1 & 2.6 & 2.6 & 3.1 & 1.5 & 12.1 \\
\hline Tetranucleate embryo sacs....... & $\ldots$ & $\ldots$ & 0.3 & 0.1 & 1.2 & 0.7 & 1.6 & 0.4 & 4.3 \\
\hline Seven-celled embryo sacs......... & $\ldots$ & $\ldots$ & $\ldots$ & $\ldots$ & ... & $\ldots$ & 0.7 & 0.1 & 0.8 \\
\hline Degenerated material........... & $\ldots$ & $\ldots$ & 0.1 & 0.6 & 0.2 & 0.1 & 0.5 & 0.1 & 1.6 \\
\hline Total... & 4.2 & 11.2 & 19.7 & 23.4 & 18.3 & 11.0 & 9.6 & 2.6 & $\ldots$ \\
\hline
\end{tabular}

their products. The ovule in figure 1, $A$-one from a 36-chromosome plantcontains tetrads. It is an ovule of the smallest size class that shows tetrads in table 2. Figure 1, B-I, drawn from ovules of 72-chromosome guayule, illustrates the lack of orderly relation between ovule size and the stage of development of the contents. Megaspore mother cells are shown in ovules of classes 2, 3 , and 5 (fig. $1, B-F$, and $H$ ) ; the ovule of class 4 in figure $1, G$, contains dyads, while the larger ovules in figure $1, F$ and $H$, still contain megaspore mother cells. The meiotic prophase in the ovule of class 5 (fig. $1, H$ ) and the tetrads in the ovule of class 6 (fig. $1, I$ ) indicate that meiosis may occur relatively late in the development of the ovule. Plate 5, $A$ and $B$, compares for size (at different magnifications) an ovule of class 5 from a 36 -chromosome plant containing a dyad and another of class 8 from a 72-chromosome plant containing a megaspore mother cell that had crushed the nucellar epidermis (unreduced uninucleate embryo sac).

As was stated previously, the megaspore mother cell persists through many developmental stages of ovules in 72-chromosome guayule (table 3), because the division that gives rise to an unreduced binucleate embryo sac is delayed. Some of the resting megaspore mother cells listed in table 3 had reached the stage of unreduced uninucleate embryo sac (plate $4, A$ ). Dividing megaspore 
mother cells were encountered rarely, and most of these were in meiotic prophases (fig. 2, $C-E$; plate $3, A$ and $B$ ). The scarcity of dyads shown in table 3 is not a criterion for omission of meiosis, since dyads are rare also in the material from normally reproducing plants (table 2 ). The difference in percentages of views with megaspores ("tetrads of megaspores" and "uninucleate embryo sacs with crushed megaspores") in tables 2 and 3 is significant : the small numbers of such views in the 72-chromosome material (table 3 ) is good evidence of frequent omission of meiosis. Their presence, on the other hand, proves that apomeiosis is not total in the 72-chromosome plants, but that it is combined with production of spores. Table 3, in contrast to table 2, indicates no orderly sequence of events in the development of the embryo sacs : the figures are spread out all over the table, instead of dropping down from left to right with the increase in ovule size. Indeed, various young stages occurred in ovules still larger than those recorded in table 3. Ultimately many of these young embryo sacs cease developing and become disorganized. Even in the young ovules used for table 3 , the contents had sometimes degenerated (item "degenerated material").

In studying the nature of reproduction, one should always use plants that have developed under favorable environmental conditions. A situation that affects adversely the development of flowers may obscure the differences between the normal and apomeiotic plants. The 36-chromosome plant of lot 4 (tables 1 and 2) was for a time affected by thrips, and the flowers were making little progress in development. The 65 ovules collected at this time showed 29.2 per cent of resting and 16.9 per cent of dividing megaspore mother cells; no dyads; 4.6 per cent of tetrads and uninucleate embryo sacs with crushed megaspores; and 30.8 per cent of degenerated structures. The remaining 18.5 per cent of ovules contained embryo sacs older than the uninucleate. (These figures were not used in preparing table 2.) The high per cent of resting megaspore mother cells apparently was not associated with apomeiosis, because all these cells occurred in small ovules (23.1 per cent in size $1 ; 4.6$ per cent in size $2 ; 1.5$ per cent in size 3 ). They seemed to have stopped developing and eventually degenerated. Nevertheless, this material could have been confused with the apomictic if other samplings from the same plant had not yielded entirely different results (table 2).

As was previously shown (Esau, 1944b), the degree of megasporogenesis or apomeiosis may be estimated from data like those in tables 2 and 3 . The item "resting megaspore mother cells" may be considered as indicating apospory, the four items "dividing megaspore mother cells," "dyads," "tetrads of megaspores," and "uninucleate embryo sacs with crushed megaspores" may be looked upon as evidences of megasporogenesis. Naturally, this estimate is an approximation: not all the megaspore mother cells that were resting at the time of sampling would have omitted meiosis ; but, on the other hand, the division of the nucleus in the dividing megaspore mother cells was not necessarily meiotic.

Table 4 compares megasporogenesis in different lots of 72-chromosome guayule and estimates the degree of apomeiosis in these lots. The ovules that contained binucleate, tetranucleate, and 7-celled embryo sacs were excluded from the calculations for table 4 . To emphasize that many of the resting megaspore 
mother cells differentiated into unreduced uninucleate embryo sacs, the enlarged megaspore mother cells associated with crushed nucellar epidermis were counted separately under "uninucleate embryo sacs with crushed nucellar epidermis" (table 4). The values for resting megaspore mother cells and uninucleate embryo sacs with crushed nucellar epidermis were added in an attempt to estimate the per cent of apomeiosis (table 4, last column). The difference between this total and 100 per cent, that is, the total of the fifth, sixth, seventh, and ninth columns, would represent the per cent of flowers showing megaspore formation. The range of variation of per cent of apomeiosis (from 69.0 per cent to 90.9 per cent) in the different samples and the average of 77.8 per cent compare favorably with the findings on apomixis by Powers and Rollins

TABLE 4

Megasporogenesis IN 72-Chromosome GUAYULE

\begin{tabular}{|c|c|c|c|c|c|c|c|c|c|}
\hline \multirow[b]{2}{*}{$\begin{array}{c}\text { Lot } \\
\text { no. } \\
\text { in } \\
\text { table } \\
1\end{array}$} & \multirow[b]{2}{*}{$\begin{array}{l}\text { Date of } \\
\text { collection }\end{array}$} & \multirow[b]{2}{*}{$\begin{array}{c}\text { Number } \\
\text { of ovules } \\
\text { examined }\end{array}$} & \multicolumn{6}{|c|}{$\begin{array}{l}\text { Percentages of ovules showing generative tissue } \\
\text { in the following stages }\end{array}$} & \multirow[b]{2}{*}{$\begin{array}{l}\text { Esti- } \\
\text { mated } \\
\text { per cent } \\
\text { of } \\
\text { apomei- } \\
\text { osist }\end{array}$} \\
\hline & & & $\begin{array}{l}\text { Resting } \\
\text { mega- } \\
\text { spore } \\
\text { mother } \\
\text { cells }\end{array}$ & $\begin{array}{c}\text { Dividing } \\
\text { mega- } \\
\text { spore } \\
\text { mother } \\
\text { cells }\end{array}$ & Dyads & Tetrads & $\begin{array}{c}\text { Uni- } \\
\text { nucleate } \\
\text { embryo } \\
\text { sacs with } \\
\text { crushed } \\
\text { nucellar } \\
\text { epi- } \\
\text { dermis* }\end{array}$ & $\begin{array}{c}\text { Uni- } \\
\text { nucleate } \\
\text { embryo } \\
\text { sacs } \\
\text { with } \\
\text { crushed } \\
\text { mega- } \\
\text { spores }\end{array}$ & \\
\hline 9 & April, 1943. & 341 & 65.1 & 14.1 & 2.1 & 8.2 & 9.1 & 1.4 & 74.2 \\
\hline 10 & April, 1943.. & 88 & 56.8 & 14.8 & 0.0 & 13.6 & 14.8 & 0.0 & 71.6 \\
\hline 11 & May $2,1944 \ldots$ & 242 & 62.8 & 15.7 & 2.1 & 7.4 & 11.6 & 0.4 & 74.4 \\
\hline 11 & August $21,1944 \ldots$ & 162 & 56.2 & 6.2 & 1.2 & 12.9 & 17.3 & 6.2 & 73.5 \\
\hline 12 & May $2,1944 \ldots \ldots \ldots$ & 208 & 67.3 & 6.7 & 1.0 & 1.4 & 23.6 & 0.0 & 90.9 \\
\hline 12 & August $21,1944 \ldots$. & 161 & 52.8 & 8.7 & 1.2 & 18.0 & 16.2 & 3.1 & 69.0 \\
\hline \multirow[t]{2}{*}{13} & June and July, 1944 & 184 & 83.7 & 7.6 & 0.0 & 3.8 & 4.9 & 0.0 & 88.6 \\
\hline & Average.... & $\ldots$ & 64.5 & 10.9 & 1.3 & 8.5 & 18.3 & 1.5 & 77.8 \\
\hline
\end{tabular}

* Enlarged megaspore mother cells.

† Sum of per cent of resting megaspore mother cells and of uninucleate embryo sacs with crushed nucellar epidermis.

(1945). In the work of these authors the degree of apomixis was revealed by the percentage of maternal types of plants in the $\mathrm{F}_{1}$ generation from interspecific crosses. In the $F_{1}$ progenies of 16 plants of 72-chromosome guayule crossed with mariola, the percentage of maternals varied from $61.6 \pm 6.8$ to $95.2 \pm 4.7$, with an average of $85.58 \pm 1.2$ (Powers and Rollins, 1945, table 4, p. 107).

In table 4, lots 11-13 were derived from single plants; lots 9 and 10 from groups of plants. The collections of lots 11 and 12 were made at two different dates (table 4). In lot 11 the two collections gave comparable values for per cent of apomeiosis. In lot 12, however, the May sample showed 90.9 per cent of apomeiosis, as contrasted with 69.0 in the August collection. The chief difference between these two collections in lot 12 is in the percentage of views showing tetrads and crushed megaspores-views that are not easily misinterpreted. Externally there was no evidence of any kind of injury to the plant at one or the other time during the season. This instance of variability in degree of apospory in samples taken at different times permits no conclusion regarding 
seasonal influences upon the method of reproduction, but it suggests that such influence may occur.

In both lots 11 and 12, the two collections differed in the vigor of growth of the aposporic embryo sacs; sacs that had emerged into the ovarian cavity occurred mostly in the August collection (plate 6,C).

Lots 11-13, being single-plant collections, show that meiosis and apomeiosis occur in the same plant (facultative apomeiosis). Views indicating megaspore formation and apomeiosis occur among flowers of the same head. An attempt was made to determine whether there was any tendency toward dominance of one or the other kind of flower in a given head. Figure 3 shows the relative

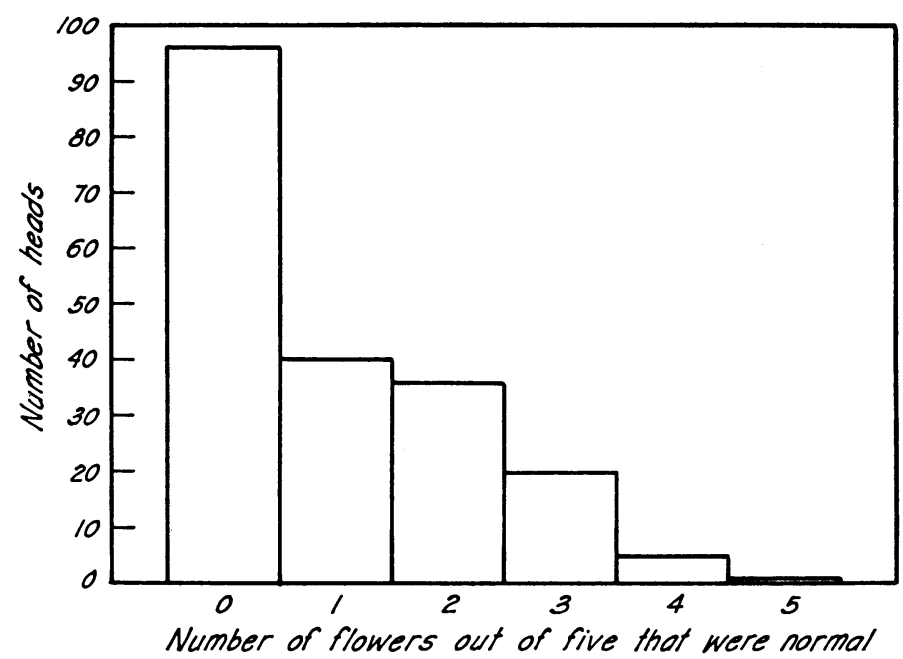

Fig. 3.-Diagram showing the relative frequency of flower heads with the different proportions of normal flowers. This diagram was based on a study of 195 heads of 72-chromosome guayule.

frequency of flower heads with the different numbers of normal flowers. Apparently the normal flowers are distributed perfectly at random among the aposporic ones.

The degree of apomeiosis in the 36-chromosome material was estimated as 4.2 per cent (table 7). Even this value may be too high, because, for example, the 2.6 per cent of resting megaspore mother cells in table 2 occurred in the youngest ovules and probably would have undergone meiosis later on. The 0.3 per cent of uninucleate embryo sacs with crushed nucellar epidermis in table 7 , however, is a good indication of apomeiosis. The embryo that was found in an achene from a self-pollinated, self-sterile 36-chromosome plant also suggests apomictic reproduction, though 36 -chromosome plants are not always entirely self-incompatible. Powers and Rollins (1945, table 5, p. 110) obtained 3.8 per cent of seedlings upon selfing one of the 36 -chromosome plants. On the other hand, their data also indicate that apomeiosis may occur in these plants. In the $\mathrm{F}_{1}$ generation from a cross between a 36-chromosome guayule and mariola, no maternals occurred (Powers and Rollins, 1945, table 4, p. 107); but among the hybrids 3.6 per cent were of aberrant type. According to a personal communi- 
cation from Dr. R. C. Rollins, the aberrants were presumably triploids that arose through fertilization of unreduced, 36-chromosome eggs. The 3.6 per cent of nonreduction agrees well with the 4.2 per cent apomeiosis estimated for the 36-chromosome material in the present study.

TABLE 5

Relation between Size of Ovule and Stage of Embryo-Sac Development in 54-Chromosome Guayule, as Determined by Classifying 285 OVULES OF LOT 7 IN TABLE 1

\begin{tabular}{|c|c|c|c|c|c|c|c|c|c|}
\hline \multirow{2}{*}{ Contents of ovules } & \multicolumn{8}{|c|}{$\begin{array}{l}\text { Percentages of different contents in ovules } \\
\text { of the various size classes }\end{array}$} & \multirow{2}{*}{$\begin{array}{l}\text { Total } \\
\text { per cent } \\
\text { for } \\
\text { each } \\
\text { item }\end{array}$} \\
\hline & 1 & 2 & 3 & 4 & 5 & 6 & 7 & 8 & \\
\hline Resting megaspore mother cells.. & 3.5 & 10.2 & 9.1 & 10.6 & 6.9 & 2.5 & 1.8 & $\ldots$ & 44.6 \\
\hline Dividing megaspore mother cells. & $\ldots$ & $\ldots$ & 2.8 & 0.7 & 0.9 & 0.5 & $\ldots$ & $\ldots$ & 4.9 \\
\hline Dyads........................ & $\ldots$ & $\ldots$ & $\ldots$ & $\ldots$ & 0.2 & 0.2 & $\ldots$ & $\ldots$ & 0.4 \\
\hline Tetrads of megaspores............ & $\ldots$ & $\ldots$ & $\ldots$ & $\ldots$ & 0.4 & 0.3 & $\ldots$ & $\ldots$ & 0.7 \\
\hline $\begin{array}{l}\text { Uninucleate embryo sacs with } \\
\text { crushed megaspores........... }\end{array}$ & & & $\ldots$ & $\ldots$ & & & & & \\
\hline Binucleate embryo sacs.......... & $\ldots$ & $\ldots$ & 0.3 & 0.7 & 4.4 & $\dddot{3.3}$ & 4.9 & 1.1 & $\dddot{14.7}$ \\
\hline Tetranucleate embryo sacs....... & $\ldots$ & ... & $\ldots$ & 0.3 & 2.0 & 2.6 & 7.0 & 2.1 & 14.0 \\
\hline Seven-celled embryo sacs......... & $\ldots$ & $\ldots$ & $\ldots$ & $\ldots$ & $\ldots$ & $\ldots$ & 1.8 & 0.7 & 2.5 \\
\hline Degenerated material $\ldots \ldots \ldots \ldots$ & $\cdots$ & 0.3 & $\cdots$ & 1.1 & 5.9 & 7.0 & 3.2 & 0.7 & 18.2 \\
\hline Total. & 3.5 & 10.5 & 12.2 & 13.4 & 20.7 & 16.4 & 18.7 & 4.6 & $\ldots$ \\
\hline
\end{tabular}

TABLE 6

Relation between Size of OvUle and Stage of Embryo-Sac Development in 54-Chromosome Mariola, as Determined by Classifiying 235 OVULES OF LOT 17 IN TABLE 1

\begin{tabular}{|c|c|c|c|c|c|c|c|c|c|}
\hline \multirow{2}{*}{ Contents of ovules } & \multicolumn{8}{|c|}{$\begin{array}{l}\text { Percentages of different contents in ovules } \\
\text { of the various size classes }\end{array}$} & \multirow{2}{*}{$\begin{array}{c}\text { Total } \\
\text { per cent } \\
\text { for } \\
\text { each } \\
\text { item }\end{array}$} \\
\hline & 1 & 2 & 3 & 4 & 5 & 6 & 7 & 8 & \\
\hline Resting megaspore mother cells... & 11.9 & 7.2 & 15.3 & 11.0 & 4.3 & 0.4 & $\ldots$ & 0.4 & 50.5 \\
\hline Dividing megaspore mother cells. & $\ldots$ & 3.4 & 0.9 & 1.3 & $\ldots$ & $\ldots$ & $\ldots$ & $\ldots$ & 5.6 \\
\hline 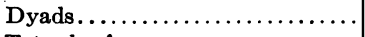 & $\cdots$ & $\cdots$ & $\cdots$ & $\ldots$ & $\ldots$ & $\cdots$ & $\cdots$ & $\ldots$ & $\ldots$ \\
\hline Tetrads of megaspores........... & $\ldots$ & ... & $\ldots$ & $\ldots$ & $\ldots$ & $\ldots$ & ... & $\ldots$ & $\ldots$ \\
\hline $\begin{array}{l}\text { Uninucleate embryo sacs with } \\
\text { crushed megaspores........... }\end{array}$ & $\cdots$ & & & & & & $\ldots$ & $\ldots$ & \\
\hline Binucleate embryo sacs......... & $\ldots$ & 0.4 & $\ldots$ & 1.7 & 1.4 & 1.2 & 0.9 & 0.4 & 6.0 \\
\hline Tetranucleate embryo sacs....... & $\ldots$ & $\ldots$. & $\ldots$ & 0.4 & 1.0 & 0.3 & $\ldots$ & 0.4 & 2.1 \\
\hline Seven-celled embryo sacs... & $\ldots$ & $\ldots$ & $\ldots$ & $\ldots$ & 2.8 & 2.7 & 2.6 & 1.7 & 9.8 \\
\hline Degenerated material........... & 1.3 & 0.9 & 4.7 & 8.5 & 5.0 & 3.1 & 2.5 & $\ldots$ & 26.0 \\
\hline Total.. & 13.2 & 11.9 & 20.9 & 22.9 & 14.5 & 7.7 & 6.0 & 2.9 & $\therefore$. \\
\hline
\end{tabular}

Table 5 relates embryo-sac development to ovule size in a 54-chromosome guayule plant. The course of events essentially resembles that in the 72-chromosome material. Here, too, the predominance of resting megaspore mother cells, their persistence during ovule enlargement, and the scarcity of views with megaspores point to facultative apomeiosis. Degeneration of contents of ovules was more prominent in this plant than in the 72-chromosome lots. The esti- 
mated per cent of apomeiosis was 88.2 (table 7, lot 7). A mass collection from the mixed polyploid variety marked lot 8 in table 1 , which contained some 54and 58-chromosome individuals, showed only 52.1 per cent of apomeiosis (table $7, \operatorname{lot} 8$ ).

A 108-chromosome type of plant (table 1, lot 14) exhibited a rather low percentage of apospory. Its estimated per cent of apomeiosis was 56.0 (table 7 ). The resting megaspore mother cells occurred in ovules of classes 1-7; and among 164 ovules only 3.7 per cent contained degenerated material.

TABLE 7

Megasporogenesis in Guayule with Various Numbers of Chromosomes, AND IN MARIOLA

\begin{tabular}{|c|c|c|c|c|c|c|c|c|c|}
\hline \multirow[b]{2}{*}{$\begin{array}{l}\text { Lot no. } \\
\text { in } \\
\text { table } 1\end{array}$} & \multirow[b]{2}{*}{$\begin{array}{l}\text { Approximate } \\
2 n \text { number of } \\
\text { chromosomes }\end{array}$} & \multirow[b]{2}{*}{$\begin{array}{l}\text { Number } \\
\text { of ovules } \\
\text { examined }\end{array}$} & \multicolumn{6}{|c|}{$\begin{array}{l}\text { Percentages of ovules showing generative tissue } \\
\text { in the following stages }\end{array}$} & \multirow[b]{2}{*}{$\begin{array}{c}\text { Esti- } \\
\text { mated } \\
\text { per cent } \\
\text { of } \\
\text { apomei- } \\
\text { osis† }\end{array}$} \\
\hline & & & $\begin{array}{l}\text { Resting } \\
\text { mega- } \\
\text { spore } \\
\text { mother } \\
\text { cells }\end{array}$ & $\begin{array}{l}\text { Dividing } \\
\text { mega- } \\
\text { spore } \\
\text { mother } \\
\text { cells }\end{array}$ & Dyads & Tetrads & $\begin{array}{c}\text { Uni- } \\
\text { nucleate } \\
\text { embryo } \\
\text { sacs with } \\
\text { crushed } \\
\text { nucellar } \\
\text { epi- } \\
\text { dermis* }\end{array}$ & $\begin{array}{l}\text { Uni- } \\
\text { nucleate } \\
\text { embryo } \\
\text { sacs } \\
\text { with } \\
\text { crushed } \\
\text { mega- } \\
\text { spores }\end{array}$ & \\
\hline
\end{tabular}

Guayule

\begin{tabular}{r|c|r|r|r|r|r|r|r|r}
\hline $1-6$ & 36 & 311 & 3.9 & 40.5 & 4.8 & 31.5 & 0.3 & 19.0 & 4.2 \\
7 & 54 & 144 & 69.4 & 9.7 & 0.7 & 1.4 & 18.8 & 0.0 & 88.2 \\
8 & $54,58,72$ & 119 & 43.7 & 46.2 & 0.0 & 1.7 & 8.4 & 0.0 & 52.1 \\
$9-13$ & 72 & 1,386 & 64.5 & 10.9 & 1.3 & 8.5 & 13.3 & 1.5 & 77.8 \\
14 & 108 & 116 & 49.1 & 27.6 & 1.7 & 13.8 & 6.9 & 0.9 & 56.0 \\
\hline
\end{tabular}

* Enlarged megaspore mother cells.

t Sum of per cent of resting megaspore mother cells and of uninucleate embryo sacs with crushed nucellar epidermis.

The mariola plant examined in this study showed considerable degeneration of ovular contents, and the breakdown began in the smallest ovules (table 6). Some undetermined environmental condition may have been the cause of so much degeneration, and perhaps the estimated 90.2 per cent of apomeiosis for this plant (table 7) is too high. The presence of aposporic reproduction is proved, nevertheless, by the occurrence of megaspore mother cells in so many classes of ovules, and by the enlargement of some of them to such an extent that the nucellar epidermis is crushed. According to Powers and Rollins (1945, table 4, p. 107), $18.2 \pm 11.6$ to 100 per cent of maternals occurred in $F_{1}$ progenies of mariola crossed with guayule. Some of these progenies also showed a fairly high per cent of aberrant hybrids.

Table 7 summarizes the megasporogenesis in all guayule lots and in the mariola plant used in the present study. The striking difference in the per cent of apomeiosis between the 36-chromosome plants and the other types of guayule has been sufficiently emphasized. This table gives no evidence that the degree 
of apospory in the polyploid plants is related to the chromosome numbers. Thus the 54-chromosome plant shows a higher per cent of apomeiosis than the average for the 72-chromosome plants, while the value for the 108-chromosome plant is below this average. As shown by Powers and Rollins's (1945) data, the per cent of apomixis may vary considerably within a given chromosomal group of guayule.

\section{EMBRYO AND ENDOSPERM DEVELOPMENT IN GUAYULE AND MARIOLA}

Table 8 illustrates the lack of definite relation between the development of the embryo and that of the endosperm in apomictic types of Parthenium-a

TABLE 8

Relation between Embryo and Endosperm Development in Guayule and in Mariola

\begin{tabular}{|c|c|c|c|c|c|c|c|c|c|}
\hline \multirow[b]{2}{*}{$\begin{array}{l}\text { Lot no. } \\
\text { in } \\
\text { table } 1\end{array}$} & \multirow[b]{2}{*}{$\begin{array}{l}\text { Approximate } \\
2 n \text { number of } \\
\text { chromosomes }\end{array}$} & \multirow[b]{2}{*}{$\begin{array}{l}\text { Number } \\
\text { of ovules } \\
\text { examined }\end{array}$} & \multicolumn{7}{|c|}{ Percentages of ovules with the various contents } \\
\hline & & & $\begin{array}{c}\text { Egg } \\
\text { and polar } \\
\text { fusion } \\
\text { nucleus }\end{array}$ & $\begin{array}{l}\text { Egg and } \\
\text { develop- } \\
\text { ing endo- } \\
\text { sperm }\end{array}$ & $\begin{array}{c}\text { Embryo } \\
\text { and polar } \\
\text { fusion } \\
\text { nucleus }\end{array}$ & $\begin{array}{l}\text { Embryo } \\
\text { and } \\
\text { develop- } \\
\text { ing } \\
\text { endo- } \\
\text { sperm }\end{array}$ & $\begin{array}{c}\text { Polar } \\
\text { fusion } \\
\text { nucleus } \\
\text { only }\end{array}$ & $\begin{array}{l}\text { Develop- } \\
\text { ing endo- } \\
\text { sperm } \\
\text { only }\end{array}$ & $\begin{array}{c}\text { Degener- } \\
\text { ated } \\
\text { material }\end{array}$ \\
\hline \multicolumn{10}{|c|}{ Guayule } \\
\hline 4 & 36 & 74 & 28.4 & 0.0 & 1.3 & 66.2 & 0.0 & 0.0 & 4.1 \\
\hline 5 & 36 & 111 & 25.2 & 0.0 & 0.0 & 55.0 & 0.0 & 19.8 & 0.0 \\
\hline 12 & 72 & 91 & 8.8 & 2.2 & 12.1 & 42.9 & 18.7 & 3.3 & 12.0 \\
\hline 13 & 72 & 95 & 3.2 & 0.0 & 33.7 & 46.2 & 0.0 & 5.3 & 11.6 \\
\hline 14 & 108 & 47 & 10.6 & 0.0 & 17.0 & 27.7 & 25.5 & 6.4 & 12.8 \\
\hline \multicolumn{10}{|c|}{ Mariola } \\
\hline 17 & 54 & 55 & 1.8 & 0.0 & 20.0 & 60.0 & 3.7 & 1.8 & 12.7 \\
\hline
\end{tabular}

lack already mentioned in the review of literature. This development was studied in all chromosomal types of guayule and in mariola. The headings concerning the contents of the embryo sacs in table 8 are best explained by reference to illustrations. Eggs and polar fusion nuclei of a 36-chromosome plant appear in plate $9, B$ and $C$. As was mentioned previously, in apomictic guayule the polar fusion nucleus becomes very large and lobed; it reminds one of the views given, in the literature, to illustrate triple fusion (plates $8, C$; and 12,C). The term "polar fusion nucleus" in table 8 is used, therefore, with the reservation that possibly some of the structures listed under this term were products of triple fusion. Plate $9, A$, shows an egg and some developing endosperm (the second endosperm nucleus appeared in the adjacent section) ; plate $11, D$, an embryo and a polar fusion nucleus. The embryos in plate 12, $A$ and $B$, were also accompanied by polar fusion nuclei. Incidentally, plate $12, B$, shows an intact synergid to the left of the embryo. The other synergid was also intact, 
and the presence of both these structures is usually taken to indicate that the pollen tube had failed to enter the embryo sac. Figure 4, $K$, illustrates a belated initiation of endosperm in the presence of an embryo. Embryos and developing endosperm appear in plates $11, A-C ; 12, D$; and 13 . The heading "polar fusion nucleus only" is illustrated diagrammatically in figure $4, I$; "developing endosperm only" in figure $5, E$. Because of degeneration, eggs or embryos are absent in embryo sacs appearing under the above two headings in table 8. If degeneration had progressed far enough to make the contents unidentifiable (fig. 4, $W$ ), the embryo sac was classified as "degenerated." Figures 4 and 5 show many of

TABLE 9

Embryo and Endosperm Development in 72-Chromosome Guayule, Variously Pollinated

\begin{tabular}{|c|c|c|c|c|c|c|c|}
\hline \multirow{2}{*}{$\begin{array}{l}\text { Number of days } \\
\text { (collection no.) } \\
\text { after pollination }\end{array}$} & \multirow{2}{*}{$\begin{array}{l}\text { Number } \\
\text { of ovules } \\
\text { examined }\end{array}$} & \multicolumn{3}{|c|}{$\begin{array}{l}\text { Percentages of ovules with the } \\
\text { various kinds of embryo }\end{array}$} & \multicolumn{3}{|c|}{$\begin{array}{l}\text { Percentages of ovules with the } \\
\text { various kinds of endosperm }\end{array}$} \\
\hline & & $\underset{\text { in }}{\text { Normal }}$ & $\begin{array}{l}\text { Under- } \\
\text { developed }\end{array}$ & $\mid \begin{array}{c}\text { None or } \\
\text { degenerated }\end{array}$ & $\begin{array}{l}\text { In stage of } \\
\text { few to } \\
\text { many cells }\end{array}$ & $\begin{array}{l}\text { In stage } \\
\text { of single } \\
\text { nucleus }\end{array}$ & $\begin{array}{l}\text { Degener- } \\
\text { ated }\end{array}$ \\
\hline $1 \ldots$ & 97 & 84.6 & 4.1 & 11.3 & 43.3 & 47.5 & 9.2 \\
\hline 2. . & 117 & 76.0 & 6.0 & 18.0 & 48.7 & 41.0 & 10.3 \\
\hline $3 \ldots$ & 93 & 63.5 & 3.2 & 33.3 & 56.0 & 31.2 & 12.8 \\
\hline
\end{tabular}

Plant no. 427-4

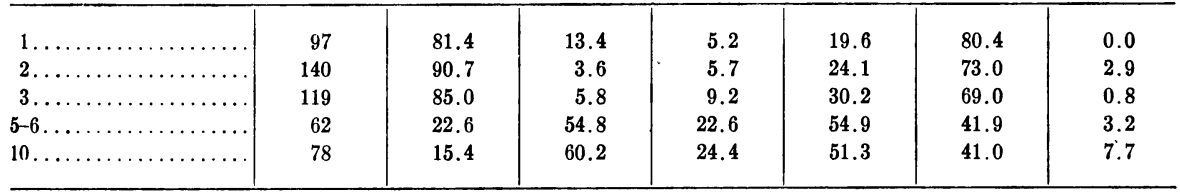

the variations in the manner of embryo and endosperm development in apomictic guayule.

The material in table 8 was derived from open-pollinated plants. The degree of maturity of the achenes varied somewhat in the different lots, and this variation probably caused in part the differences in percentages of eggs and polar fusion nuclei in these lots.

Judging from table 8 , the initiation of the embryo and endosperm are closely related in the predominantly sexual 36 -chromosome guayule. This probability is indicated by the lack of views of eggs with developing endosperm and the scarcity of views showing an embryo with a polar fusion nucleus. Usually, when an embryo is present, there is also some developing endosperm. Abnormalities, however, occur in the 36-chromosome guayule. In lot 5 many embryo sacs contained developing endosperm, but no eggs or embryos; in lot 4 one embryo sac contained an embryo and a polar fusion nucleus, and several others had degenerated contents. 
In contrast to the 36 -chromosome guayule (table 8 , lots 4 and 5), the predominantly apomictic types of Parthenium (table 8, lots 7-17) show many embryos not associated with developing endosperm and occasionally the endosperm begins to develop before the embryo. Many eggs and embryos degenerate, while the polar fusion nuclei or the endorsperm remain intact, at least temporarily ; or the endosperm or its precursor also degenerate.

Thus the 36-chromosome guayule used in this study showed a close correlation between embryo and endosperm in their development, the former rarely appearing without the latter. In the other types of guayule and in the mariola, the embryo and the endosperm usually developed together; but often the for-

TABLE 10

Embryo and Endosperm Development in Nonpollinated 72-Chromosome Guayule

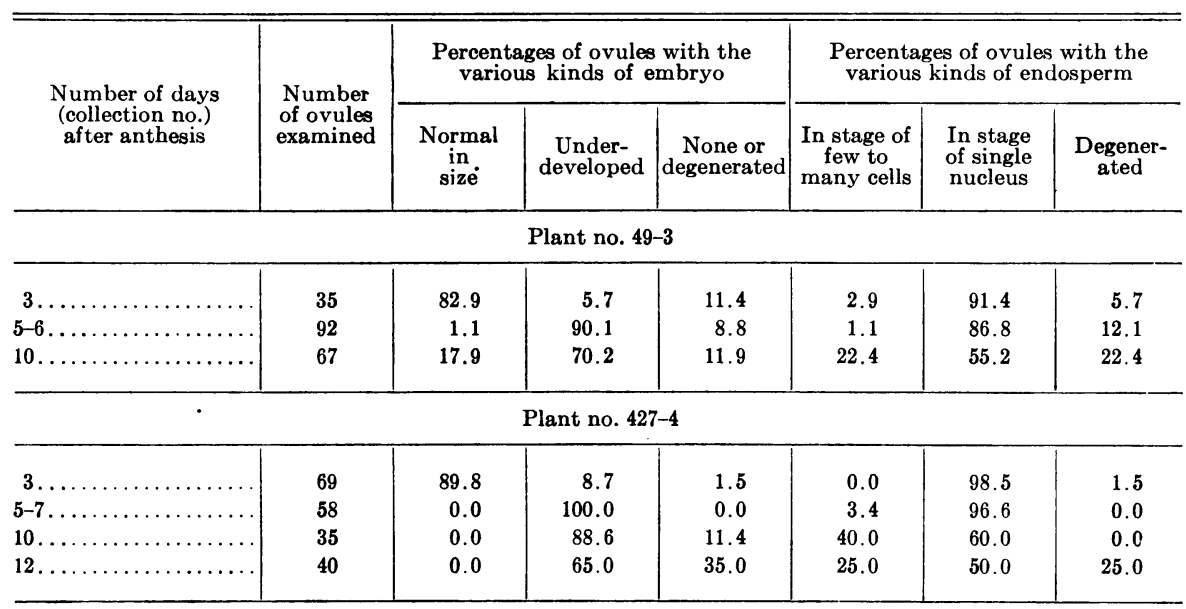

mer appeared first. The rather close correlation in development appears to be associated with the tendency toward normal sexuality in the 36-chromosome guayule; whereas the lack of such correlation in the other types of Parthenium represented in table 8 must be one of the phenomena of apomictic reproduction in these types.

Apomeiosis usually results in the formation of a diploid gametophyte with an unreduced egg capable of producing an embryo without fertilization. Powers and Rollins (1945) found proof of the common occurrence of such embryos in 72-chromosome guayule and in mariola in observing that maternal types predominated in the $\mathrm{F}_{1}$ hybrid generation from such plants. Though initiated without fertilization, an apomictic embryo may fail to develop if pollination is excluded. In their comprehensive pollination studies, Powers and Rollins (1945, tables 1 and 2) first obtained some viable seed from emasculated and bagged flower heads of apomictic guayule. With subsequent refinement of methods, no viable seeds were obtained from nonpollinated flowers, and therefore these authors concluded that such seed was not formed in apomicts unless pollination occurred. They also found that self-pollination and intraspecific cross-pollination were about equally effective in inducing development of viable seed in apomicts. 
Besides the series of plants used by Powers and Rollins (1945) to obtain the data for their table 1, two plants, nos. 43-3 and 427-4, were similarly treated; and the material was sent to the present writer for a morphologic study on the
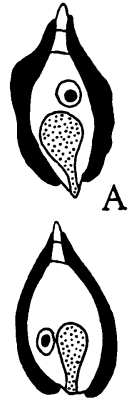

B

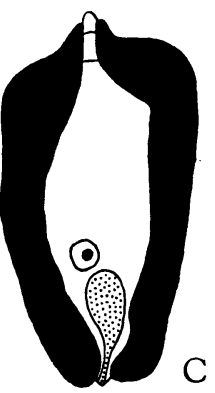

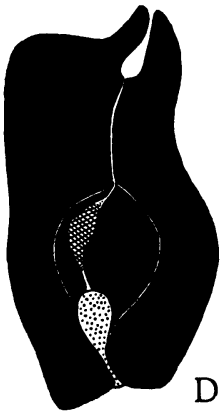
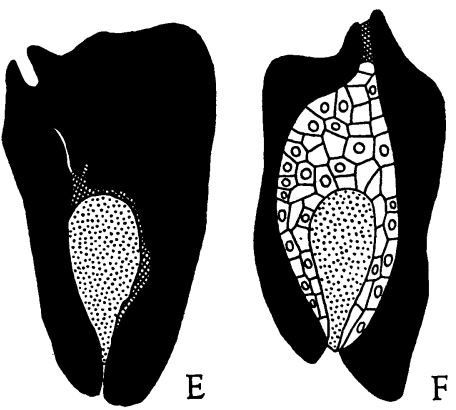

Nonpollinated, 3 to 12 days after anthesis

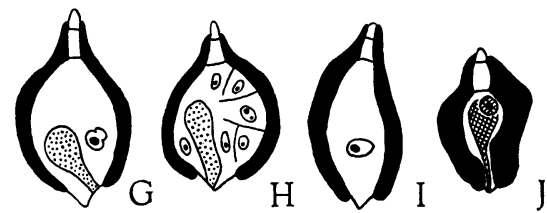

Cross-pollinated, 1 day

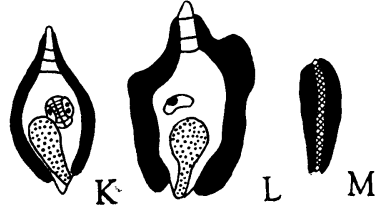

self-pollinated, 1 day
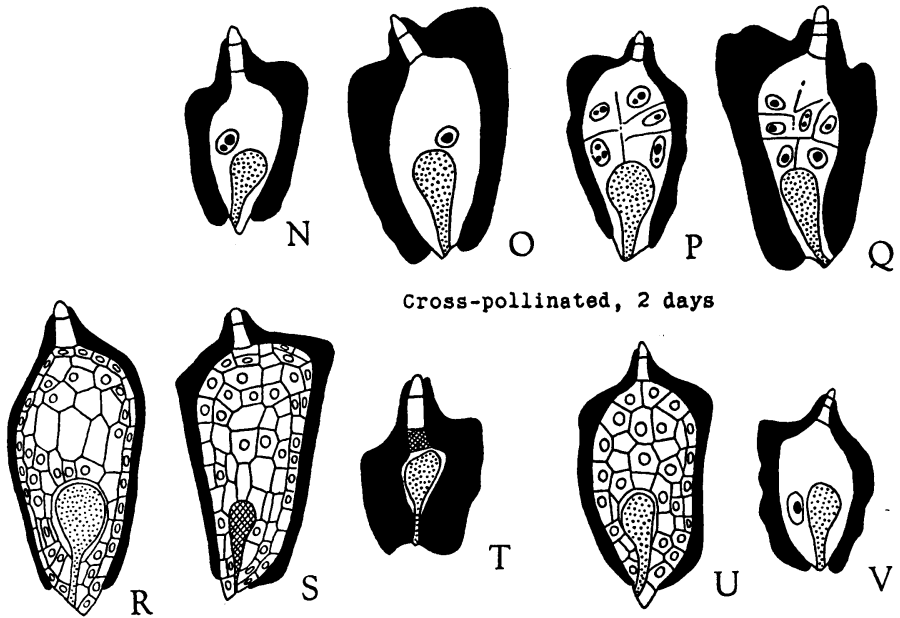

Cross-pollinated, 3 days

$\mathrm{T}$

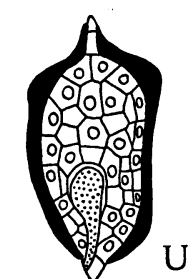

Self-pollinated, 3 days

Fig. 4.-Diagrams of longitudinal sections of embryo sacs from 72-chromosome guayule plants that were used in pollination experiments. Six groups of embryo sacs appear in this figure, each from a differently treated group of flowers. The treatment and the number of days (collection no.) between pollination (or anthesis) and collection are given under each group of embryo sacs. In the diagrams the nutritive jacket is shown in solid black, the embryo is stippled, and the degenerating structures are cross-hatched. The endosperm or its precursor is represented by outlines of nuclei or of cells with nuclei; the antipodals by cell outlines. $A-E$ and $G-W$ are from plant $49-3 ; F$, from plant $427-4$. (All $\times 80$.) 
effect of pollination upon the development of apomictic embryos. The collections for this study were made at successive intervals after pollination (or after anthesis in the nonpollinated flowers). All treatments described by Powers
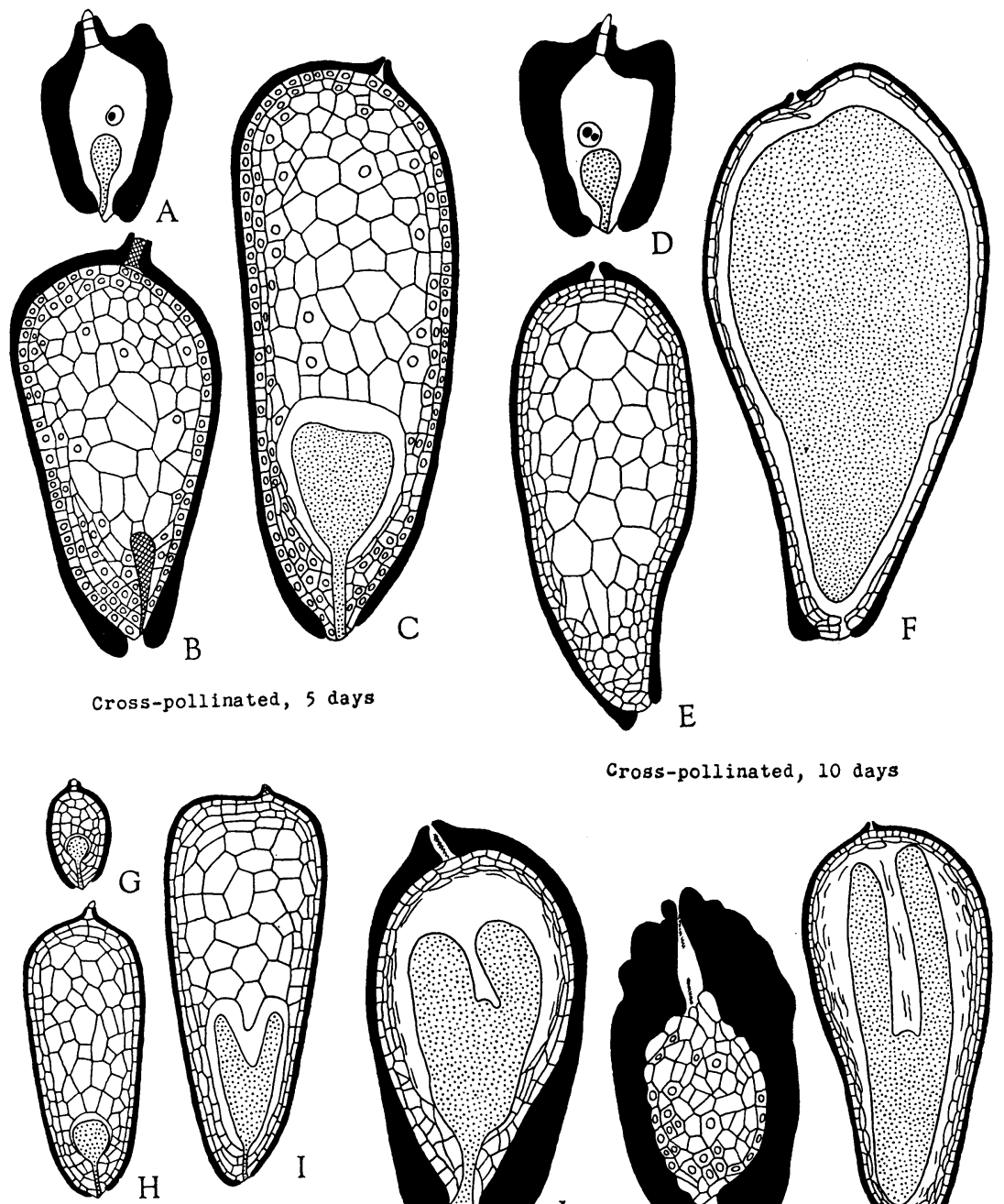

Open-pollinated, 5 days

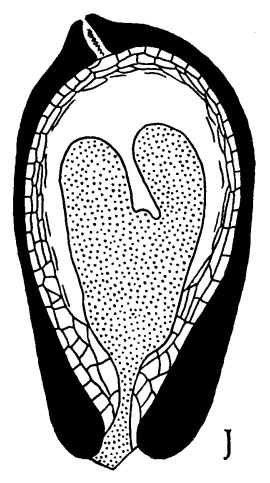

Cross-pollinated, 10 days

$$
\text { Cross-pollinated, } 10 \text { days }
$$

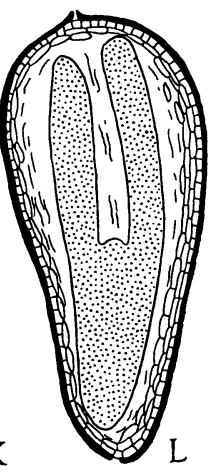

Fig. 5.-Diagrams of longitudinal sections of embryo sacs from 72-chromosome guayule plants that were used in pollination experiments. Details of presentation are as in figure 4 , except that figure 5 shows only four groups of ovules. $A-F$ are from plant $49-3 ; G-L$, from plant $427-4$. $(A-D, J$, and $K, \times 80 ; E-I$ and $L, \times 34$. $)$

and Rollins (1945) in their table 1, except treatment 3, were represented in the material sent to Davis. Tables 9 and 10 show the results of the morphologic study of this material. Since all the treatments involving pollination (open pollination, and controlled self- and cross-pollinations) yielded similar results (see also Powers and Rollins, 1945), the data from the variously pollinated 
material were combined in table 9. Results with the nonpollinated flowers have heen compiled in table 10.

Tables 9 and 10 give the data on embryo and endosperm separately. Apparently under all conditions of growth and pollination, embryo development in guayule lacks uniformity, especially in the apomictic types of plants. Shortly after anthesis, embryos tend to vary within a narrow size range; but later the variation is very great. To determine the normal size for an embryo at a given time after anthesis was therefore problematical; the estimate was made somewhat arbitrarily for tables 9 and 10 . One to three days after pollination (table 9 ), the embryos were somewhat similar in size. Figures $4, G, H, K$, and $L$, illustrate normal-sized embryos in collection 1 (made 1 day after pollination); the embryo in plate $11, B$, however, was grouped with the eggs (or zygotes) among the underdeveloped embryos in collections 1 . Normal embryos for collections 2 appear in figure $4, N-Q$, and in plates $11, C$, and $12, B$. Plate $11, A$, shows a small embryo of a collection 3 ; normal embryos for collections 3 are represented in plate $11, D$, and figure $4, R, T, U$, and $V$. The collections made 5 days after pollination contained such underdeveloped embryos as in plate 12, $A$, and in figure 5, $A$ and $G$. The normal-sized embryos in these collections showed cotyledons in several stages of initiation and early development (plate $13, A$ and $B$, and fig. 5, $C, H$, and $I$ ). Plate $12, D$, depicts an underdeveloped embryo from collection 7 ; figure $5, D$ and $J$, such embryos from collection 10. Embryos of normal size for the collections taken 10 days after pollination are shown in plate $13, C$, and figure $5, F$ and $L$. These are full-sized or nearly so. "Degenerated embryos" occur in figures $4, J, M, S, W ; 5, B$, and in plate 14 , $B$; embryos are absent in figures $4, I ; 5, E$ and $K$, and in plate $16, C$. The endosperm is "in stage of few to many cells" in figures 4, H, K, $P-S, U ; 5, B, C, E$ $L$; and in plates $11, A-C, 12, D$, and 13. It is "in stage of single nucleus" (probably mostly polar fusion nucleus) in figures $4, G, I, L, N, O$, and $V ; 5, A$ and $D$; and plates $11, D$, and 12, $A-C$. Endosperm was degenerated in embryo sacs like those in figure $4, J, M, T$, and $W$; and plate $14, B$.

According to table 9 , in both plants $49-3$ and $427-4$ over 80 per cent of the ovules contained normal-sized embryos 1 day after pollination. Such embryos continued to predominate on the two following days. The remaining embryos were underdeveloped or degenerated. Despite the good start, however, many embryos stopped or slowed down their enlargement, so that 5 to 10 days after pollination the per cent of normal-sized embryos dropped perceptibly. On the last day of collection the predominant type became either the underdeveloped (plant 427-4) or the degenerated embryo (plant 49-3). In the first 3 days after pollination the endosperm lagged behind the embryos in development; but later it overtook them, in samples taken 5 to 10 days after pollination. The endosperm was less susceptible to degenerative changes than the embryo.

The degeneration of the embryos depends, at least partly, on the behavior of the endosperm. According to all observations thus far, if the endosperm does not develop, the embryo may start, but degenerates eventually. No embryos associated with a single nucleus in the primary endosperm cell were found to be larger than that in plate 14, $C$. Those underdeveloped embryos that are associated with an "endosperm in stage of single nucleus" (table 9 ) may therefore be expected to degenerate eventually. Some of the underdeveloped embryos 
that were imbedded in cellular endosperm may have continued development. The presence of normal-appearing endosperm, however, does not always assure continuous development of embryos : the latter frequently degenerate in the presence of good endosperm (figs. $4, S ; 5, B, E$, and $K$ ). The endosperm seems to depend less on the embryo than the embryo on the endosperm: the former may continue developing even if the embryo degenerates early or is not formed at all (fig. 5, $E$ ). Some of the endosperm developing without an embryo shows the usual thin cytoplasm of normal embryo sacs and develops large cells in the center of the sac, in contrast to the smaller cells near the periphery. Thus in figure 5, $E$, the endosperm without an embryo resembled in all respects that of the normal embryo sac in figure 5, $C$. Other endosperm developed abnormally, lacked differentiation in cell size, and had rather dense cytoplasm (fig. $5, K$, and plate $16, C)$.

The final per cent of achenes with normal embryos in plant 49-3 approaches the average values for per cent of viable seed in the different pollination treatments performed by Powers and Rollins (1945, table 1 ) ; plant 427-4 shows a lower value. Both plants had a lower per cent of normal-sized embryos than the per cent of "seeds with cotyledons and presumably embryos" in the selfed plants of Powers and Rollins (1945, table 2). One cause of these discrepancies may be the relatively small number of achenes examined in the present study, as contrasted with the large numbers used by Powers and Rollins (1945). Second, since these authors harvested their seed at maturity (it was at least 2 months old ), some of the underdeveloped embryos may have had time to complete their development.

Judging by table 10, exclusion of pollination does not affect the initiation of embryos : 3 days after anthesis, over 80 per cent of ovules from nonpollinated flowers had embryos of normal size. In one plant (427-4) no embryo reached full size at the end of the experiment; in the other (49-3), 17.9 per cent developed into full-sized embryos or nearly so. The endosperm was delayed, as compared with that in the pollinated flowers, and ultimately developed in fewer ovules. That it was formed at all in the nonpollinated flowers may mean that the polar fusion nucleus itself is capable of giving rise to endosperm. On the other hand, according to Powers and Rollins (1945, p. 99), some accidental pollination might have occurred in this batch of material. Later an additional nonpollinated sample was investigated: heads of plant 593-I, which was also used in the fertilization studies (see "Material and Methods"), were emasculated and bagged. Among 55 mature achenes, 12.7 per cent had degenerated embryo sacs; 61.9 per cent contained embryos not larger than the one in plate $14, C ; 1.8$ per cent had good eggs, and 23.6 per cent degenerated eggs ; 87.3 per cent showed single nuclei in the primary endosperm cells, and none had any developing endosperm. Figure 4, $A-F$, shows some ovules from the nonpollinated material used for table 10. These were taken the following number of days after anthesis : $4, B, 1$ day ; $4, A, C$ and $D, 3$ days ; $4, E$, 10 days ; $4, F, 12$ days. Plate $14, C$ and $D$, shows embryos and polar fusion nuclei in ovules collected 6 and 18 days after anthesis, respectively.

Judging from these pollination experiments, exclusion of pollination does not prevent the initiation of embryos; pollination is beneficial or perhaps even indispensable for endosperm development; and the absence of developing 
endosperm precludes complete development of the embryos. These data and the results of the pollination studies of Powers and Rollins (1945) permit a conclusion-namely, that apomeiosis leads to the initiation of an embryo without fertilization, but that pollination promotes endosperm development and is necessary for the formation of viable seed (pseudogamy). In the work of Powers and Rollins (1945), the maternal plants in the $\mathrm{F}_{1}$ hybrid progenies of apomictic guayule - and consequently also the embryos from which these maternals grew-had the same numbers of chromosomes as the mother plants. Hence in apomictic guayule, apospory is followed by unreduced pseudogamy.

The ultimate cause of degeneration of so many embryos in pollinated flowers has not been revealed by the present study. The lack of endosperm development-and with it the cessation of growth of any embryos initiated-may result from some deficiency in fertilization in the apomicts. This suggestion is borne out by the common occurrence of normally developing endosperm in the open-pollinated predominantly sexual 36-chromosome plants (table 8). Many embryos or eggs, however, degenerate in the presence of developing endosperm; such degeneration occurs in both the apomicts and the sexual guayule (table 8, ninth column). Powers and Rollins (1945) also found comparatively low germination in seeds of 36 - and 72-chromosome guayule. Though environmental conditions influence the quality and quantity of seed produced by guayule (Whitehead and Mitchell, 1943; Mitchell et al., 1944), internal factors must be involved also.

Powers and Rollins (1945) observed a pronounced difference in the degree of self-compatibility in the 36- and 72-chromosome plants. The former were found highly self-sterile; in the latter, self-pollination and cross-pollination within the species were found similarly effective in producing viable seed. In fact, selfing sometimes gave more good seed than intraspecific crosses (Powers and Rollins, 1945, table 1, p. 100). Interspecific crosses, however, consistently gave higher amounts of viable seed than selfing. Some material was available for a morphologic study of self-sterility and self-fertility. Heads with a total of 30 flowers of the 36-chromosome plant of lot 5 (table 1) were emasculated and selfed. Fourteen days after pollination, none of these contained embryos or endosperm; a few had eggs and polar fusion nuclei; and the rest showed only degenerated contents. The 36-chromosome plant of lot 4 bloomed for a time at Davis, in a greenhouse where no other guayule plant was flowering. The 120 oldest achenes collected after this blooming period contained the following : 97.5 per cent of eggs and polar fusion nuclei; 1.7 per cent of embryos and developing endosperm; 0.8 per cent of embryo sacs younger than 7-celled. Similar achenes from open-pollinated material had over 60 per cent of embryo sacs with embryos and developing endosperm (table 8 ). Plate $9, C$, shows an egg and a polar fusion nucleus from an old nonpollinated flowër, as contrasted with those just ready for fertilization in plate $9, B$. Self-sterility is well illustrated by the observations just mentioned and the 1.7 per cent of embryos in one of the self-pollinated samples might have been apomictic. As a further check on apomixis in 36-chromosome guayule, some flower heads were emasculated and bagged. The 36 ovules collected from these heads had neither embryos nor endosperm.

From 5 to 10 days after pollination, plant 427-4 showed, upon self-pollina- 
tion, 82.9 per cent of embryos and 45.1 per cent of sacs with developing endosperm in 82 ovules; and upon cross-pollination (intraspecific cross), 67.2 per cent of embryos and 63.5 per cent of sacs with developing endosperm in 58 ovules. Plant $4 \dot{9}-3$ was for a time the only guayule growing in a green house at Davis. The 133 fully developed achenes collected at this time had 54.1 per cent of full-sized embryos, 15.8 per cent of underdeveloped embryos, and 54.9 per cent of sacs with developing endosperm. The two 72-chromosome plants above obviously showed a high degree of self-compatibility.

To check whether or not apomictic embryos tend to start developing before the normal ones, the development of the embryo sac was related to that of the

TABLE 11

Relation between Development of the Pistillate Flower and Development of the Embryo Sac in the 36-Chromosome Guayule of Lot 4 in Table 1

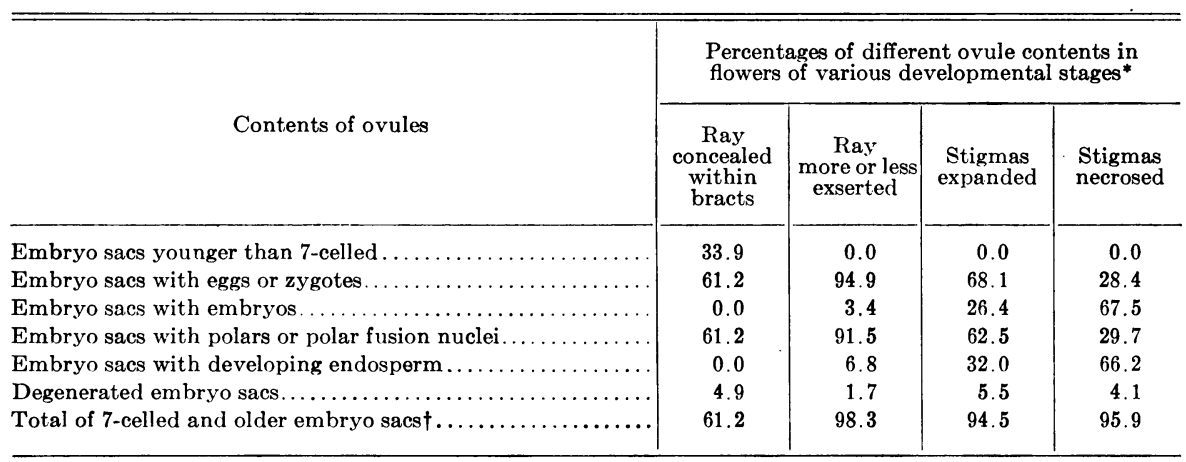

* Numbers of ovules examined for the respective data columns reading from left to right are: $121,59,72$, and 74

+ Total of embryo sacs with eggs, zygotes, and embryos; or total of embryo sacs with polars, polar fusion nuclei, and developing endosperm.

pistillate flower, and these data were compared for the sexual and apomictic types of guayule. Four stages of flower development were used (tables 11, 12, and 13) : in the first and youngest, the ray of the corolla was still concealed within the involucral bracts; in the second, it was more or less exserted; in the third, the stigmas of the pistillate flowers were fully extruded and expanded; in the fourth, they were brown and withered.

As table 11 shows, in a 36-chromosome plant the maturation of the female gametophyte occurs before the pistillate flowers emerge from the bracts. When the ray corollas become exserted, the flowers contain no embryo sacs younger than 7-celled. Judging by the first appearance of the embryos, pollination and fertilization occur before the stigmas are fully expanded. In some ovules the endosperm develops slightly before the embryos-a fact evidenced in table 11, by the higher per cent of embryo sacs with developing endosperm than of sacs with embryos. In the oldest achenes this lag disappears. (Among the old achenes, 1.3 per cent contained embryos without endosperm, as shown in table 8.) Some embryo sacs in all four kinds of flowers had degenerated contents.

The polyploid types of guayule differed from the 36-chromosome plants in details of development in the embryo sacs, but embryos were initiated in flowers at the same stage of development as in the sexual guayule (tables 12 and 13). The endosperm began to develop somewhat later in the 72-chromosome 
plants. According to these data, the apomictic embryos do not appear earlier than the normal ones.

The lack of orderly sequence in the development of the embryo sac in the polyploid guayule, which was discussed earlier in this paper, is also apparent from tables 12 and 13 : embryo sacs younger than 7-celled and unfused polars occurred in flowers of all stages. In the 36-chromosome plant (table 11) only the youngest flowers contained immature gametophytes and polars. (The latter were so few that they were not counted separately from the polar fusion

TABLE 12

Relation between Development of the Pistillate Flower and Development of the Embryo SaC in 72-Chromosome Guayule

(Combined data from lots 9 and 10 in table 1 )

\begin{tabular}{|c|c|c|c|c|}
\hline \multirow[b]{2}{*}{ Contents of ovules } & \multicolumn{4}{|c|}{$\begin{array}{l}\text { Percentages of different ovule contents in } \\
\text { flowers of various developmental stages* }\end{array}$} \\
\hline & $\begin{array}{c}\text { Ray } \\
\text { concealed } \\
\text { within } \\
\text { bracts }\end{array}$ & $\begin{array}{c}\text { Ray } \\
\text { more or less } \\
\text { exserted }\end{array}$ & $\begin{array}{c}\text { Stigmas } \\
\text { expanded }\end{array}$ & $\begin{array}{l}\text { Stigmas } \\
\text { necrosed }\end{array}$ \\
\hline Embryo sacs younger than 7-celled. & 65.6 & 23.8 & 5.8 & 0.0 \\
\hline Embryo sacs with eggs or zygotes....... & 11.0 & 37.3 & 50.3 & 3.7 \\
\hline Embryo sacs with embryos.......................... & 0.0 & 0.4 & 7.2 & 63.1 \\
\hline 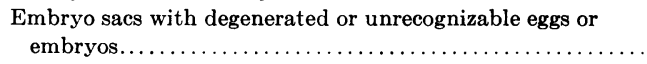 & 10.9 & 16.0 & 20.9 & 20.1 \\
\hline Embryo sacs with polar nuclei....................... & 16.4 & 19.3 & 7.9 & 0.5 \\
\hline Embryo sacs with polar fusion nuclei..... & 5.5 & 34.4 & 56.8 & 31.3 \\
\hline Embryo sacs with developing endosperm.. & 0.0 & 0.0 & 13.7 & 55.1 \\
\hline Entirely degenerated embryo sacs........ & 10.9 & 16.4 & 12.2 & 11.7 \\
\hline Unidentified embryo sacs............. & 1.6 & 6.1 & 3.6 & 1.4 \\
\hline Total of identified 7-celled and older embryo sacs $\dagger . .$. & 21.9 & 53.7 & 78.4 & 86.9 \\
\hline
\end{tabular}

${ }^{*}$ Numbers of ovules examined for the respective data columns reading from left to right are: $128,244,139$, and 214 .

$\dagger$ Total of embryo sacs with eggs, zygotes, embryos, and unrecognizable eggs and embryos; or total of embryo sacs with polar nuclei, polar fusion nuclei, and developing endosperm.

nuclei in table 11.) Among the unidentified embryo sacs (tables 12 and 13), many showed abnormal structure. Sometimes they had extra nuclei; or they consisted of several uni- or binucleate cells, as though all four megaspores were developing into embryo sacs; or one cell had several nuclei, and another had one. Parts of some sacs resembled those of a 7-celled embryo sac, but seemed incompletely differentiated. The mixed polyploid lot (table 13) had more of these abnormal and also of degenerating embryo sacs than the 72-chromosome guayule (table 12). As a rule, degeneration was more pronounced in the polyploid plants (tables 12 and 13) than in the diploid (table 11).

The degenerative changes in the embryo sac of guayule merit a brief characterization. The most striking feature is the-hyperplastic development of the nutritive jacket, similar to the development described by Brink and Cooper (1940) and Cooper and Brink (1940) in their studies on somatoplastic sterility. The normal nutritive jacket is one cell thick. In hyperplastic development it becomes multiseriate through a series of periclinal divisions (plates $12, A ; 14, B-D ; 15, A$; and 16$)$. Through this growth the nutritive jacket may more or less occlude the lumen of the embryo sac (figs. $4, D, E, M, T$, and $W$; 
$5, K$; plates $14, B$; and 16$)$. The degree of thickening of the nutritive jacket occurs without relation to any obvious morphologic features of the embryo sac. As figures 4 and 5 show, either thinner or thicker nutritive jackets may enclose embryo saes with and without embryos and with and without developing endosperm. In plate $14, B$, the nutritive jacket was occluding a degenerating embryo ; in plate $16, A$, on the other hand, the embryo was still actively dividing, especially on the periphery, as though resisting the encroachment by the highly hyperplastic nutritive jacket. In both these embryo sacs the endosperm (or its precursor) had previously degenerated. The antipodals, however, were still

TABLE 13

Relation between Development of the Pistillate Flower and Development of the Embryo Sac in Mixed Polyploid Guayule Collection of Lot 8 in Table 1

\begin{tabular}{|c|c|c|c|c|}
\hline Contents of ovules & \multicolumn{4}{|c|}{$\begin{array}{l}\text { Percentages of different ovule contents in } \\
\text { flowers of various developmental stages* }\end{array}$} \\
\hline Embryo sacs with eggs or zygotes $\ldots \ldots \ldots \ldots \ldots \ldots \ldots \ldots \ldots$ & 43.5 & 42.9 & 28.4 & 17.0 \\
\hline 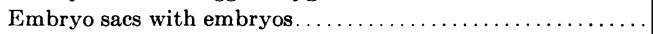 & 0.0 & 1.0 & 2.1 & 41.2 \\
\hline $\begin{array}{l}\text { Embryo sacs with degenerated or unrecognizable eggs or } \\
\text { embryos } \ldots \ldots \ldots \ldots \ldots \ldots \ldots \ldots \ldots \ldots \ldots \ldots \ldots\end{array}$ & 4.4 & 4.0 & 7.4 & 8.8 \\
\hline Embryo sacs with polar nuclei $\ldots \ldots \ldots \ldots \ldots \ldots \ldots$ & 4.4 & 3.0 & 9.5 & 3.1 \\
\hline Unidentified embryo sacs.............. & 7.7 & 5.1 & 12.6 & 7.7 \\
\hline Total of identified 7-celled and older embryo sacs $\dagger$. & 47.9 & 47.9 & 37.9 & 67.0 \\
\hline
\end{tabular}

* Numbers of ovules examined for the respective data columns reading from left to right are: $90,98,95$, and 194 .

$\dagger$ Total of embryo sacs with eggs, zygotes, embryos, and degenerated eggs and embryos; or total of embryo sacs with polar nuclei, polar fusion nuclei, and developing endosperm.

intact in the embryo sac in plate $14, B$. In plate $16, B$, the hyperplastic nutritive jacket had enveloped a rather large embryo of abnormal shape and had almost separated it from the endosperm. The thick jacket in plate $16, C$, surrounds an embryo sac without an embryo but with some abnormal endosperm. Plate 14, $C$ and $D$, characterize embryo sacs from nonpollinated flowers of 72 . chromosome guayule. Six days after anthesis, the jacket cells still had dense cytoplasm (plate 14, $C$ ); but 18 days after anthesis, the cytoplasm was thin, and the jacket apparently had ceased to grow (plate 14, D). The embryo sacs in nonpollinated and self-pollinated flowers of 36-chromosome guayule, which contained no embryos, were frequently characterized by thickened nutritive jackets. Some, however, had thin jackets that were breaking down. Degenerative changes may occur during the early megasporogenesis. For example, plate 14, $A$, illustrates collapsed nucellar epidermis (cells with thin cytoplasm in the center of the picture) enclosed by a nutritive jacket that is somewhat thickened in the region toward the micropyle (below in the photograph). Such early degeneration may be followed by a perceptible thickening of the nutritive jacket (fig. 4, $M$ ). Apparently many kinds of abnormalities in embryo-sac development may induce hyperplastic proliferation in the nutritive jacket. 


\section{FERTILIZATION EXPERIMENTS WITH GUAYULE}

The fertilization studies were designed to compare the phenomena of fertilization in a 36- and a 72-chromosome guayule plant. Both plants were pollinated with pollen from 72-chromosome guayule. (See "Material and Methods.") The flower heads were emasculated before the ray-florets had emerged from the involucral bracts and been bagged. The flowers were pollinated when the stigmas had expanded and appeared receptive. The collections were made at emasculation time; at pollination, before the pollen was applied to the stigmas ; and every hour for 6 hours thereafter. The choice of the earliest time for collection after pollination was based on the report by Dianowa and her coworkers (1935) that fertilization in Parthenium argentatum occurred 1 hour after pollination. In the experiment with the 72-chromosome plant, the first collection was made $1 / 2$ hour after pollination. Tables 14 and 15 give the numbers of ovules in each collection. Because of technical difficulties, the pollinations and collections had to be repeated on different days. In consequence, as will be indicated later, some differences occurred in the flowers treated.

The results of the fertilization experiments with 36-chromosome guayule, are given in table 14. As a rule, indications of accomplished fertilization were obvious; but the early stages of sperm entry into the embryo sac were not observed. Even the collections made 1 hour after pollination (table 14) showed the male nucleus within the egg, more or less fused with the nucleus of the latter; and the second sperm nucleus was at this time fused with the polar fusion nucleus. The wormlike male nuclei described by Gerassimova (1933-34) for Crepis capillaris were not recognized. Possibly the stages studied were too old to indicate the original appearance of the sperms when they occur in the pollen tube or emerge from the latter. All male nuclei were of ordinary appearance and resembled those depicted by Land (1900) for Erigeron. Plate 10 illustrates some typical evidences of fertilization in 36-chromosome guayule. In plate 10, $A$, the egg nucleus (with the distinct nucleolus) is in contact with the male nucleus. The primary endosperm nucleus is lobed because of recent fusion with a male nucleus ; it also shows two small nucleoli beside the large nucleolus of the polar fusion nucleus. Remnants of the pollen tube, in the form of a dark streak, partly envelop the egg. These remnants appear massive in the view in plate $10, B$. The egg in $10, B$, contained a male nucleus; but the latter came into view at a lower focus than the image in plate $10, B$. The endosperm nucleus in this embryo sac, though not lobed, contained two extra small nucleoli derived from the male nucleus. (Only one is in focus in plate 10,B.) Plate 10, $C$, shows parts of one pollen tube in the micropyle and in the embryo sac. The egg in this sac was fertilized. As a rule one or both synergids were unmistakably broken down, in the presence of signs that a pollen tube had entered the embryo sac. Synergids, however, may present a disorganized aspect in unpollinated material ; moreover, they are easily damaged in the preparation of the material for slide making. Their appearance, therefore, was not used to identify the occurrence of fertilization.

The eggs and the endosperm (or its precursor) were classified separately in table 14. The values for the eggs add up to 100, as do those for the endosperm. In addition, a separate item gives the per cent of ovules that showed remnants 
of pollen tubes. The latter were counted only if they were positively identified and were clearly distinguishable from disintegrating synergids. If the embryo sac showed no evidence of fertilization, it fell into the group of sacs containing unfertilized eggs and polar fusion nuclei. If the male nucleus was observed within the egg (in no view did it occur outside), the egg was classed as fertilized. Apparently after the complete fusion of the sperm and egg nuclei, the evidence of accomplished fertilization becomes obscured until the zygote begins to divide. Nowhere in this study, therefore, has a separate classification of eggs and zygotes been attempted. If the egg carried no clear indication of

TABLE 14

Fertilization Data on 36-Chromosome Guayule Pollinated with Pollen From a 72-Chromosome GUA yule

\begin{tabular}{|c|c|c|c|c|c|c|c|c|}
\hline \multirow{2}{*}{ Contents of ovules } & \multicolumn{2}{|c|}{$\begin{array}{c}\begin{array}{c}\text { Percentages of } \\
\text { different } \\
\text { ovule contents }\end{array} \\
\text { ove }\end{array}$} & \multicolumn{6}{|c|}{$\begin{array}{l}\text { Percentages of different ovule contents at the } \\
\text { given number of hours after pollination* }\end{array}$} \\
\hline & $\begin{array}{c}\text { At time } \\
\text { of } \\
\text { emascu- } \\
\text { lation }\end{array}$ & $\begin{array}{c}\text { At time } \\
\text { of } \\
\text { pollina- } \\
\text { tion }\end{array}$ & 1 & 2 & 3 & 4 & 5 & 6 \\
\hline Unfertilized eggs. . & 100.0 & 100.0 & 65.4 & 50.0 & 20.0 & 14.8 & 10.3 & 3.7 \\
\hline Fertilized eggs.... & 0.0 & 0.0 & 11.5 & 5.0 & 46.7 & 63.0 & 75.9 & 66.7 \\
\hline Unidentified eggs.... & 0.0 & 0.0 & 23.1 & 45.0 & 20.0 & 11.1 & 13.8 & 29.6 \\
\hline Embryos............. & 0.0 & 0.0 & 0.0 & 0.0 & 13.3 & 11.1 & 0.0 & 0.0 \\
\hline Polar fusion nuclei.. & 100.0 & 100.0 & 65.4 & 50.0 & 20.0 & 14.8 & 10.3 & 3.7 \\
\hline Primary endosperm nuclei. & 0.0 & 0.0 & 7.7 & 10.0 & 30.0 & 63.0 & 86.2 & 66.7 \\
\hline Developing endosperm............. & 0.0 & 0.0 & 0.0 & 0.0 & 16.7 & 11.1 & 0.0 & 0.0 \\
\hline Unidentified endosperm. . & 0.0 & 0.0 & 26.9 & 40.0 & 33.3 & 11.1 & 3.5 & 29.6 \\
\hline Pollen tubes......... & 0.0 & 0.0 & 34.6 & 50.0 & 63.3 & 70.4 & 89.8 & 63.0 \\
\hline
\end{tabular}

* Numbers of ovules examined for the respective data columns reading from left to right are: $26,23,26,20,30$, 27,29 , and 27 .

having been fertilized, but other marks of fertilization were present in the same embryo sac (fertilization of the polar fusion nucleus, remnants of pollen tube), the egg was grouped with the unidentified ones. Embryos were easily recognized.

As was mentioned above, polar fusion nuclei occurred in embryo sacs that showed no evidence of fertilization. Primary endosperm nuclei were those that indicated recent triple fusion. In the literature the presence of extra nucleoli in the endosperm nucleus is usually assumed to be an evidence of fertilization. The study of the 36-chromosome material supports this assumption. Upon maturation the embryo sac contains a nonlobed polar fusion nucleus with a single large nucleolus (plate 9, $B$ ). Even if fertilization is omitted and the embryo sac ages, the polar fusion nucleus retains essentially the same characteristics (plate $9, C$ ). After a recent triple fusion, the nucleus of the primary endosperm cell commonly shows lobing (plate $10, A$ ) and contains extra nucleoli (plate 10, $A$ and $B$ ). Later, however, the nucleus rounds off, the nucleoli seem to fuse, and the nature of the nucleus in the primary endosperm cells becomes uncertain until the endosperm begins to develop. If the nucleus in the primary endosperm cell showed no certain evidence of triple fusion, but was associated with some other signs of fertilization in the same embryo sac (rem- 
nants of pollen tube, male nucleus within the egg), it was classified as "unidentified endosperm." The developing endosperm (that is, endosperm consisting of more than one cell) was recognized as easily as the embryos.

Table 14 shows that at emasculation and pollination the embryo sacs were mature; they contained eggs and polar fusion nuclei. One hour after pollination about one third of the embryo sacs contained pollen tubes, and several showed fertilized eggs and primary endosperm nuclei. The per cent of embryo sacs with pollen tubes and with primary endosperm nuclei continued to increase up to and including the fifth collection after pollination. Excepting the

TABLE 15

Fertilization Data on 72-Chromosome Guayule Pollinated with Pollen From Another 72-Chromosome Guayule Plant

\begin{tabular}{|c|c|c|c|c|c|c|c|c|c|}
\hline \multirow{2}{*}{ Contents of ovules } & \multicolumn{2}{|c|}{$\begin{array}{c}\begin{array}{c}\text { Percentages of } \\
\text { different } \\
\text { ovule contents* }\end{array} \\
\text { ovis }\end{array}$} & \multicolumn{7}{|c|}{$\begin{array}{l}\text { Percentages of different ovule contents at the given } \\
\text { numbers of hours after pollination* }\end{array}$} \\
\hline & $\begin{array}{c}\text { At time } \\
\text { of } \\
\text { emascu- } \\
\text { lation }\end{array}$ & $\begin{array}{c}\text { At time } \\
\text { of } \\
\text { pollina- } \\
\text { tion }\end{array}$ & $1 / 2$ & 1 & 2 & 3 & 4 & 5 & 6 \\
\hline Unfertilized eggs. & 57.2 & 40.0 & 54.6 & 50.0 & 49.0 & 65.4 & 42.5 & 25.8 & 23.6 \\
\hline Fertilized eggs..... & 0.0 & 0.0 & 0.0 & 0.0 & 0.0 & 1.9 & 0.0 & 3.2 & 7.9 \\
\hline Degenerated eggs...... & 9.5 & 14.3 & 13.6 & 14.0 & 17.6 & 7.7 & .15 .0 & 3.2 & 23.7 \\
\hline Embryos............... & 0.0 & 20.0 & 9.1 & 18.0 & 5.9 & 1.9 & 0.0 & 6.5 & 2.6 \\
\hline Polars or polar fusion nuclei.... & 66.7 & 74.3 & 77.3 & 82.0 & 68.6 & 75.0 & 57.5 & 38.7 & 55.2 \\
\hline Primary endosperm nuclei....... & 0.0 & 0.0 & 0.0 & 0.0 & 0.0 & 1.9 & 0.0 & 0.0 & 0.0 \\
\hline Developing endosperm...... & 0.0 & 0.0 & 0.0 & 0.0 & 3.9 & 0.0 & 0.0 & 0.0 & 2.6 \\
\hline Young or degenerated embryo sacs & 33.3 & 25.7 & 22.7 & 18.0 & 27.5 & 23.1 & 42.5 & 61.3 & 42.2 \\
\hline Pollen tubes.................. & 0.0 & 0.0 & 0.0 & 0.0 & 5.9 & 7.7 & 2.0 & 16.1 & 15.5 \\
\hline
\end{tabular}

* Numbers of ovules examined for the respective data columns reading from left to right are: $42,35,22,50$, $51,52,40,31$, and 38 .

second hourly collection (collection made 2 hours after pollination), the samples showed a similar successive increase in per cent of fertilized eggs, up to and including the fifth hourly collection. The drop in per cent of fertilized eggs the second hour may be only apparent: the first collection after pollination consisted of two samples prepared 5 days apart. The first sample that was prepared on the same day as the second hourly collection showed no fertilized eggs or primary endosperm nuclei and only a few pollen tubes. Similarly the third and fourth hourly collections consisted of two samples each, and those made later contained all the embryos and all the developing endosperm. Apparently the flowers used in the later set of treatments were farther advanced in their development than those used 5 days earlier. The drop in the per cent of views indicating fertilization in the collections made 6 hours after pollination may have resulted from natural variability (the fifth and sixth hourly collections were prepared on the same day); or it may have been caused by the obliteration of the evidences of fertilization, through the complete fusion of male and female nuclei and the disintegration of pollen-tube remnants. Though no developing endosperm was present in the last collection, 18.6 per cent of the primary endosperm nuclei were in division.

Regardless of these variations, table 14 clearly shows that fertilization nor- 
mally occurs in 36-chromosome guayule. This observation agrees with those made previously on the predominantly normal sequence in the megasporogenesis and embryo-sac development and on the close relation between endosperm and embryo development in this type of guayule. Obviously, normal sexual reproduction predominates in the 36-chromosome guayule used in the present study.

The 72-chromosome material (table 15) presents a different picture with regard to fertilization. Before table 15 is analyzed, the times of collection of the material must be indicated. The experiments with the 36 -chromosome plant were carried out during the first week of April; those with the 72-chromosome plant during the last week in June of the same year. Both plants were located in a greenhouse at Salinas. There were two series of collections from the 72 chromosome plant. The first, prepared on June 23, consisted of collections from emasculation time up to and including 6 hours after pollination. No collection was made $1 / 2$ hour after pollination in this series. The second series, prepared on June 30, contained collections from emasculation time up to and including 4 hours after pollination. The ovules of the second series proved to be more advanced than those of the first and contained most of the embryos recorded in table 15, but most of the pollen tubes occured in the first collection. Only one embryo sac showed both an embryo and remnants of a pollen tube.

As compared with the 36-chromosome plant, the 72-chromosome guayule showed little evidence of accomplished fertilization. There were few embryo sacs with remnants of pollen tubes and very few obviously fertilized eggs or primary endosperm nuclei. Undoubtedly these results are related to the tendency toward apomictic reproduction in 72-chromosome guayule. The particular plant used in the fertilization experiments was highly apomictic. According to a personal communication from Dr. R. C. Rollins, among 48 classifiable plants in the $\mathrm{F}_{1}$ generation from this guayule plant, crossed with mariola, 95.84 per cent were maternals and only 4.16 per cent were hybrids. The latter could only have come from fertilized eggs. For proper development, however, embryos must be accompanied by developing endosperm-a product of triple fusion. Although several fertilized eggs were found in the ovules used for table 15, the evidence for the occurrence of triple fusion was extremely weak. The ehief difficulty in the recognition of triple fusion in 72-chromosome guayule is caused by the peculiar morphology of the polar fusion nucleus. As was mentioned previously, this nucleus is large and lobed and mostly contains several nucleoli. Figure $6, H-J$, illustrates three sections of such a nucleus. It occurred in an ovule containing an egg and two good synergids, which was collected 3 days after pollination. That the peculiar characteristics of the polar fusion nucleus are not associated with fertilization is proved by the occurrence of large, lobed, multinucleolate nuclei in samples collected at times of emasculation and pollination (table 15) and in flowers that were left entirely unpollinated (table 10). If a sperm nucleus were to occur in contact with such a nucleus, its distinction from one of the lobes of the polar fusion nucleus would probably be difficult. In one instance only (see the third hourly collection in table 15) the view seemed to indicate triple fusion (fig. $6, F$ and $G$ ). In this view there appeared to be two polars, each with a single nucleolus, partly fused with a sperm nucleus that had three small nucleoli. If such a nuclear configura- 
tion had occurred in a 36-chromosome plant, it would have been regarded as evidence of triple fusion ; but in a 72-chromosome guayule its identity remains somewhat uncertain. Kokieva (1932) has described triple fusion and has even suggested that two sperm nuclei may fuse with the polar fusion nucleus; but the illustrations that are intended to support her interpretations resemble pictures of the enlarged and lobed polar fusion nuclei. Further studies are necessary to reveal the origin of endosperm in apomictic guayule-particularly endosperm that develops in association with apomictic embryos.

Besides indicating infrequency of fertilization in the 72-chromosome plant, table 15 gives other data that agree with the previously observed peculiarities in reproduction of apomictic guayule. The embryo sac matures unevenly. Some sacs younger than the 7-celled occurred in all stages of development; polars were still present in the collection made at emasculation; and a considerable number of sacs were undergoing degeneration. Embryos occurred before pollination, and most of the embryos recorded in table 15 were not associated with developing endosperm.

\section{SOMATIC APOSPORY IN GUAYULE}

A variable, but usually small, per cent of ovules of guayule show one, rarely two or three embryo sacs besides the one in normal position (plate $15, B-D$ ). These extra sacs are located almost invariably at the antipodal end of the sac that is in normal position, and typically the two sacs are connected with each other through their antipodals (plate 15, $C$ ). Sometimes the extra sac is entirely outside the one located normally (plate $15, C$ ); or it occurs within the latter (lower supernumerary sac in plate $15, D$ ); or it appears to emerge from the cavity of the sac in normal position by breaking through the nutritive jacket of the latter (plate 15, $B$ ). The supernumerary sacs have no nutritive jackets of their own and often are surrounded by crushed cells (plate 15, $B$ ). Antipodals, eggs, synergids, embryos, polars, polar fusion nuclei (usually lobed), but never any developing endosperm, were observed in the extra embryo sacs. In early stages of development these sacs may be uni-, bi-, or tetranucleate. Sometimes the organization of an extra sac is not definable.

The frequency of the supernumerary embryo sacs varied from a fraction of 1 per cent to about 20 per cent in the material used in the present study. They were found in 36-, 54-, 72-, and 108-chromosome guayule and in mariola. Apparently their occurrence does not depend on the condition of the sac that is in normal position. Among 369 ovules in the variously pollinated material from plant 49-3 (table 9), 19.2 per cent showed supernumerary embryo sacs. The sacs in normal position that were associated with the supernumerary were grouped as follows : 35.2 per cent had developing endosperm ; 38.0 per cent had polar fusion nuclei; 26.8 per cent were degenerating. Plate $15, B$, shows a degenerating embryo and a hyperplastic nutritive jacket in the embryo sac located normally ; in plate $15, C$, the sac that is in normal position has developing endosperm and an ordinary nutritive jacket.

According to the literature (see "Review of Literature"), supernumerary embryo sacs like those in guayule are commonly derived from somatic cells, and their formation is referred to as somatic apospory. Unless very early stages of somatic apospory are available, its origin is difficult to ascertain, because the 
growing aposporic cell crushes and displaces the adjacent cells and thus markedly changes its original environment. Two features are particularly characteristic of the supernumerary embryo sacs in guayule: they appear late in the ontogeny of the sac that is in normal position, and arise at its antipodal end. Rarely is a supernumerary sac associated with one (located normally) that has not reached the 7-celled stage (fig. $6, E$ ). Some figures support this observation. In a collection from plant $49-3$, the flowers were divided into three classes : (1) 283 flowers that contained megaspore mother cells to just matured 7-celled embryo sacs; (2) 95 flowers with fully expanded stigmas that had eggs and young embryos; (3) 562 flowers taken 1 to 10 days after anthesis. The following percentages of flowers in each class contained supernumerary embryo sacs : class $1,0.0$ per cent ; class $2,9.5$; class $3,18.5$.

Judging from the data given above, the early stages of somatic apospory must be sought in connection with 7-celled embryo sacs in normal position. Many views seemed to suggest that the antipodals were involved in the formation of the extra aposporic sacs : some antipodals appeared unusually large and were protruding into the chalazal region. In figure $6, B$, the upper antipodal is enlarged, as contrasted with the upper antipodal in figure $6, A$. The interpretation that antipodals develop into embryo sacs has been made in the literature. Chamberlain (1895) found extra embryo sacs in Aster Novae-angliae closely resembling those of guayule in morphology and in relation to the normally placed embryo sacs. He thought they arose from antipodal cells, but today a search in the guayule material reveals views that require a different interpretation. The antipodal cells, even if they enlarge, usually have rather dense cytoplasm (fig. 6, B). According to Stebbins and Jenkins (1939), however, aposporic cells are characterized by high degree of hydration. Such strongly vacuolated and obviously enlarging cells were found at the antipodal end of some embryo sacs in guayule. They appeared to be in proper position to produce a supernumerary embryo sac characteristic of guayule (fig. $6, C$ ) and, through intermediate stages of binucleate and tetranucleate embryo sacs (fig. $6, D)$, were connected with the mature supernumerary embryo sacs. In their enlargement they crushed the adjacent cells (fig. $6, D$ ) and perhaps the antipodals also. Views like those in plate $15, B$ and $D$, indicate that the cell forming the aposporic sac is not always located outside the embryo sac in normal position. Perhaps cells of the nucellar epidermis or nutritive-jacket cells produce sacs that intrude into the sacs in normal position (plate $15, D$ ) or break the continuity in the nutritive jacket (plate $15, B$ ). The present study therefore suggests that the supernumerary embryo sacs in Parthenium arise from some somatic cells located near the antipodals of the normally placed embryo sac.

No supernumerary embryo sac has been found to contain developing endosperm, and many were degenerating. Probably somatic apospory rarely results in the production of viable embryos. More than one embryo sometimes occurs in one achene in guayule. The extra embryo may arise not only through somatic apospory, but also in some other way. Achenes containing two ovules have occasionally been found. Sometimes two embryos occur in the same embryo sac that is in normal position; views of dividing synergids (plate 15, A) suggest that the second embryo could arise from a synergid. Sometimes the pair of embryos appear to have arisen through lobing of a single embryo. Two mega- 
spore mother cells enclosed within the same nucellar epidermis occur in some ovules, but usually one is much smaller and shows signs of being crowded out by the other (fig. 2, $H$ and $I$ ). All these phenomena-somatic apospory, synergid embryos, double ovules, and double megaspore mother cells-are rather infrequent. The main features characterizing the apomixis in the Parthenium material used in this study are generative apospory and pseudogamy.
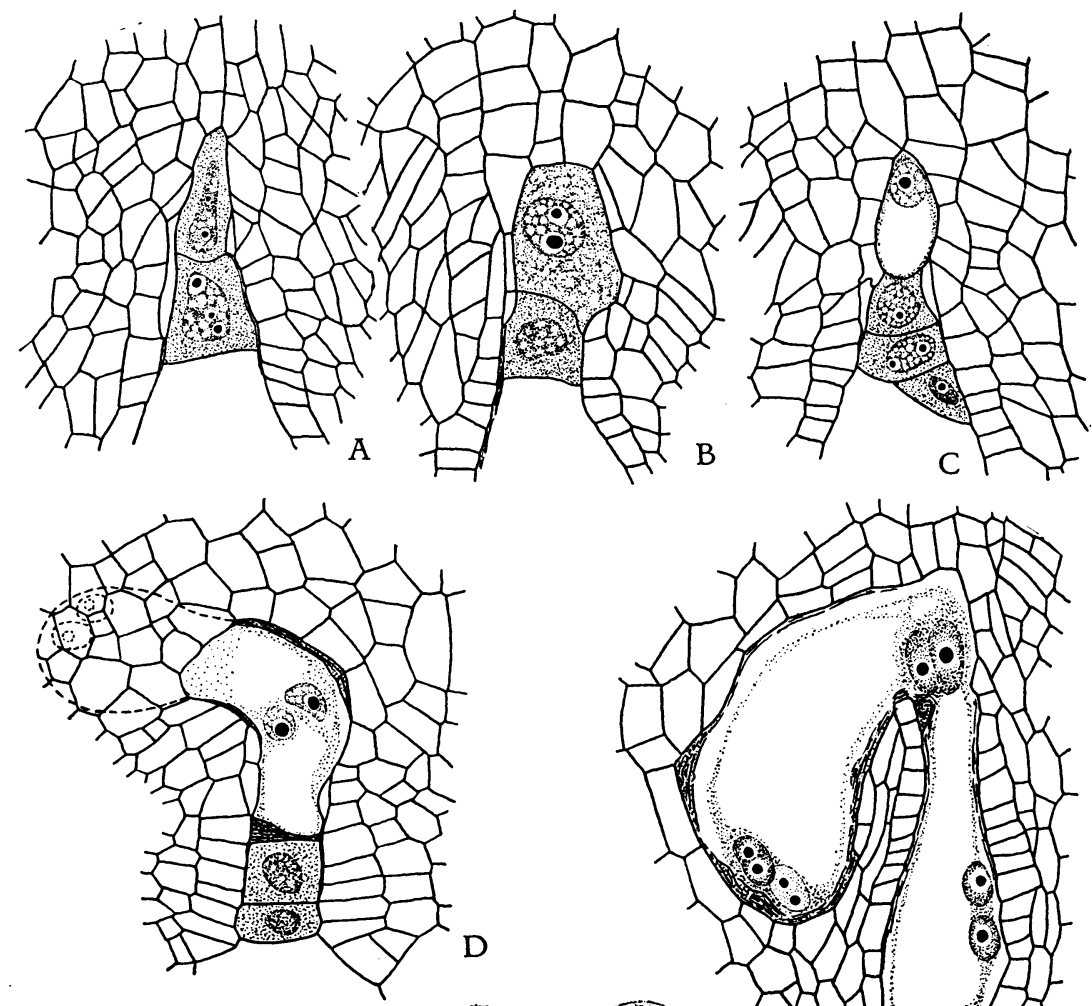

C
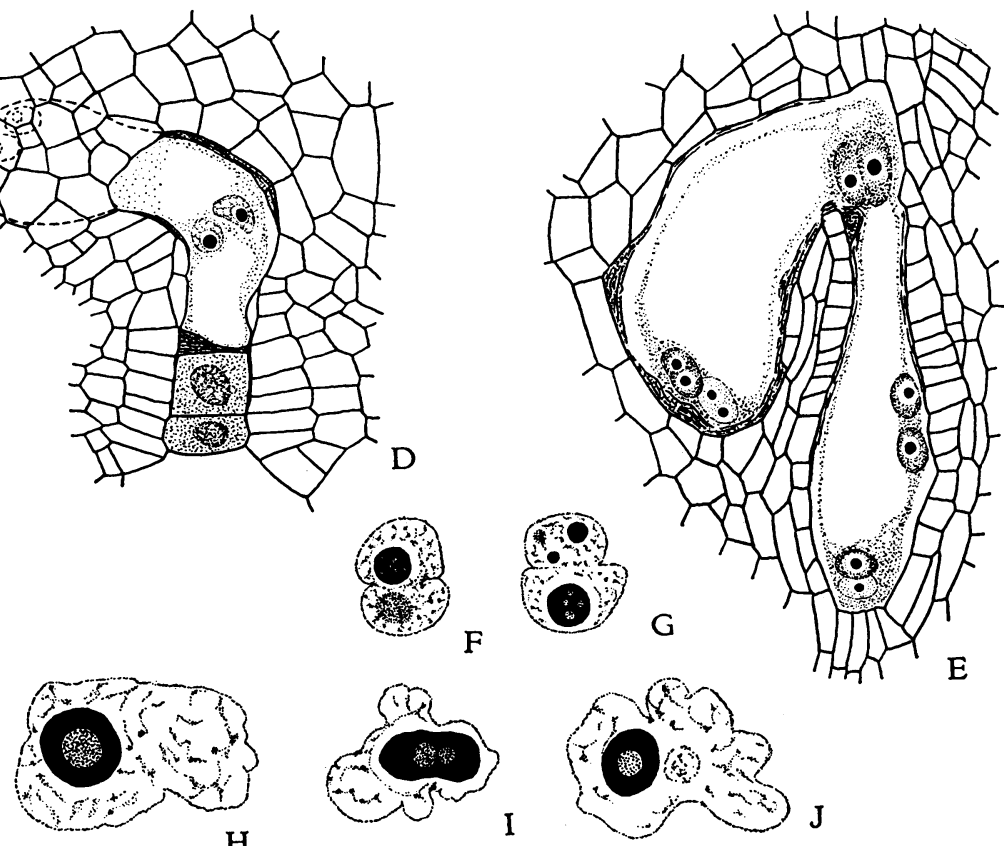

E

Fig. 6. $-A-D$, Antipodals (stippled throughout) and some adjacent ovular cells. In $B$ the upper of the two antipodals is somewhat enlarged. In $C$ a somatic cell next to the upper of the three antipodals is differentiating into an aposporic embryo sac. In $D$ the aposporic sac above the antipodals has four nuclei and has crushed some ovular cells and apparently also one antipodal. $E$, Two tetranucleate embryo sacs connected with each other. The sac to the left might have arisen through somatic apospory. $F, G$, Two sections of the same group of three partly fused nuclei; one polar in $F$, above; second polar in $F$ and $G$, below; and a sperm nucleus in $G$, above. $H, I, J$, Three sections of the same lobed polar fusion nucleus. All these drawings are from 72 -chromosome guayule. $(A-E, \times 357 ; F-J, \times 850$.) 


\section{REPRODUCTION IN PARTHENIUM HYSTEROPHORUS}

To obtain, early in this study, a clear picture of the differences between normal and apomictic types of Parthenium, the annual $P$. hysterophorus was used as a plant known to have sexual reproduction. Table 16 gives the data obtained with this plant. The flowers were divided into small, medium, and large according to the degree of development of the achenes and corollas. The stages of embryo-sac development were recorded for each flower as in the study of gua-

TABLE 16

Relation between Flower Size and Embryo-Sac Development in

Parthenium hysterophorus $\mathrm{L}$.

(Combined data from lots 15 and 16 in table 1 )

\begin{tabular}{|c|c|c|c|}
\hline \multirow{2}{*}{ Contents of ovules } & \multicolumn{3}{|c|}{$\begin{array}{l}\text { Percentages of different ovule contents in } \\
\text { flowers of various sizes* }\end{array}$} \\
\hline & Small & Medium & Large \\
\hline Dividing megaspore mother cells. & 13.3 & 0.0 & 0.0 \\
\hline Dyads...................... & 1.7 & 0.0 & 0.0 \\
\hline Tetrads of megaspores........... & 50.0 & 0.7 & 0.0 \\
\hline Uninucleate embryo sacs with crushed megaspores .......... & 13.3 & 0.0 & 0.0 \\
\hline Binucleate embryo sacs $\ldots \ldots \ldots \ldots \ldots \ldots \ldots \ldots \ldots \ldots \ldots$ & 11.7 & 0.7 & 0.0 \\
\hline 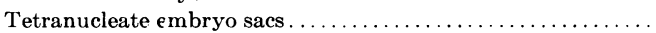 & 6.7 & 3.4 & 0.7 \\
\hline Seven-celled embryo sacs with polars..................... & 3.3 & 9.7 & 0.0 \\
\hline 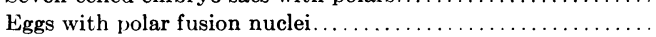 & 0.0 & 75.8 & 12.0 \\
\hline Embryos with developing endosperm $\ldots \ldots \ldots \ldots \ldots \ldots \ldots$ & 0.0 & 8.3 & 83.3 \\
\hline Degenerated embryo sacs............. & 0.0 & 1.4 & 4.0 \\
\hline
\end{tabular}

* Numbers of ovules examined for the respective data columns reading from left to right are: 60,145 , and 150.

yule. P. hysterophorus showed normal sequence of megasporogenesis and gametophyte development. As table 16 shows, all the megaspore mother cells were dividing (and all the divisions were meiotic), tetrads of megaspores were numerous (but dyads were few as in 36-chromosome guayule), and all uninucleate embryo sacs were associated with crushed megaspores. With the increase in flower size, the young stages were disappearing, and the embryo sacs matured. The polars fused during this maturation. The embryos were all associated with developing endosperm. Some embryo sacs were degenerated, apparently after they had reached the 7-celled stage.

Thus Parthenium hysterophorus resembles 36-chromosome guayule in the morphologic development of reproductive structures. Together with this guayule, it strikingly differs from the apomictic types of guayule of the polyploid series and from mariola.

\section{SUMMARY AND CONCLUSIONS}

The present study gives morphologic evidence of the occurrence of two repro. ductive methods in Parthenium argentatum-namely, sexual and apomictic. The former was characteristic of the 36-chromosome plants, and the latter of guayule with higher (polyploid) numbers of chromosomes. The $P$. incanum material also showed apomixis ; that of $P$. hysterophorus, sexual reproduction.

The apomixis in Parthenium mainly involves generative apospory followed 
by unreduced pseudogamy. Since some flowers on a given plant show stages of apomictic development and others show those of the sexual reproductive cycle, apomixis in guayule is facultative.

Plants characterized by normal sexual reproduction showed an orderly sequence of events in megasporogenesis and in gametophyte developmentevents that succeeded each other, stage by stage, with the increase in the size of ovules. The megaspore mother cells mostly occurred in division (usually recognized as meiosis); views of tetrads of megaspores were abundant; and the uninucleate embryo sacs were associated with crushed nonfunctioning megaspores. All these features indicated that meiosis preceded embryo-sac formation. Views of fertilization of eggs, of triple fusion, and of remnants of pollen tubes in embryo sac were common in artificially pollinated flowers. Embryo and endosperm development were closely correlated. No embryos occurred in the nonpollinated material.

The morphologic features of apomictic reproduction contrasted sharply with those of sexual reproduction. Embryo-sac formation showed no orderly sequence of stages. Young stages tended to persist in fairly large ovules and overlapped, in time of occurrence, with older stages in ovules of the same size. Megaspore mother cells mostly had resting nuclei, persisted in ovules of many sizes, enlarged, became vacuolate, and assumed the characteristics of uninucleate embryo sacs. This behavior indicated omission of meiosis (apomeiosis) and formation of the embryo sac directly from the megaspore mother cell-the generative cell-without interpolation of the dyad and tetrad stages (generative apospory). Meiosis occurred but was rare, judging by the scarcity of views of megaspores, intact or degenerating. The embryo and endosperm were not closely correlated in their development. Small embryos were present in nonpollinated flowers, a fact indicating that the egg of an unreduced gametophyte may start to develop into an embryo without fertilization. Pollination, however, was highly beneficial or, perhaps, even necessary for endosperm development and for the attainment of normal embryo size. This observation agrees with the data of Powers and Rollins (1945) showing that pollination is necessary for the formation of viable seed in apomictic guayule (unreduced pseudogamy).

\section{ACKNOWLEDGMENTS}

The writer appreciates the coöperation of Dr. LeRoy Powers, Dr. Reed C. Rollins, and Dr. A. Dorothy Bergner, all of the Guayule Research Project of the United States Department of Agriculture, in furnishing plant material, together with relevant information. Dr. Rollins deserves special thanks for preparing material used in the pollination and fertilization studies. Dr. G. L. Stebbins, Jr., showed a constant interest in the progress of the work; his help with interpretation and analysis of certain data is thankfully acknowledged. 


\section{LITERATURE CITED}

Afzelius, KarL.

1936. Apomixis in der Gattung Arnica. Svensk Bot. Tidskr. 30:572-79.

Å KERBERG, ERIK.

1943. Further studies of the embryo- and endosperm-development in Poa pratensis. Hereditas 29:199-201.

ARtschWager, ERnst.

1943. Contribution to the morphology and anatomy of guayule (Parthenium argentatum). U. S. Dept. Agr. Tech. Bul. 842:1-33.

Bergman, Bengst.

1937. Eine neue apomiktische Antennaria. Svensk Bot. Tidskr. 31:391-94.

BERGNER, A. D.

1944. Guayule plants with low ehromosome numbers. Science 99:224-25.

BRINK, R. A., and D. C. COOPER.

1940. Double fertilization and development of the seed in angiosperms. Bot. Gaz. 102:125.

Chamberlain, C. J.

1895. The embryo sac of Aster Novae-Angliae. Bot. Gaz. 20:205-12.

Chiarugi, Alberto.

1926. Aposporia e apogamia in "Artemisia nitida" Bertol. Nuovo Gior. Bot. Ital. 33:501626.

Chiarugi, Alberto, and Eleonora Francini.

1930. A pomissia in "Ochna serrulata" Walp. Nuovo Gior. Bot. Ital. 37:1-250.

COOPER, D. C., and R. A. BRINK.

1940. Somatoplastic sterility as a cause of seed failure after interspecific hybridization. Geneties 25:593-617.

Dianowa, W. J., A. A. Sosnovetz, and N. A. Steschina.

1935. Vergleichende zytoembryologische Untersuchung der Varietäten von Parthenium argentatum Gray und $P$. incanum Gray. Bot. Centbl. Beihefte 53:293-308.

EsAU, Katherine.

1944a. Anatomical and cytological studies on beet mosaic. Jour. Agr. Res. 69:95-117.

1944b. Apomixis in guayule. Natl. Acad. Sci. Proc. 30:352-55.

FAGERLIND, FolKe.

1940. Zytologie und Gametophytenbildung in der Gattung Wikstroemia. Hereditas 26: $23-50$.

Foster, A. S.

1939. Problems of structure, growth and evolution in the shoot apex of seed plants. Bot. Rev. 5:454-70.

Gentchefr, G., and A. Gustafsson.

1940. Parthenogenesis and pseudogamy in Potentilla. Bot. Notiser 1940:109-32.

Gerassimova, Helen.

1933-34. Fertilization in Crepis capillaris. Cellule 42:101-41.

HÄFLINGER, ERNST.

1943. Zytologisch-embryologische Untersuchungen pseudogamer Ranunkeln der Auricomus-Gruppe. Ber. Schweiz. Bot. Ges. 53:317-82. In: Biol. Abstr. 19(5):989. Entry 9153. 1945.

HÅkansson, Artur.

1943. Die Entwicklung des Embryosacks und die Befruchtung bei Poa alpina. Hereditas 29:25-61.

HOLMGREN, IVAR.

1919. Zytologische Studien über die Fortpflanzung bei den Gattungen Erigeron und Eupatorium. Svenska Vetensk. Akad, Handl. 59:1-118.

JUEL, H. O.

1900. Vergleichende Untersuchungen über typische und parthenogenetische Fortpflan. zung bei der Gattung Antennaria. Svenska Vetensk. Akad. Handl. 33:1-59. 
Kiellander, C. L.

1935. Apomixis bei Poa serotina. Bot. Notiser 1935:87-95.

1937. On the embryological basis of apomixis in Poa palustris L. Svensk Bot. Tidskr. 31: $425-29$.

KIRKWOOD, J. E.

1910. The life history of Parthenium (guayule). Amer. Rev. Trop. Agr. 1:193-205.

KoKIEva, E.

1932. Istoriia razvitiia zhenskogo gametofita u Parthenium argentatum G. ("Guayule"). [The development of the female gametophyte in Parthenium argentatum G.

LAND, W. J. G. ("Guayule").] Bot. Zhur. S.S.S.R. (Jour. Bot. de l' U.R.S.S.) 17:72-99.

1900. Double fertilization in Compositae. Bot. Gaz. 30:252-60.

Mitchell, J. W., H. M. Benedict, and A. G. Whiting.

1944. Growth, rubber storage, and seed production by guayule as affected by boron supply. Bot. Gaz. 106:148-57.

MURBECK, Sv.

1901. Parthenogenetische Embryobildung in der Gattung Alchemilla. Lunds Univ. Årsskr. 36:1-41.

Powers, LeRoy, and R. C. Rollins.

1945. Reproduction and pollination studies on guayule, Parthenium argentatum Gray and P. incanum H. B. K. Amer. Soc. Agron. Jour. 37:96-112.

ROSENBERG, O.

1908. Cytological studies on the apogamy in Hieraceum. Svensk Bot. Tidskr. 28:143-70.

1930. Apogamie und Parthenogenesis bei Pflanzen. Handbuch der Vererbungswissenschaft Lief. 12, (Vol. 2, L.) 66p. Gebr. Borntraeger, Berlin.

Satina, Sophie.

1945. Periclinal chimeras in Datura in relation to the development and structure of the ovule. Amer. Jour. Bot. 32:72-81.

SCHNEIDER, C. K.

1917. Illustriertes Handwörterbuch der Botanik. Ed. by K. Linsbauer. 12th ed. 824 p. Wilhelm Engelmann, Leipzig.

Stebbins, G. L., JR.

1932. Cytology of Antennaria. II. Parthenogenetic species. Bot. Gaz. 94:322-63.

1941. Apomixis in the angiosperms. Bot. Rev. 7:507-42.

Stebbins, G. L., JR., and J. A. Jenkins.

1939. Aposporic development in the North American species of Crepis. Genetica 21:191224.

Stebbins, G. L., JR., and Masuo Kodani.

1944. Chromosomal variation in guayule and mariola. Jour. Hered. 35:163-72.

Tinney, F. W.

1940. Cytology of parthenogenesis in Poa pratensis. Jour. Agr. Res. 60:351-60.

WhiteheAd, M. R., and J. W. MitcheLL.

1943. Effects of nutrient, photoperiod, and night temperature on the development of guayule seeds. Bot. Gaz. 105:14-24. 



\section{PLATES}





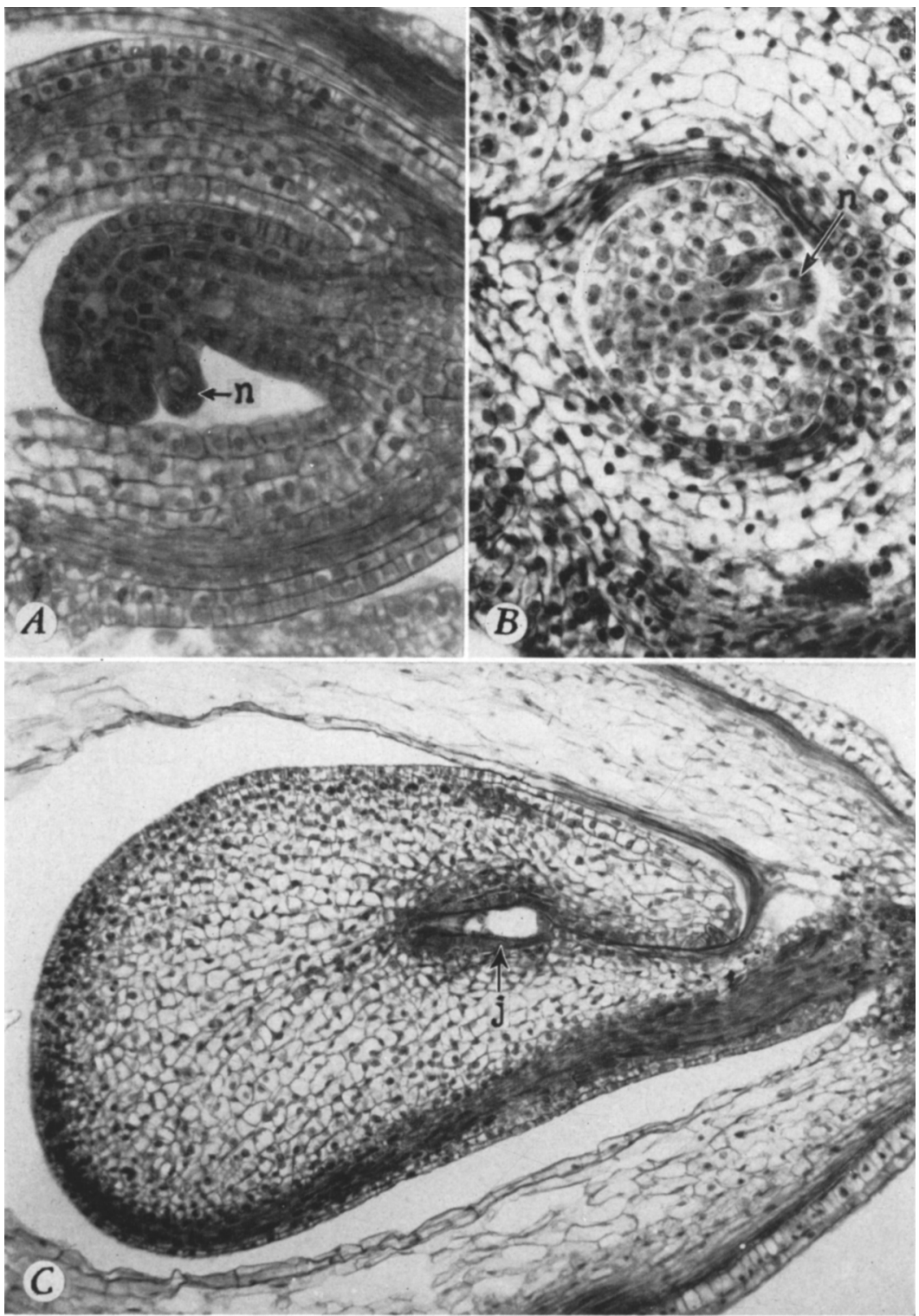

Plate. 1.-Longitudinal sections of guayule ovules (within ovaries) in different stages of development. In $A$ the ovule is incompletely inverted; the nucellus $(n)$ projects laterally (downward in the figure); and the integument forms a bulge above (to the left in the figure) the nucellar projection. In $B$ the ovule is inverted; and the nucellar projection $(n)$, partly enveloped by the integument, points downward (toward the right in the figure). The megaspore mother cell within the nucellar epidermis is in synapsis in $A$ and in resting stage in $B$. The ovule in $C$ contains an embryo sac in 7-celled stage, surrounded by nutritive jacket $(j)$. The micropyle appears as a dark line to the right of the embryo sac. $A$ was taken from a 36 -chromosome plant; $B$ and $C$ are from a 72 -chromosome type. ( $A$ and $B, \times 290 ; C, \times 140$.) 

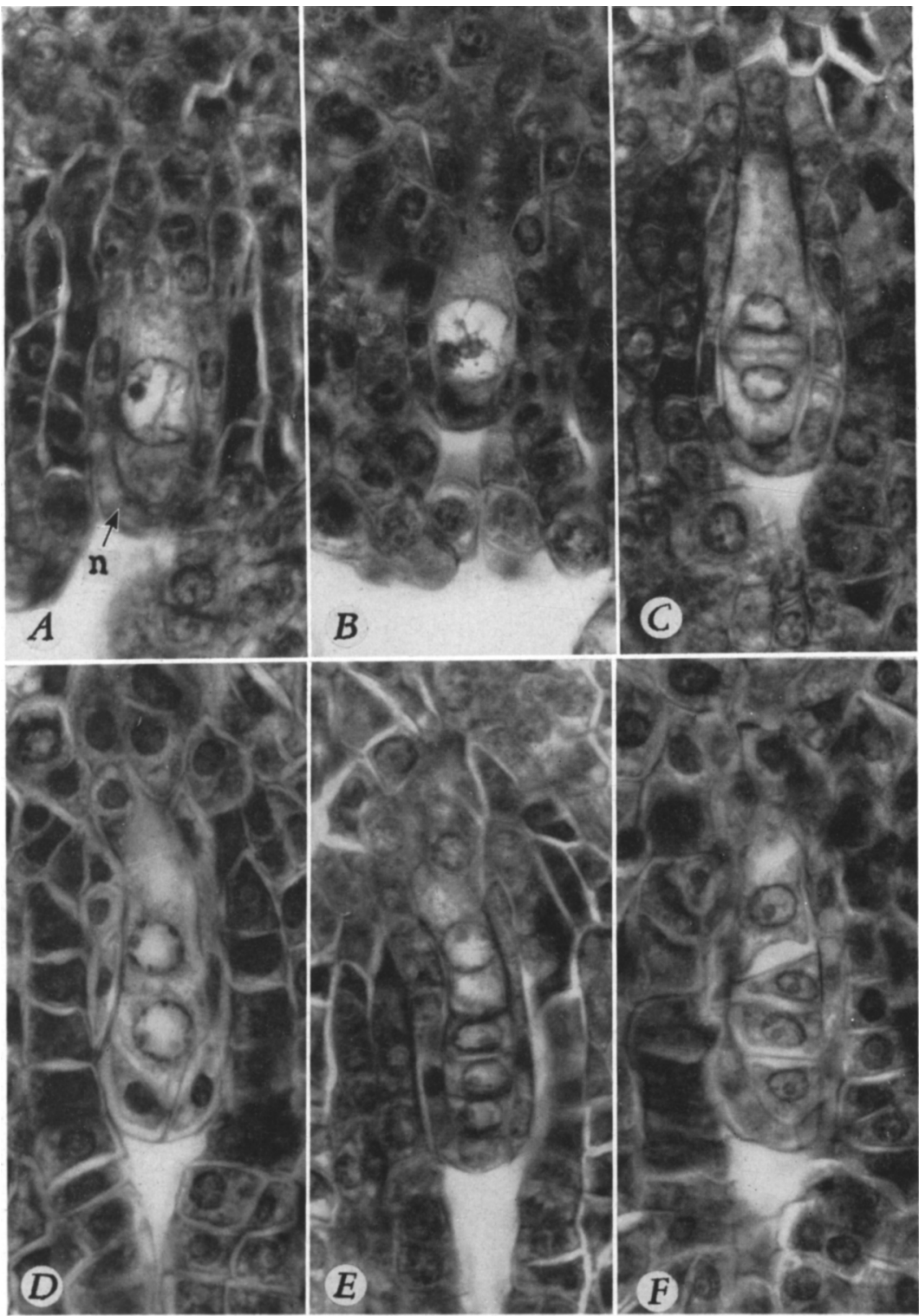

Plate 2.--Longitudinal sections of parts of nucelli and integuments from 36 chromosome guayule. The nucellar epidermis $(n)$ forms a uniseriate layer around the megaspore mother cell or its products. The megaspore mother cells in $A$ and $B$ are in meiotic prophases. $C$, Dyad in cytokinesis. $D$, Dyad formation is complete. $E, F$, Tetrads of megaspores. (All $\times 760$.) 

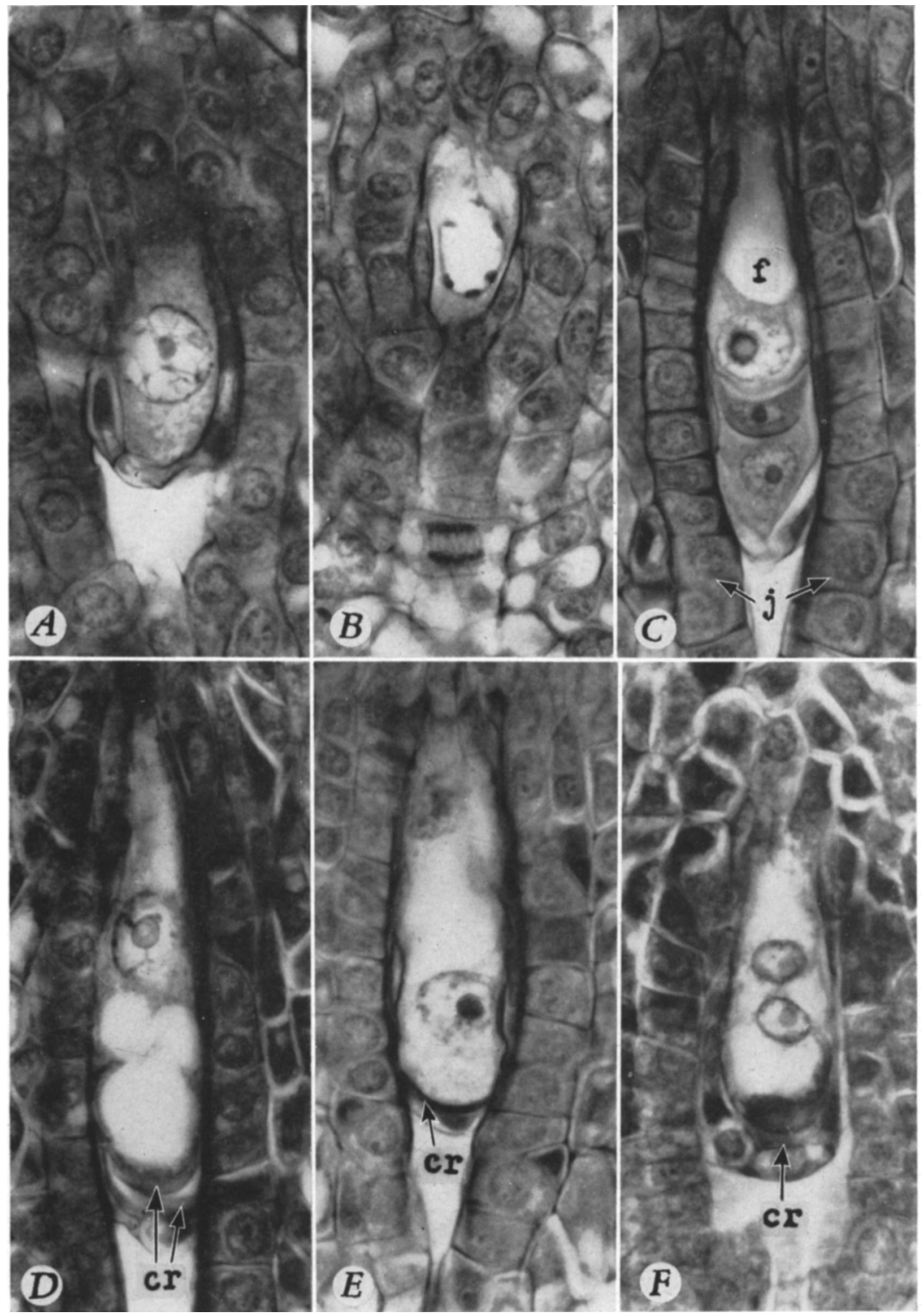

Plate 3.-A-E, Longitudinal sections ( $B$ was cut somewhat on bias) of parts of nucelli and integuments from 72-chromosome guayule. The megaspore mother cell in $A$ is in early meiotic prophase; the one in $B$ in diakinesis. $C$, Tetrad of megaspores. (The two megaspores nearest the micropyle were laterally adjacent, and only one of the two is visible.) The functioning megaspore appears at $f$ in $C . D$, Uninucleate, and $E$, binucleate embryo saes, both with crushed megaspores $(c r)$. The nutritive jacket $(j)$ is well defined in $C, D$, and $E \cdot F$, Binucleate embryo sac with erushed megaspores $(\mathrm{cr})$ from 36 -chromosome guayule. (All $\times 760$.) 


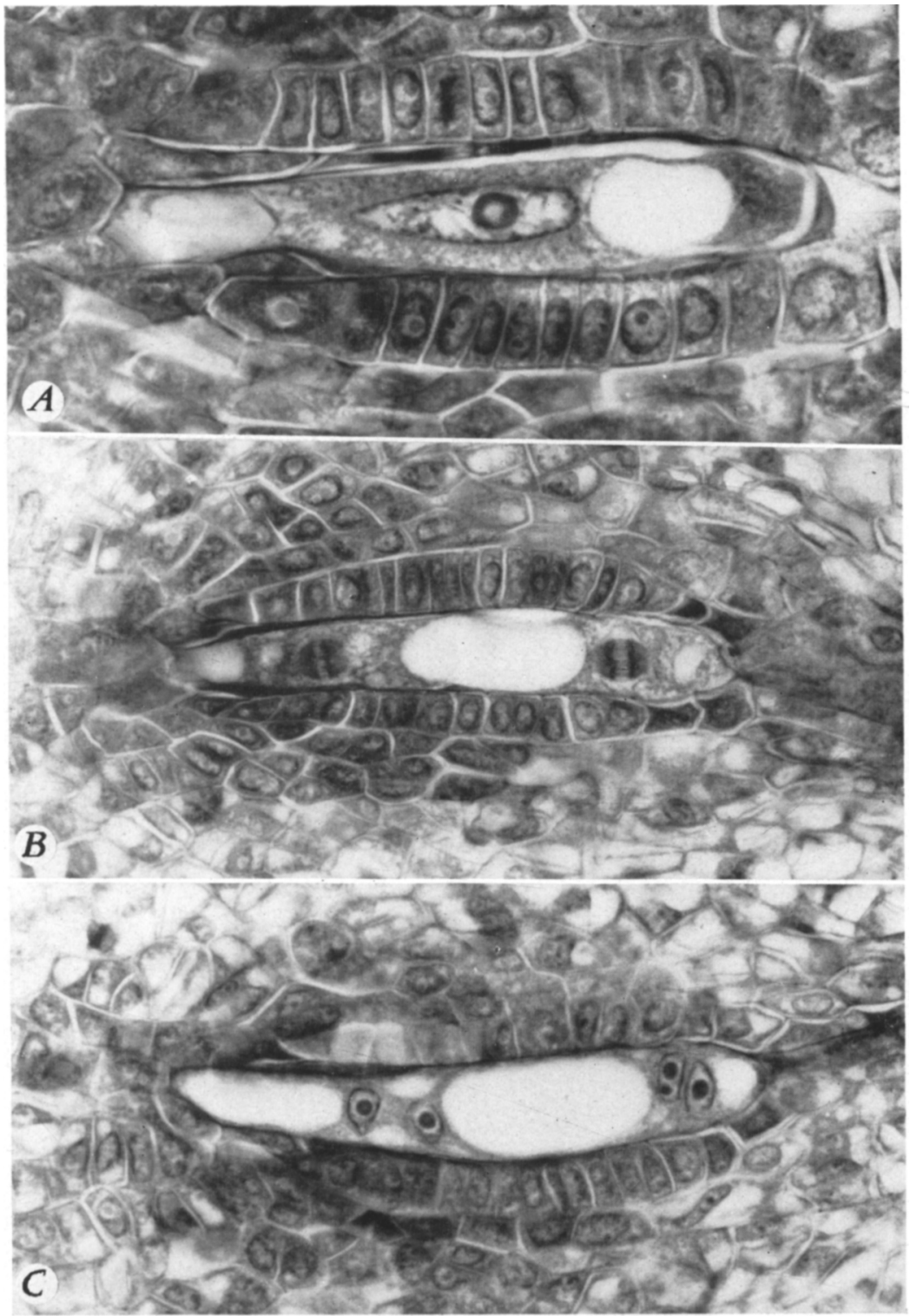

Plate 4.-Longitudinal sections of uninucleate $(A)$, binucleate $(B)$, and tetranucleate $(C)$ embryo sacs from 72 -chromosome guayule. The embryo sac in $A$ is an enlarged and highly vacuolated megaspore mother cell that failed to undergo meiosis. The nucellus in $A$ is partly crushed. Remnants of nucellar epidermis appear as dark streaks at the chalazal ends (to the left in the figures) of the embryo sacs in $B$ and $C$. In all views the embryo sacs are bordered by uniseriate nutritive jackets of narrow cells. The embryo-sac nuclei in $B$ are in division. ( $A$, $\times 760 ; B$ and $C, \times 480$.) 


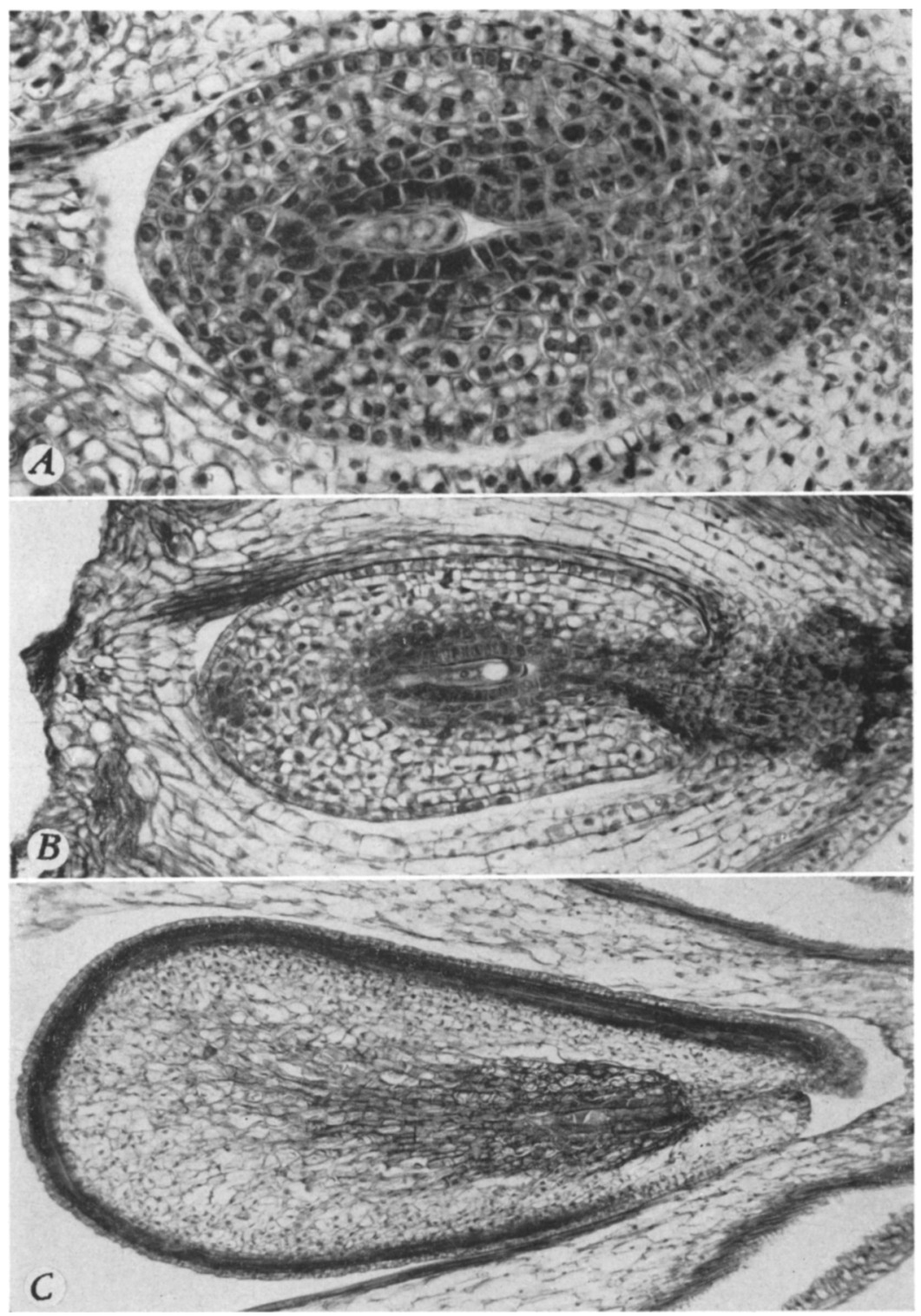

Plate 5. -Longitudinal sections of ovules (and adjacent ovarian tissues) from 36-chromosome $(A)$ and polyploid $(B$ and $C$ ) guayule. The ovule in $A$ contains the dyad shown at high magnification in plate $2, D$. The ovule in $B$ contains the aposporic uninucleate embryo sac shown at high magnification in plate $4, A$. In $C$ are shown the course and extent of the ovular vascular bundle. $(A, \times 290 ; B, \times 140$; $C, \times 90$.) 

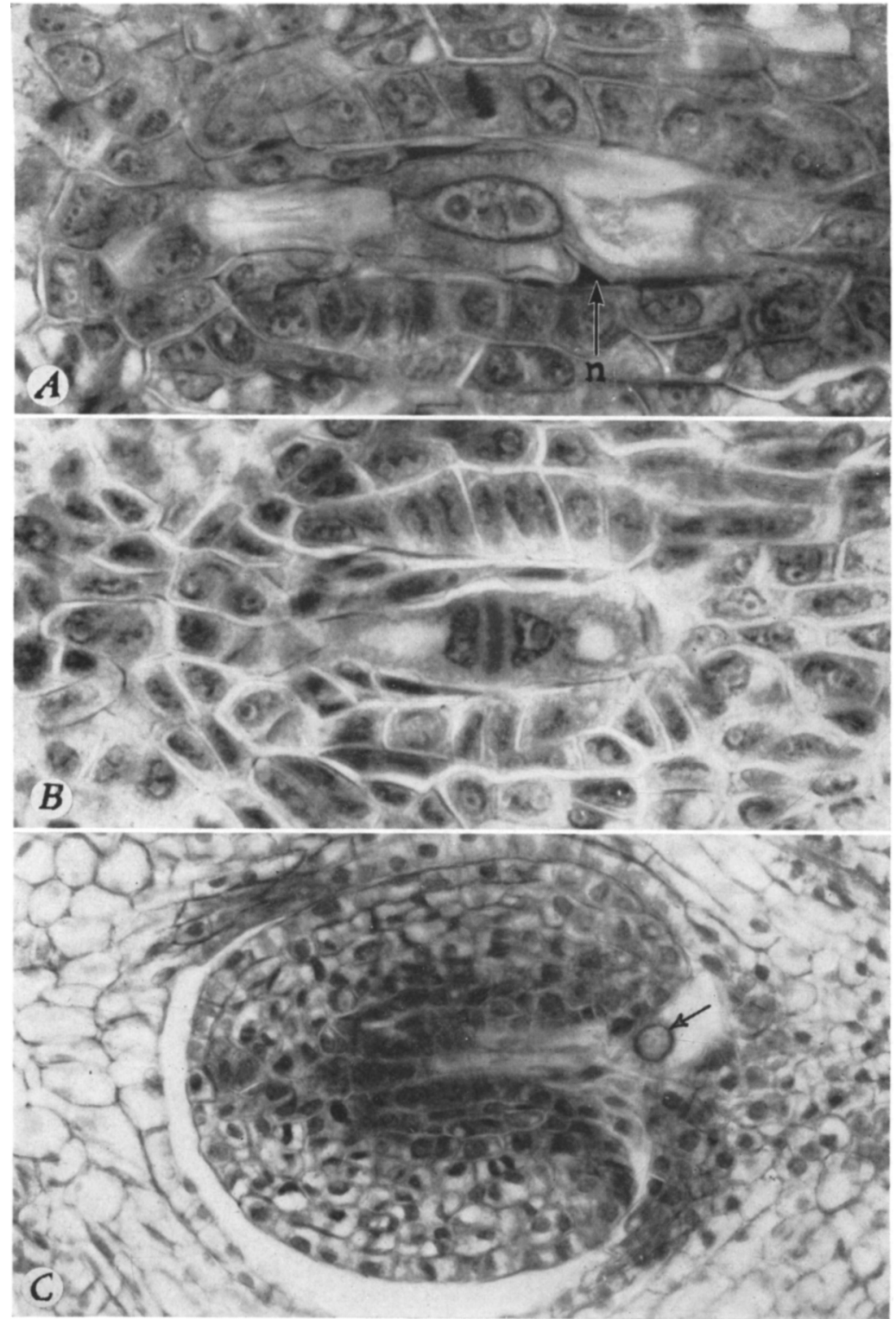

Plate 6.- $A$, An aposporic uninucleate embryo sac that has crushed and pierced the nucellar epidermis $(n) . B$, An aposporic binucleate embryo sac, with the nucellus not yet pierced. Remnants of the spindle fibers are evident between the nuclei, but no cell wall is being formed here. $C$, Ovule (and adjacent ovarian tissues) containing an aposporic binucleate embryo sac, with one nucleus (marked with an arrow) visible outside the ovule in the ovarian cavity. All longitudinal sections from 72 -chromosome guayule. ( $A$ and $B, \times 760 ; C, \times 290$.) 


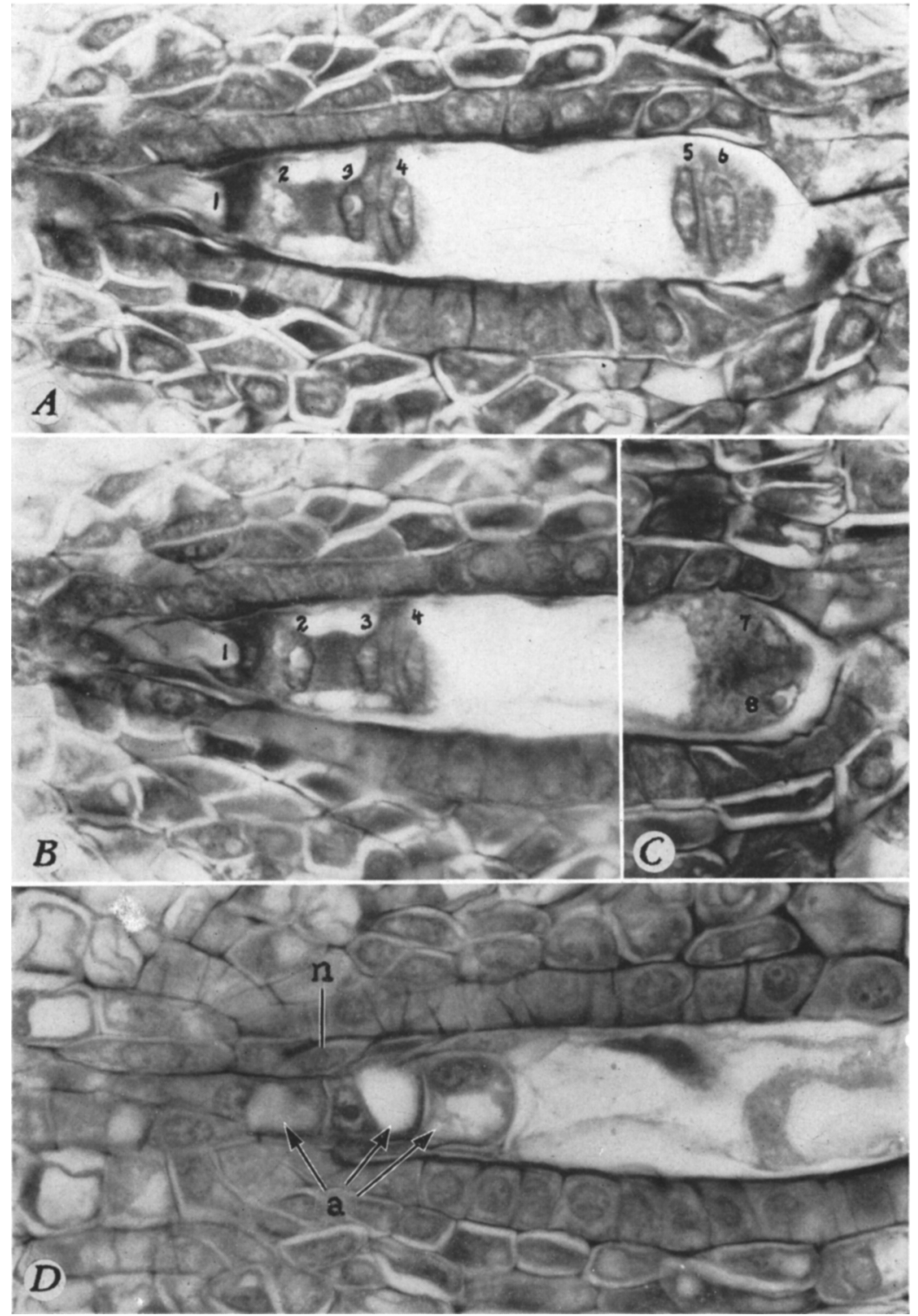

Plate 7.-A, B, and $\mathrm{C}$ show longitudinal sections of an 8-nucleate embryo sac from polyploid guayule. $A$ and $B$ present two focal planes of the same section. The section in $C$ was 10 microns from that in $A$. Cytokinesis is in progress between pairs of nuclei. At 1, 2, and 3 are the antipodal nuclei ; 4 and 5 , the polars; 6 , the egg nucleus; 7 and 8 , the synergid nuclei. $D$, Longitudinal section of an embryo sac from 72-chromosome guayule, showing the antipodals $(a)$. Some nucellar epidermal cells $(n)$ have remained at this end of the sac. The faint outline of the egg appear's to the right. $($ All $\times 760$. $)$ 

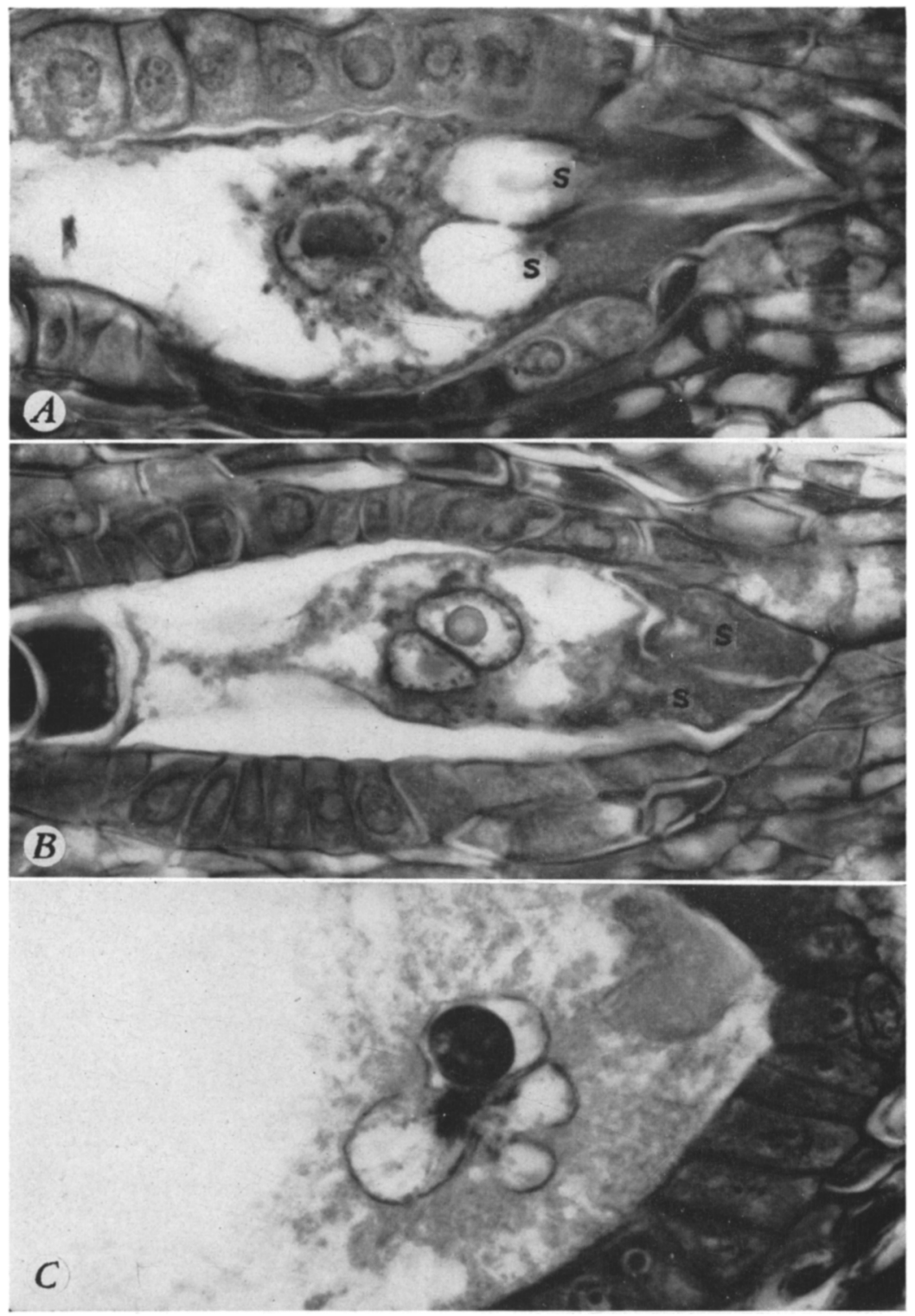

Plate 8.-Longitudinal sections of embryo sacs (and adjacent ovular layers) from 72-chromosome guayule. $A$ shows two synergids $(s)$ with their dense ends turned toward the micropyle and with the vacuolated ends toward the interior of the sac. A polar fusion nucleus appears to the left of the synergids. The view.in $B$ shows two synergids $(s)$ with collapsed vacuolated ends; fusing polars to the left of the synergids; and an antipodal cell (and part of another) at the extreme left of the sac. $C$, Part of a much lobed polar fusion nucleus. $($ All $\times 760$. $)$ 


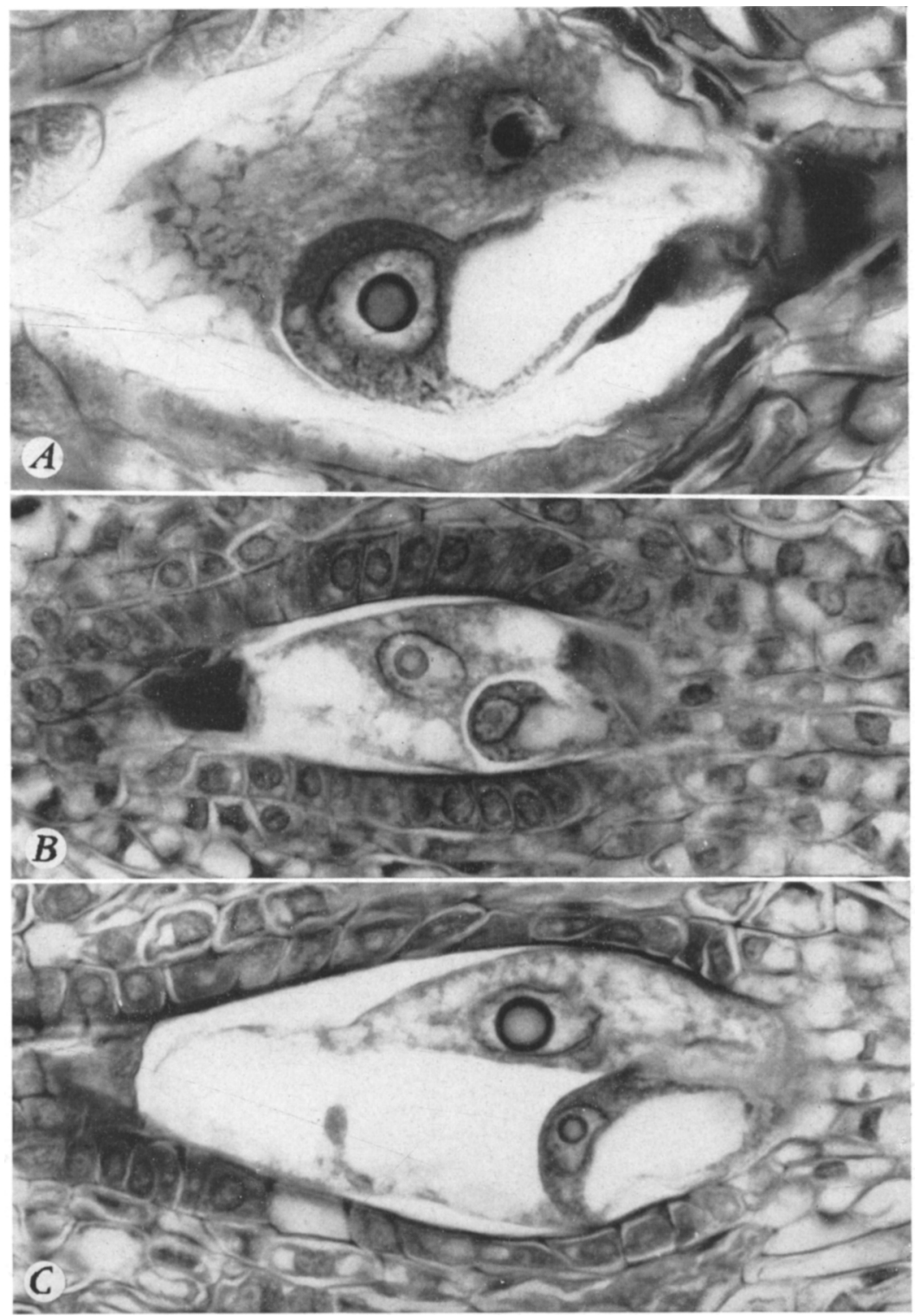

Plate 9.--Longitudinal sections of embryo sacs (and adjacent ovular layers) from 72- $(A)$ and 36-chromosome $(B$ and $C$ ) guayule. All three views show eggs with the vacuolated ends pointing toward the micropyle (to the right in the figures) ; their dense ends, containing the nuclei, are turned toward the interiors of the sacs. In $A$, a degenerated synergid appears to the right and below the egg; one endosperm nucleus is above the egg. (The second occurred in the next section.) Each sac in $B$ and $C$ contains one polar fusion nucleus to the left and above the egg. The embryo sac in $B$ is younger than the one in $C$. The latter occurred in a flower that failed to become cross-pollinated and was collected long past anthesis. $($ All $\times 760$. $)$ 


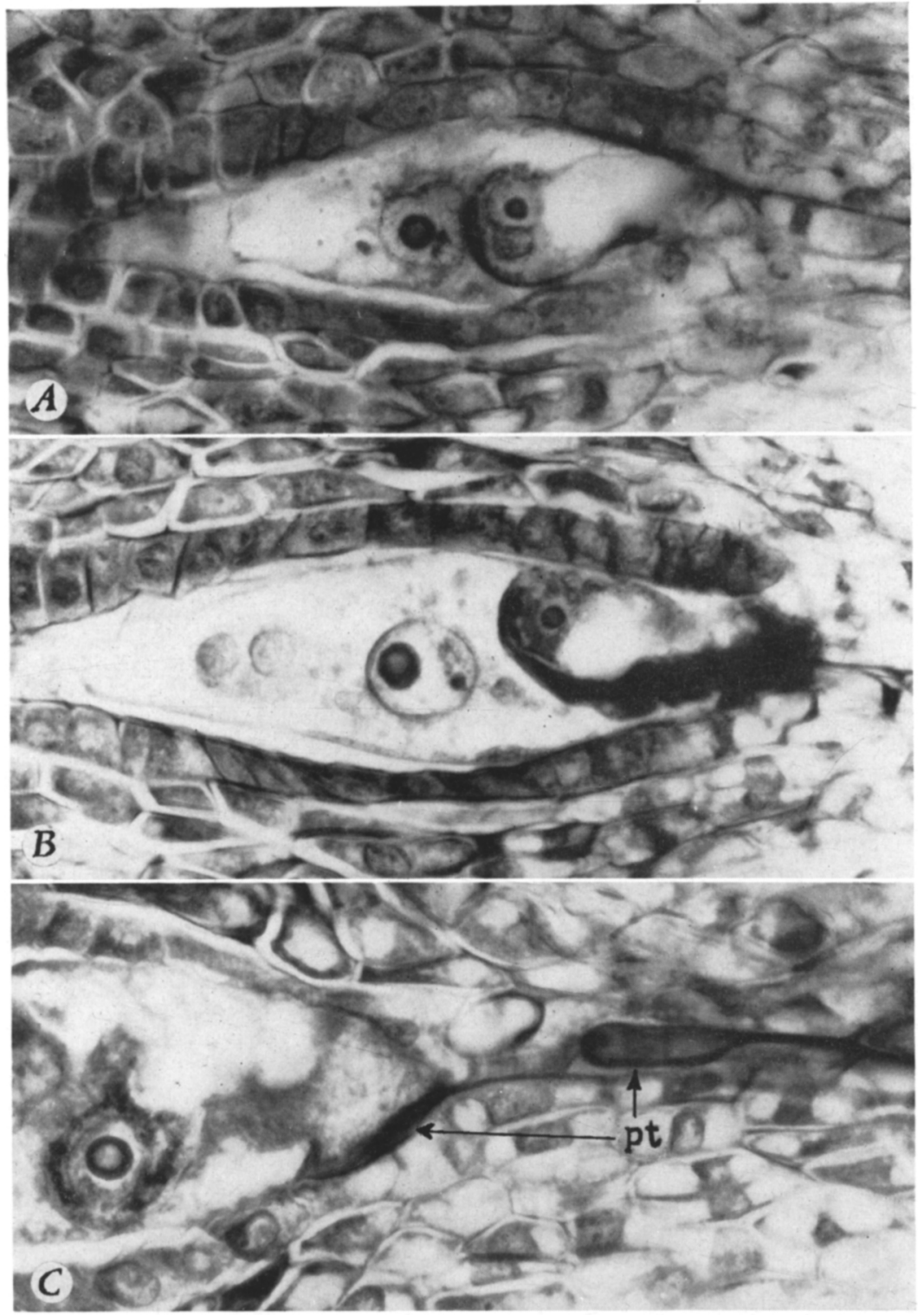

Plate 10.- $A, B$, Longitudinal sections of embryo sacs (and adjacent ovular layers) from 36-chromosome guayule. Darkly stained remnants of pollen tubes partly envelop the eggs in both sacs, and the small nucleoli in the primary endosperm nuclei (to the left of the eggs) indicate recent fertilization. In $A$ the egg and the sperm nuclei are in process of fusion. $C$, Longitudinal section of the micropylar region of an ovule from 72-chromosome guayule, with one part of the pollen tube $(p t)$ visible in the micropyle and another in the embryo sac. The egg in this sac was fertilized. The flowers used for $A$ and $B$ were collected 3 hours after pollination; the one used for $C, 5$ hours after pollination. (All $\times 760$.) 

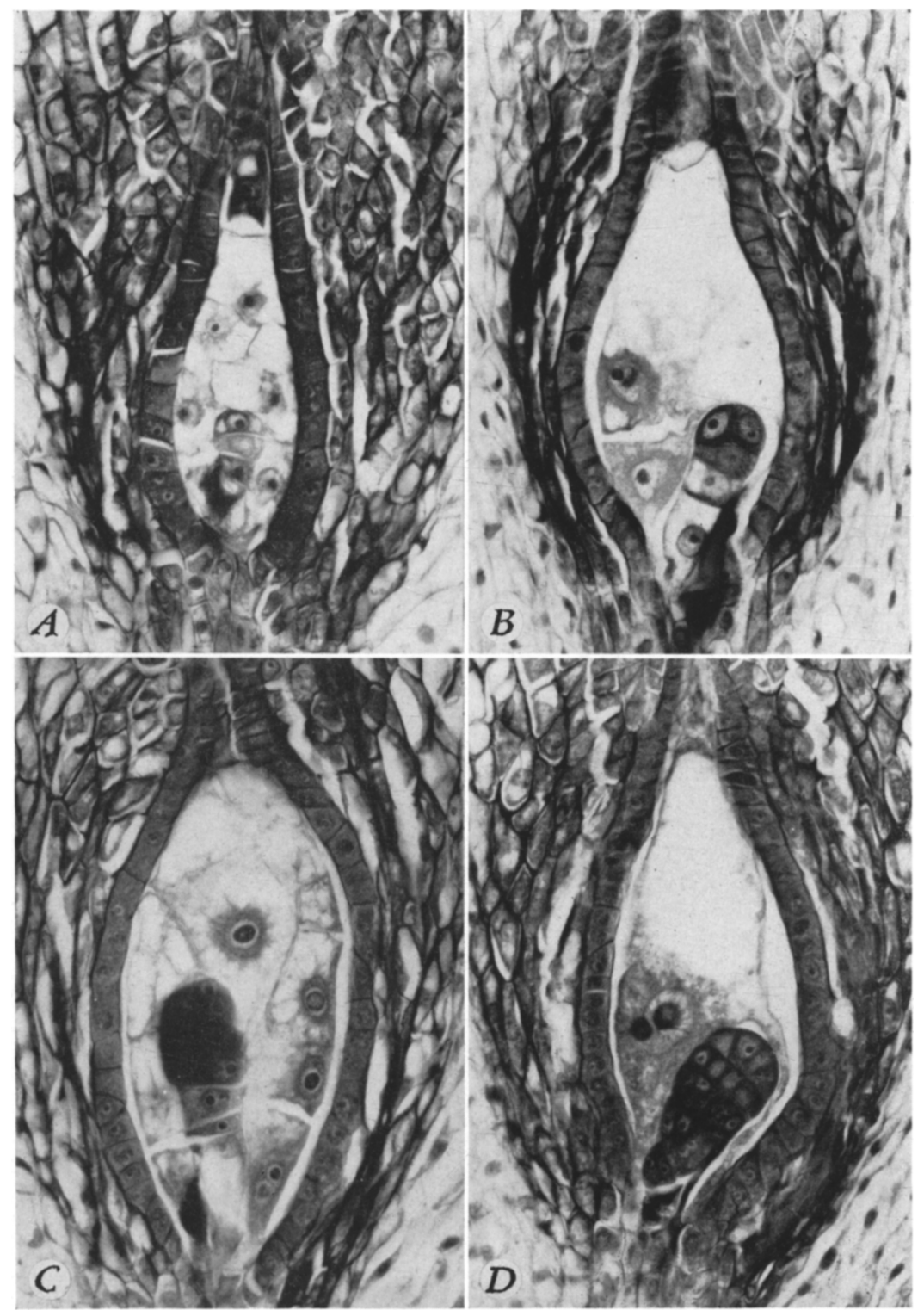

Plate 11.-Longitudinal sections of embryo sacs (and adjacent ovular layers) from 72-chromosome guayule, showing the development of embryos. The embryo sacs in $A, B$, and $C$ contain cellular endosperm; that in $D$, a lobed polar fusion nucleus. A degenerated synergid appears at the base of the embryo in $B$. In all four sacs, the nutritive jacket is of normal thickness. The embryo sacs in $A, B$, and $C$ occurred in cross-pollinated flowers collected 3,1 , and 2 days after pollination, respectively. The flower used for $D$ was selfed and was collected 3 days after pollination. (All $\times 290$. $)$ 


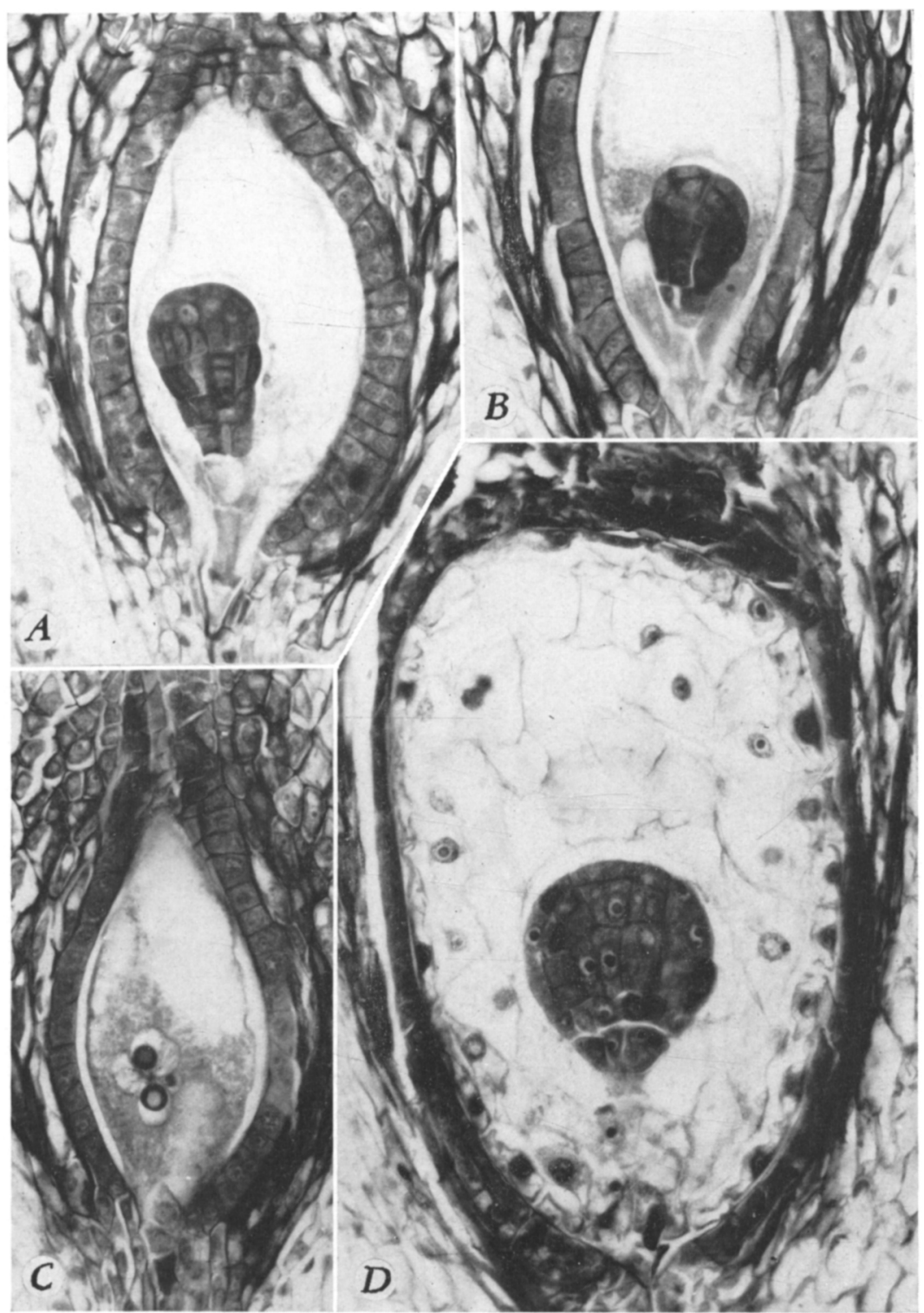

Plate 12.-Longitudinal sections of embryo sacs (and adjacent ovular layers) from 72-chromosome guayule. The embryos in $A$ and $B$ show the first appearance of the dermatogen. The nutritive jacket in $A$ is somewhat thicker than normal. An intact synergid appears at the base and to the left of the embryo in $B$. The endosperm failed to develop in $A$ and $B$. A much-lobed polar fusion nucleus is shown in $C$. The embryo in $D$ is associated with cellular endosperm. The flowers used for these views were treated as follows: $A$, selfed and collected 5 days after pollination; $B$ and $C$, cross-pollinated and collected 2 days after pollination; $D$, openpollinated and collected 7 days after anthesis. (All $\times 290$.) 

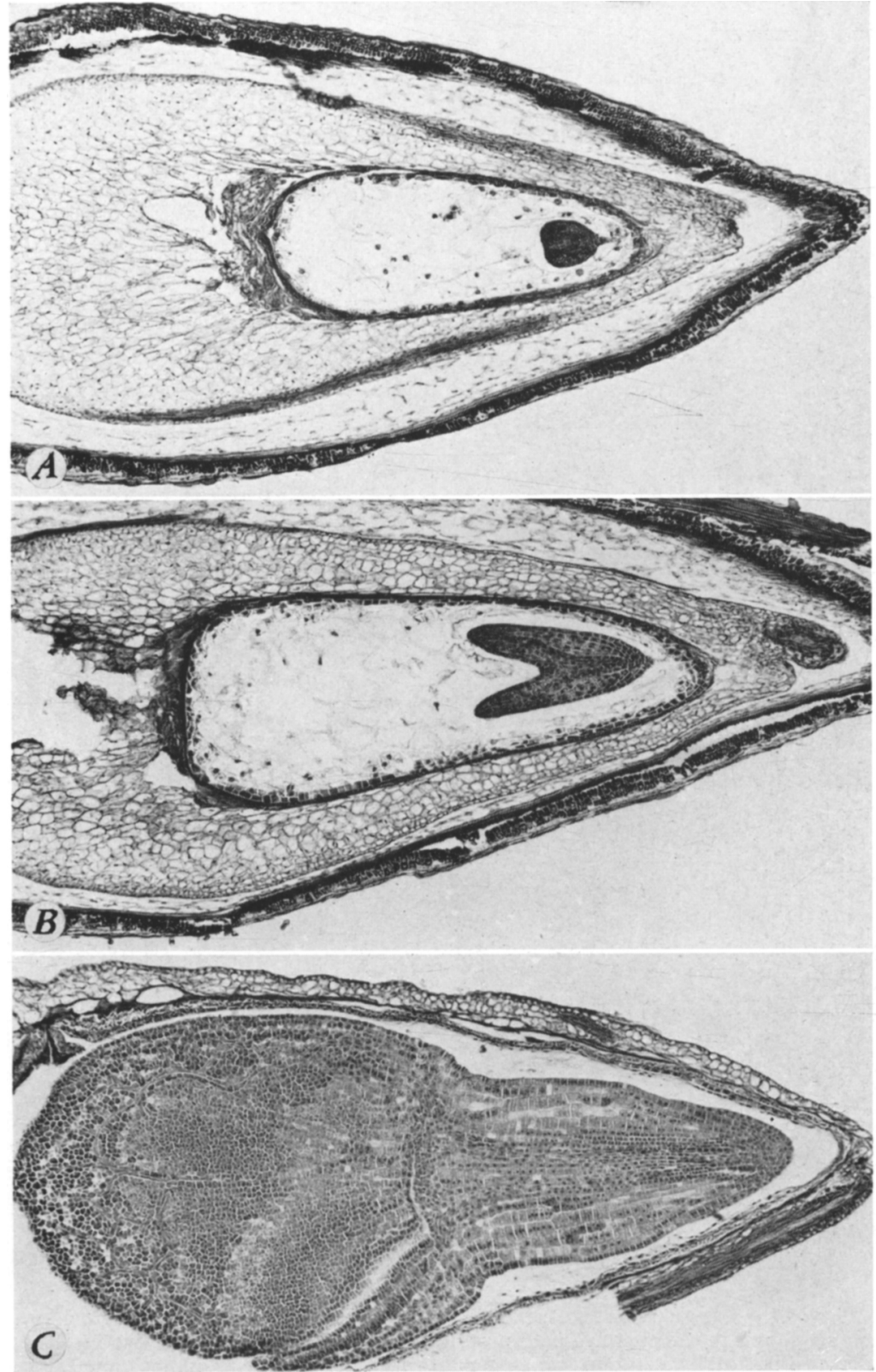

Plate 13.-Longitudinal sections of ovules (and adjacent fruit-wall layers) from 72-chromosome guayule. In $A$ and $B$ the ovules contain embryo saes with cellular endosperm, and embryos showing two stages in cotyledon development. The embryo in $C$ is of mature size. The flowers used in $A$ and $B$ were open-pollinated and were collected 5 days after pollination. The embryo in $C$ is from a cross-pollinated flower collected 10 days after pollination. (All $\times 50$. $)$ 

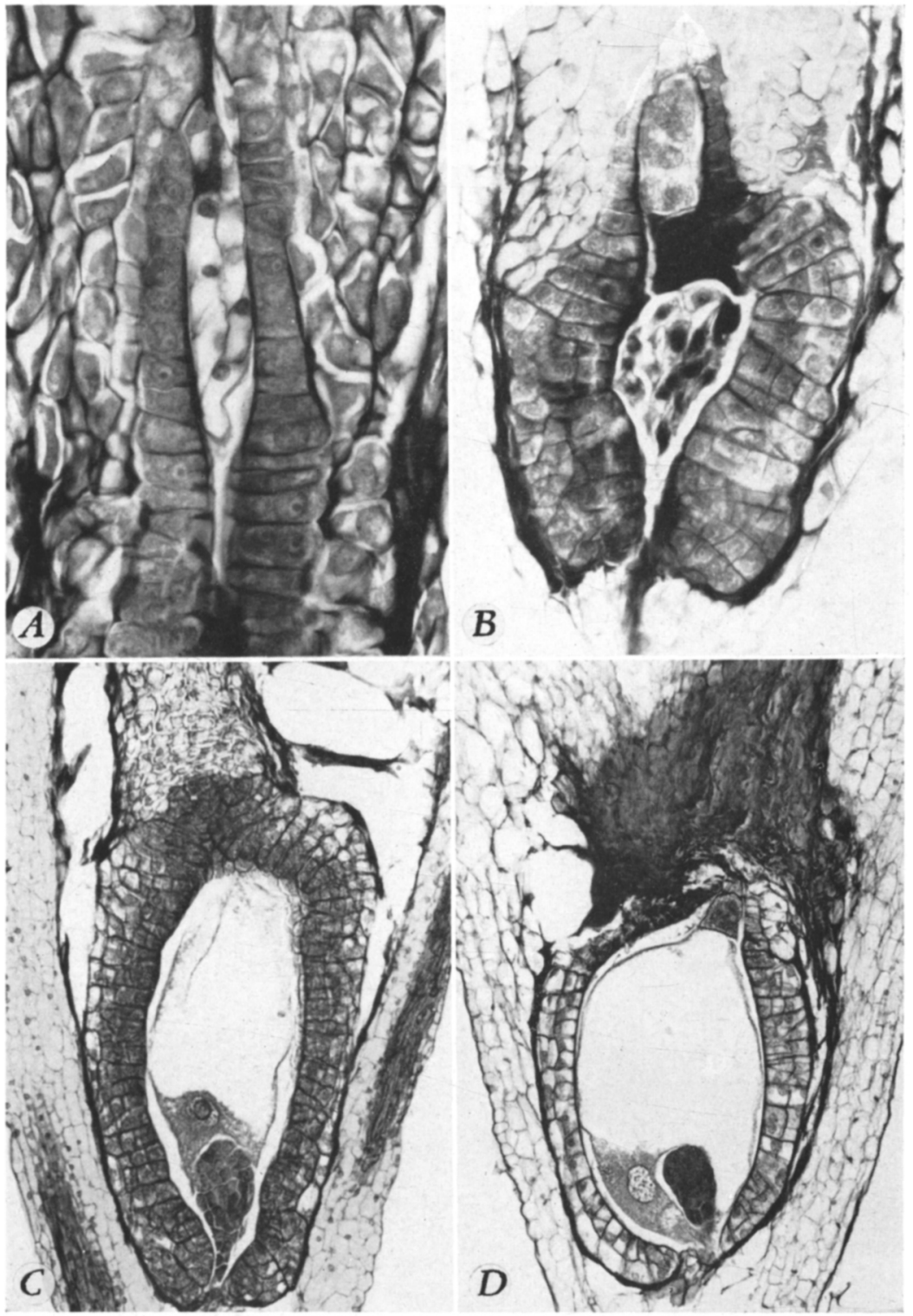

Plate 14.-Longitudinal sections of parts of ovules from 72-chromosome guayule. $A$ shows in the center a collapsed nucellar epidermis between two layers of nutritive jacket. The embryo sac in $B$ contains a degenerating embryo and is surrounded by a very thick multiseriate nutritive jacket. $C, D$, Embryo sacs from nonpollinated flowers collected 6 and 18 days after anthesis, respectively. Embryos occur in these saes, but no endosperm. $(A, \times 480 ; B, \times 290 ; C$ and $D, \times 140$. $)$ 


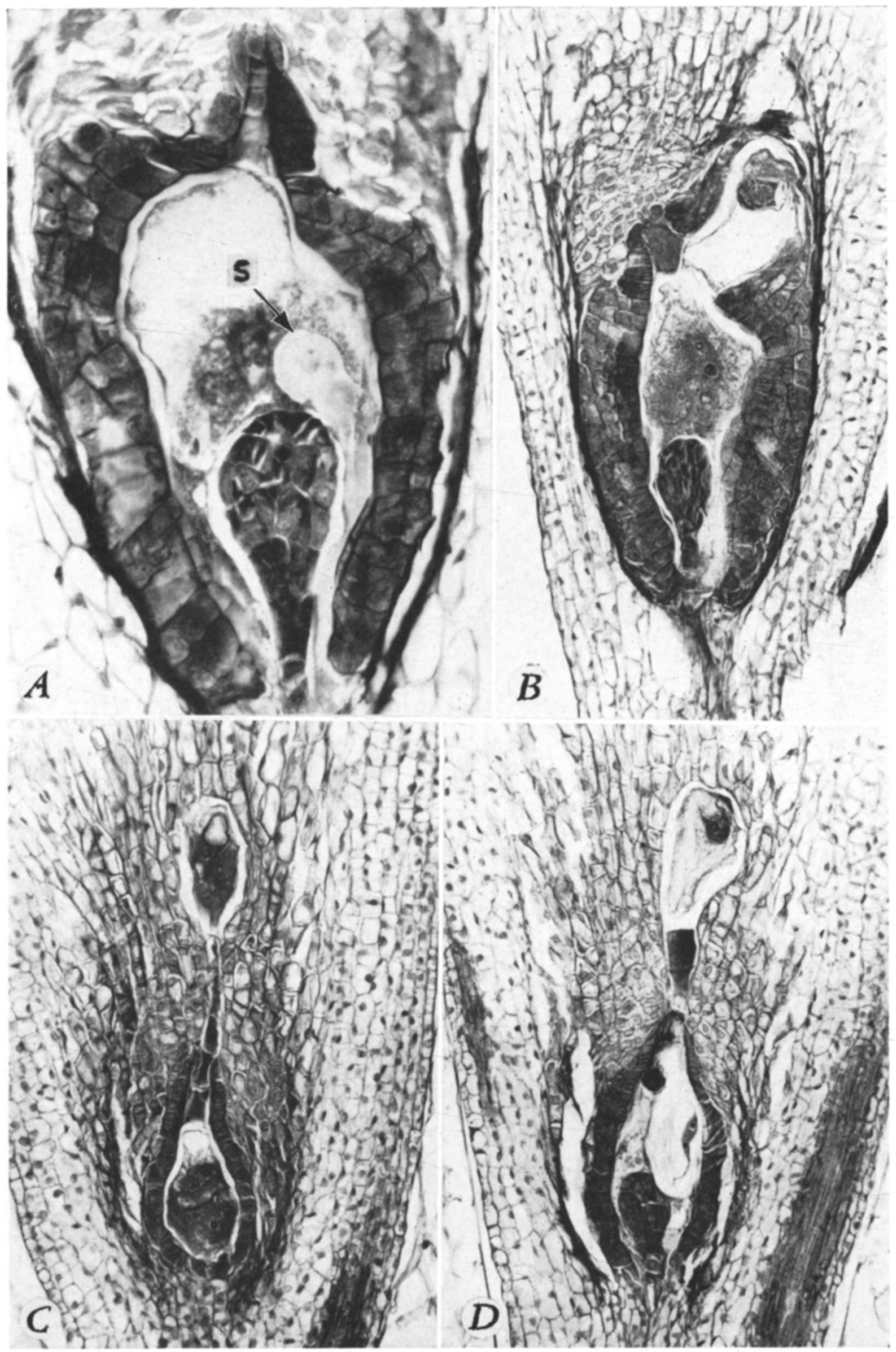

Plate 15.-Longitudinal sections of parts of ovules from 72-chromosome guayule. The embryo sac in $A$ shows an embryo and a long pale synergid $(s)$ that has divided into three cells. $B, C$, and $D$ illustrate supernumerary embryo sacs that sometimes develop in addition to the sacs appearing in normal position. In $B$ and $C$ the extra sacs are above the ones in normal position. In $D$, two extra sacs are present, one in the cavity of the sac in normal position, the other above it. An embryo $(B)$ and eggs $(C$ and $D)$ occur in the extra sacs. $(A, \times 290 ; B-D$, $\times 140$.) 

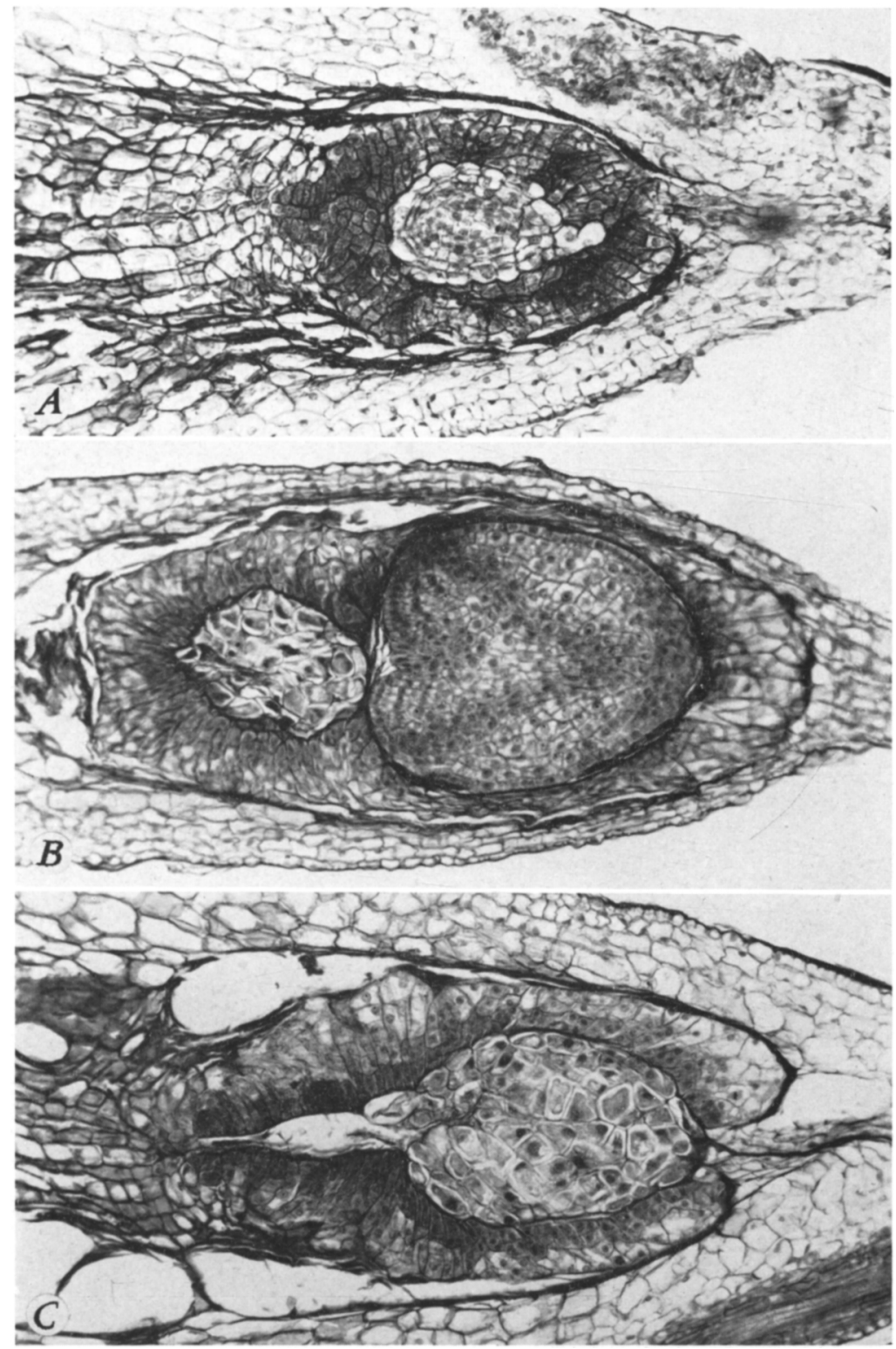

Plate 16.-Longitudinal sections of degenerating embryo sacs and ovular tissues enclosing them, from apomictic guayule. In $A$ the embryo is imbedded in the thick nutritive jacket and is associated with no endosperm. In $B$ the embryo is of abnormal shape, some endosperm occurs to the left of the embryo, and the nutritive jacket is very thick. $C$, Embryo sac without an embryo, but with some degenerating endosperm and a thick nutritive jacket. (All $\times 140$.) 